UCRL-ID-120429

\title{
THE NORTHERN MARSHALL ISLANDS RADIOLOGICAL SURVEY: A QUALITY CONTROL PROGRAM FOR RADIOCHEMICAL AND GAMMA SPECTROSCOPY ANALYSES
}

\author{
Steven R. Kehl \\ Mark E. Mount \\ William L. Robison
}

September 1995

Work performed under the auspices of the U.S. Department of Energy at Lawrence Livermore National Laboratory under contract W-7405-Eng-48. 
"? 


\section{DISCLAIMER}

This report was prepared as an account of work sponsored by an agency of the United States Government. Neither the United States Government nor any agency thereof, nor any of their employees, make any warranty, express or implied, or assumes any legal liability or responsibility for the accuracy, completeness, or usefulness of any information, apparatus, product, or process disclosed, or represents that its use would not infringe privately owned rights. Reference herein to any specific commercial product, process, or service by trade name, trademark, manufacturer, or otherwise does not necessarily constitute or imply its endorsement, recommendation, or favoring by the United States Government or any agency thereof. The views and opinions of authors expressed herein do not necessarily state or reflect those of the United States Government or any agency thereof. 


\section{DISCLAIMER}

Portions of this document may be illegible in electronic image products. Images are produced from the best available original document. 


\section{Table of Contents}

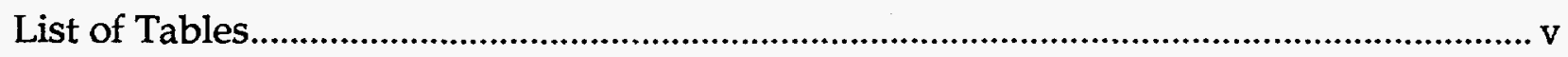

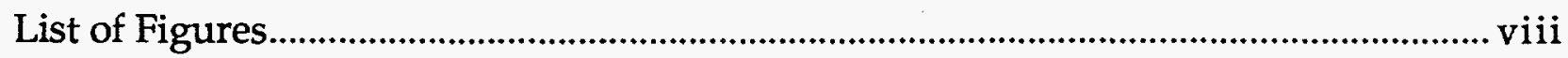

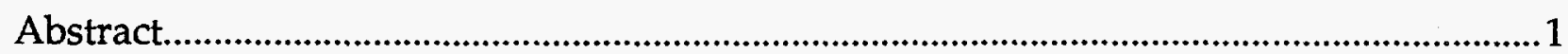

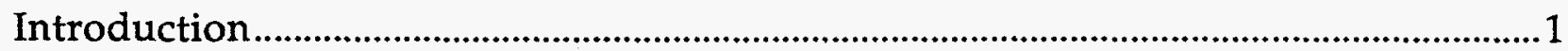

Evaluation Criteria and Radiochemistry Precision Requirements .............................2

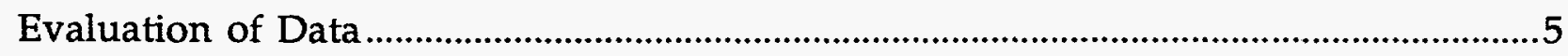

Summary of the Post Northern Marshall Islands Radiological Survey Quality

Control Results..

Summary Performance on the Duplicates and Standards of Participating Laboratories

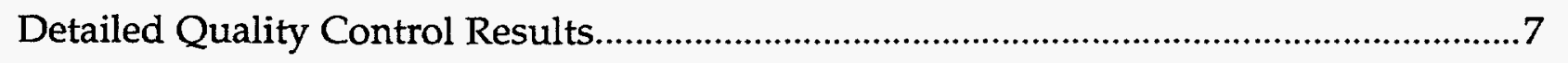

Gamma Spectroscopy Analysis - Soil and Vegetation Samples ........................9

${ }^{137} \mathrm{Cs}$ in Soil and Vegetation Duplicate Samples by Gamma

Spectroscopy.

${ }^{137} \mathrm{Cs}$ in Soil and Vegetation Standard Samples by Gamma Spectroscopy

${ }^{241} \mathrm{Am}$ in Duplicate Soil Samples by Gamma Spectroscopy ....................14

${ }^{241}$ Am in Soil Standard Samples by Gamma Spectroscopy ......................14

Radiochemistry Analysis - Soil and Vegetation Samples...............................15

$90 \mathrm{Sr}$ in Soil and Vegetation Duplicate Samples by Radiochemistry......23

$90 \mathrm{Sr}$ in Soil and Vegetation Standard Samples by Radiochemistry .......23

${ }^{137} \mathrm{Cs}$ in Soil and Vegetation Duplicate Samples by Radiochemistry ....23

${ }^{137} \mathrm{Cs}$ in Soil and Vegetation Standard Samples by Radiochemistry .....23

$239+240 \mathrm{Pu}$ in Soil and Vegetation Duplicate Samples by Radiochemistry 
$239+240 \mathrm{Pu}$ in Soil and Vegetation Standard Samples by Radiochemistry

${ }^{241} \mathrm{Am}$ in Soil and Vegetation Duplicate Samples by Radiochemistry 24

${ }^{241} \mathrm{Am}$ in Soil and Vegetation Standard Samples by Radiochemistry..25

Radiochemistry Analysis - Terrestrial Animals .....................................................25

Radiochemistry Analysis - Marine Organisms .........................................................25

Gamma to Gamma Cross-Counts Between Laboratories.......................................26

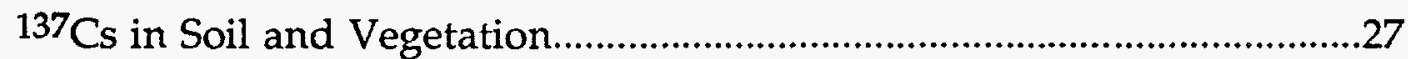

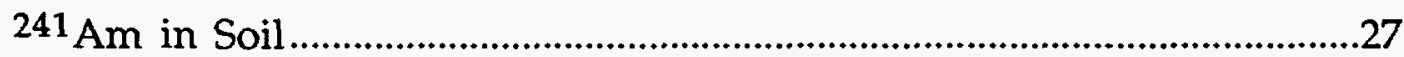

Radiochemistry Analysis Versus Gamma-Spectroscopy Analysis ....................22

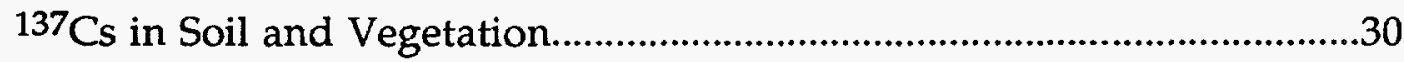

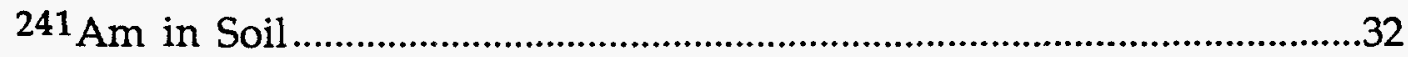

Intercalibration and Split Sample Analyses for LLNL Health and Ecological Assessment Division Analytical Facilities............................................................................32

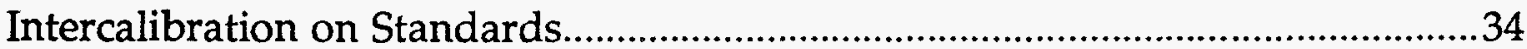

Split Sample Comparisons ...................................................................................44

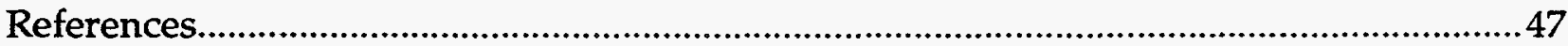

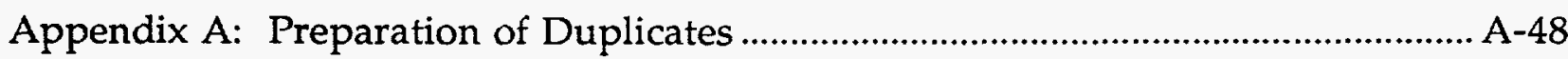

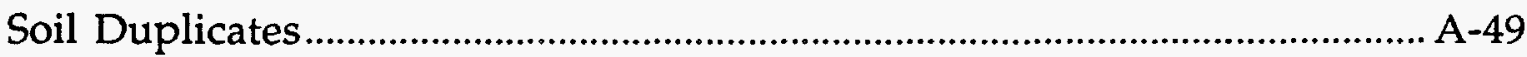

Vegetation Duplicates......................................................................................... A-49

Terrestrial Animal Duplicates .......................................................................... A-50

Marine Organism Duplicates ....................................................................... A-50

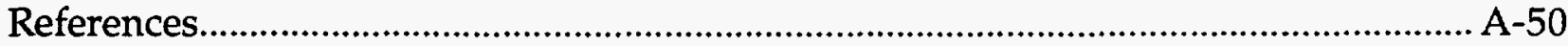

Appendix B: Preparation of Standards ...................................................................... B-51

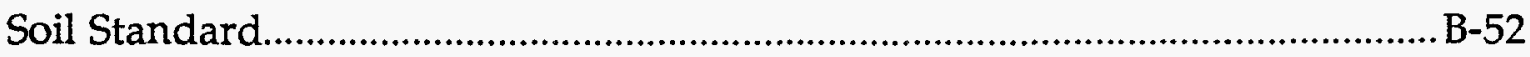

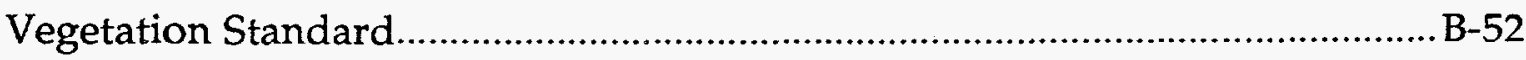




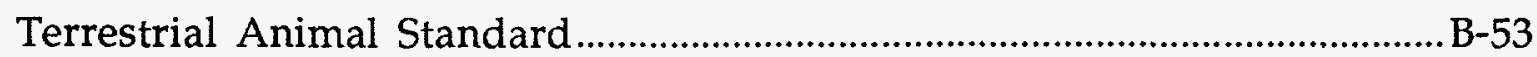

Marine Organism Standard ........................................................................ B-53

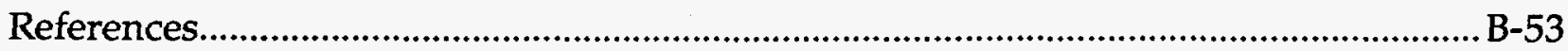

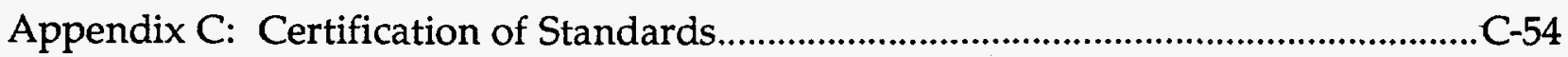

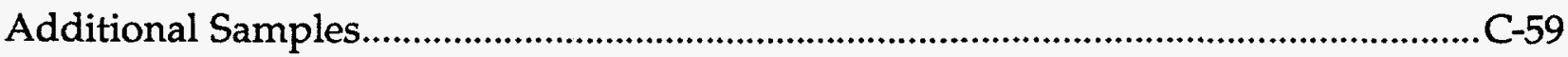

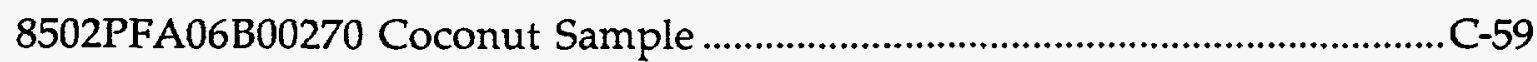

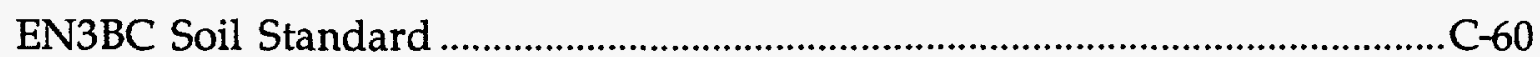

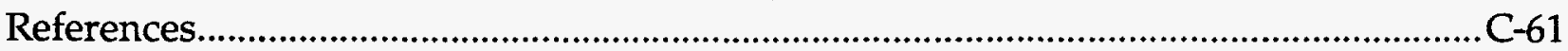




\section{List of Tables}

Table 1. Allowable counting errors according to the total activity in the sample received by the contracting laboratories......

Table 2. Summary of the Post Northern Marshall Islands Radiological Survey radiochemical and gamma spectroscopy analyses. 6

Table 3. Summary of the duplicate and standard analyses evaluated for each participating laboratory as part of the quality control program for the Post Northern Marshall Islands Radiological Survey.

Table 4. Acceptable gamma spectroscopy quality control results for duplicate pairs and standard samples analyzed in soil and vegetation by Laboratory of Radiation Ecology.

Table 5. Acceptable gamma spectroscopy quality control results for duplicate pairs and standard samples analyzed in soil and vegetation by Nuclear Energy Services, North Carolina State University.

Table 6. Acceptable radiochemistry quality control results for duplicate pairs and standard samples analyzed in soil and vegetation by the Laboratory of Radiation Ecology

Table 7. Acceptable radiochemistry quality control results for duplicate pairs and standard samples analyzed in soil and vegetation by Lawrence Livermore National Laboratory.

Table 8. Acceptable radiochemistry quality control results for duplicate pairs and standard samples analyzed in soil and vegetation by Nuclear Energy Services, North Carolina State University.

Table 9. Acceptable radiochemistry quality control results for duplicate pairs and standard samples analyzed in soil and vegetation by Thermo Analytical Norcal.... 17

Table 10. Acceptable radiochemistry quality control results for duplicate pairs and standard samples analyzed in terrestrial animals by Thermo Analytical Norcal..... 25

Table 11. Acceptable radiochemistry quality control results for duplicate pairs and standard samples analyzed in marine organisms by the Laboratory of Radiation Ecology.

Table 12. Pu-239+240 Activity Ratio (x/median value) ...................................................... 35

Table 13. Measurement of International Soil Standard No. 367 ..................................36

Table 14. Measurement of International Soil Standard No. 368...................................36 
Table 15. Measurement of International Soil Standard No. 352.

Table 16. Measurement of Lawrence Livermore National Laboratory vegetation standard 8510 .

Table 17. Activity Concentration in Sea Water (in $\mathrm{Bq} / \mathrm{m}^{3}$ ) ......................................38

Table 18. Activity Concentration in Plankton (in $\mathrm{Bq} / \mathrm{kg}$ wet) .......................................39

Table 19. Mean Radionuclide concentrations from eight laboratories in biota samples collected inside, outside and on land of Mururoa Atoll (Bq kg-1 wet weight)

Table 20. Mean Radionuclide concentrations from eight laboratories in biota samples collected inside, outside and on land of Mururoa Atoll (Bq kg-1 wet weight)

Table 21. IAEA Intercalibration Exercise as part of a Coordinated Research Program (Bq kg-1).

Table 22. Interlaboratory comparison of split samples for ${ }^{137} \mathrm{Cs}$ in Ailinginae and Rongelap vegetation samples - Rongelap Reassessment Program versus Lawrence Livermore National Laboratory.

Table 23. Interlaboratory comparison of split samples for ${ }^{137} \mathrm{Cs}$ in Bikini vegetation samples - Rongelap Reassessment Program versus Lawrence Livermore National Laboratory.

Table 24. Interlaboratory comparison of split samples for ${ }^{137} \mathrm{Cs}$ in Ailinginae and Rongelap soil samples - Rongelap Reassessment Program versus Lawrence Livermore National Laboratory.

Table 25. Intercomparison Results for Soil Samples from RMI Nationwide Radiological Survey. (All units are $\mathrm{Bq} \mathrm{kg}^{-1}$ ) 45

Table 25. Intercomparison Results for Soil Samples from RMI Nationwide Radiological Survey. (All units are $\mathrm{Bq} \mathrm{kg}^{-1}$ )

Table 26. Cross Comparison Between Lawrence Livermore National Laboratory and the RMI Nationwide Radiological Survey 46

Table C1. Cs-137 (in pCi/gram dry weight \% fractional standard deviation) measured by gamma-ray spectrometry in a random selection of vegetation and soil standards.

Table C2. Radionuclides measured in vegetation standard (7808) samples. All analyses performed radiochemically except as noted. C-56 
Table C3. Radionuclides measured in vegetation standard (8510) samples. All analyses performed radiochemically

Table C5. Radionuclides measured in soil standard (7903). All analyses performed radiochemically

Table C6. Radionuclides measured in soil standard (8112). All analyses performed radiochemically. C-58

Table C7. Radionuclides measured in soil standard (8207). All analyses performed radiochemically C-58

Table C8. Radionuclides measured in soil standard (8502). All analyses performed radiochemically. C-58

Table C9. Radionuclides measured in marine organism standard samples. All analyses performed radiochemically except as noted. C-59

Table C10. Expected values of radionuclides in terrestrial animal samples (pCi/ $\mathrm{kg}$ ).

Table C11. Radionuclides measured in vegetation standard 8502PFA06B00270. All analyses performed by gamma-ray spectroscopy C-60

Table C12. Radionuclides measured in soil standard EN3BC. C-61 


\section{List of Figures}

Figure $1 .{ }^{137} \mathrm{Cs}$ analyzed in soil and vegetation duplicates pairs by gamma spectroscopy.

Figure 2. ${ }^{241} \mathrm{Am}$ and ${ }^{137} \mathrm{Cs}$ analyzed in soil and vegetation standards by gamma spectroscopy.

Figure 3. ${ }^{241} \mathrm{Am}$ analyzed in soil and vegetation duplicates by gamma spectroscopy.

Figure 4. ${ }^{90} \mathrm{Sr}$ analyzed in soil and vegetation duplicates by radiochemistry.

Figure 5. ${ }^{90} \mathrm{Sr},{ }^{137} \mathrm{Cs},{ }^{239}+240 \mathrm{Pu}$ and ${ }^{241} \mathrm{Am}$ analyzed in soil, vegetation, terrestrial animal and marine organism standards by radiochemistry.

Figure 7. $239+240 \mathrm{Pu}$ analyzed in soil and vegetation duplicates by radiochemistry.. 21

Figure $8 .{ }^{241} \mathrm{Am}$ analyzed in soil and vegetation duplicates by radiochemistry.......22

Figure 9. Gamma to gamma cross count comparisons for ${ }^{137} \mathrm{Cs}$ analyzed in soil and vegetation

Figure 10. Gamma to gamma cross count comparisons for ${ }^{241} \mathrm{Am}$ analyzed in soil.

Figure 11. Radiochemistry to gamma spectroscopy comparisons for ${ }^{137} \mathrm{Cs}$ analyzed

in soil and vegetation. 31

Figure 12. Radiochemistry to gamma spectroscopy comparisons for ${ }^{241} \mathrm{Am}$ analyzed in soil. .33

Figure 13. Cs-137 in IAEA-367 Sediment-Intercomparison in 1991 37

Figure 14. LLNL/IAEA ${ }^{137}$ Cs Comparison.

Figure 15. LLNL/IAEA Pu Comparison 42 


\begin{abstract}
From 1979 to 1989, approximately 25,000 Post Northern Marshall Islands Radiological Survey (PNMIRS) samples were collected, and over 71,400 radiochemical and gamma spectroscopy analyses were performed to establish the concentration of ${ }^{90} \mathrm{Sr},{ }^{137} \mathrm{Cs},{ }^{241} \mathrm{Am}$, and plutonium isotopes in soil, vegetation, fish, and animals in the Northern Marshall Islands. While the Low Level Gamma Counting Facility (B379) in the Health and Ecological Assessment (HEA) division accounted for over $80 \%$ of all gamma spectroscopy analyses, approximately 4889 radiochemical and 5437 gamma spectroscopy analyses were performed on 4784 samples of soil, vegetation, terrestrial animal, and marine organisms by outside laboratories. Four laboratories were used by Lawrence Livermore National Laboratory (LLNL) to perform the radiochemical analyses: Thermo Analytical Norcal, Richmond, California (TMA); Nuclear Energy Services, North Carolina State University (NCSU); Laboratory of Radiation Ecology, University of Washington (LRE); and Health and Ecological Assessment (HEA) division, LLNL, Livermore, California. Additionally, LRE and NCSU were used to perform gamma spectroscopy analyses. The analytical precision and accuracy were monitored by including blind duplicates and natural matrix standards in each group of samples analyzed. On the basis of reported analytical values for duplicates and standards, $88 \%$ of the gamma and $87 \%$ of the radiochemical analyses in this survey were accepted. By laboratory, $93 \%$ of the radiochemical analyses by TMA; $88 \%$ of the gamma-ray spectrometry and $100 \%$ of the radiochemistry analyses by NCSU; $89 \%$ of the gamma spectroscopy and $87 \%$ of the radiochemistry analyses by LRE; and $90 \%$ of the radiochemistry analyses performed by HEA's radiochemistry department were accepted.
\end{abstract}

\title{
Introduction
}

The Post Northern Marshall Islands Radiological Survey (PNMIRS) is a continuing large-scale effort to collect soil, vegetation, terrestrial animals, marine organisms, and water to assess the radiation dose from the ingestion and inhalation pathways and external environments of Bikini, Enewetak, Utirik and Rongelap atolls in the Northern Marshall Islands. The Health and Ecological Assessment (HEA) division of Lawrence Livermore National Laboratory (LLNL) is responsible for this effort, including the collection, processing, and analysis of the various samples. A quality assurance program covering the Marshall Island Program has been established and a report prepared covering samples collected during the original survey in 1978. (Jennings and Mount, 1983)

During the time period of 1979 to 1989 , approximately 25,000 additional PNMIRS samples have been collected, with over 71,400 radiochemical and gamma spectroscopy analyses being performed to further establish the amounts of specific radionuclides present in the Northern Marshall Islands. Over $80 \%$ of the samples collected have been analyzed by HEA's Low Level Gamma Counting Facility (LLGCF); housed in building 379. While the LLGCF accounts for the major portion 
of the gamma spectroscopy analyses performed as part of the Marshall Islands Survey, it is the intent of this paper to discuss the Quality Assurance results obtained from the participating laboratories. This in mind, a discussion of the LLGCF Quality Assurance program and results will be held for a future report.

For such an extensive analytical program, four additional laboratories were used to assist the HEA division of LLNL by performing the analyses on 4784 or roughly $20 \%$ of the samples taken during the time period in question. The laboratories assisting in the radiochemical analyses were Thermo Analytical Norcal, Richmond, CA (TMA); Nuclear Energy Services, North Carolina State University; Raleigh, NC (NCSU); Laboratory of Radiation Ecology, University of Washington, Seattle, WA (LRE); and the Health and Ecological Assessment division, (specifically the radiochemistry laboratory) Lawrence Livermore National Laboratory, Livermore, CA.

\section{Evaluation Criteria and Radiochemistry Precision Requirements}

Any assessment program depends on the quality of the analytical measurements being made. Most laboratories spend a certain part of their effort to establish the accuracy and reproducibility of their analytical work. Blind inter-laboratory comparisons such as the Department of Energy (DOE) Intercalibration exercise and analysis of natural matrix standards such as those available from the National Institute of Standards and Technology and from the International Atomic Energy Agency are two methods by which the quality of a laboratory's work can be shown. In a large-scale survey such as the Northern Marshall Islands program where samples are analyzed by several laboratories, it is all the more important to assess the validity of the data by regularly having the participating laboratories analyze quality assurance $(Q C)$ standards.

For this program, we have selected three criteria for the analytical reliability of the data.

(1) The first criterion places limits of acceptability on the counting errors. Because radioactive decay is a statistical process, sufficient counts must be collected to provide a level of confidence that the number reported is a true measure of the radioactivity in the sample. Until this criterion is met it is difficult, if not impossible, to evaluate the data for the remaining two criteria. Consequently, a set of acceptable counting errors was established for each isotope of interest, scaled to the total radioactivity of the sample (Table 1 ). Compliance can be easily checked by using the measured specific activity and weight of the sample that are available to the analyst. This criterion was developed prior to initiation of the original Northern Marshall Island Radiological Survey (NMIRS) field-sample collection program to estimate the amount of sample required by any competent laboratory to measure worldwide fallout. Samples of sufficient size with higher activity are 
Table 1. Allowable counting errors according to the total activity in the sample received by the contracting laboratories.

\begin{tabular}{|c|c|c|}
\hline Radio nuclide & $\mathrm{pCi}$ & 1 error (\%) \\
\hline \multirow[t]{4}{*}{${ }^{90} \mathrm{Sr}$} & $<1.0$ & 50 to 100 \\
\hline & 1.0 to 5.0 & 40 \\
\hline & 5.0 to 8.0 & 20 \\
\hline & $>8.0$ & 10 \\
\hline \multirow[t]{4}{*}{${ }^{137} \mathrm{Cs}$} & $<1.0$ & 50 to 100 \\
\hline & 1.0 to 5.0 & 40 \\
\hline & 5.0 to 8.0 & 20 \\
\hline & $>8.0$ & 10 \\
\hline \multirow[t]{4}{*}{$238,241 \mathrm{Pu}$} & $<2.0$ & 50 to 100 \\
\hline & 2.0 to 5.0 & 40 \\
\hline & 5.0 to 20.0 & 20 \\
\hline & $>20.0$ & 10 \\
\hline \multirow[t]{4}{*}{$239+240 \mathrm{Pu}$} & $<0.1$ & 50 to 100 \\
\hline & 0.1 to 0.25 & 40 \\
\hline & 0.25 to 1.0 & 20 \\
\hline & $>1.0$ & 10 \\
\hline \multirow[t]{4}{*}{${ }^{241} \mathrm{Am}$} & $<0.1$ & 50 to 100 \\
\hline & 0.1 to 0.25 & 40 \\
\hline & 0.25 to 1.0 & 20 \\
\hline & $>1.0$ & 10 \\
\hline
\end{tabular}

therefore well above the limits of detection of the participating laboratories. This procedure avoids the reporting of machine limits that gives only the upper limits of the radionuclide concentration in the sample and thus overestimates the amount of radioactivity actually present, especially if used as real values. This situation is not an uncommon practice when assessing environmental data.

(2) The second criterion requires that the participating laboratories reproduce their results on replicate analyses. This is accomplished by including a set of blind duplicates with each group of roughly 100 samples (referred to as a DCD for the accompanying Delivery Control Document). If the results for the paired analyses agree within twice the measurement accuracy required in Table 1, they are accepted. Satisfactory performance on duplicates requires acceptability on $80 \%$ of 
all duplicate pairs included in each DCD. Additionally, an "Error of Ratios Test" (ERT) was performed on all values for duplicate pairs passing the accuracy measurement requirement in Table 1 . In use, a ratio error (expressed as a percentage) was generated from the ratio of the values (of the duplicate pair) and the standard deviation of the ratio. Any subsequent errors found greater than $30 \%$ were considered detection limit values and while plotted, were excluded from the calculation of ranges, means, and standard deviations. This was done to validate true analytical comparisons from those made between a detection limit value of one or both analyses. Generally, a failure from this test only occurred when one or both of the duplicate pairs were so low in activity, that the accuracy requirement in table 1 gave an error guaranteeing acceptance. Only data that passed both the measurement accuracy required in Table 1 , and the ERT were included in calculations. LLNL prepares and distributes all duplicate samples.

(3) The third criterion requires that the participating laboratories accurately determine the radionuclide concentrations in blind standards made up to resemble the natural matrixes of the samples. Although all three of the criteria are important, perhaps this is the most significant because it includes accuracy of measurement as well as precision (reproducibility); any systematic errors in the measurement would appear. Responsibility for preparing, standardizing, distributing, and final data analysis of the standard samples was assigned to Western Oregon State College (WOSC) and then later to Eckerd College (EC). In this way the responsibility for evaluating the analytical integrity of the data was vested in a disinterested third party.

In some cases, departures from these criteria were allowed to facilitate processing the data, but the deviations were never great enough to compromise the integrity of the data. Specifically, the error requirements shown in Table 1 were relaxed by $20 \%$ for some of the early DCDs to accommodate problems some of the laboratories had in reducing counting errors. For example, for samples where a $10 \%$ relative standard deviation was required, a $12 \%$ relative standard deviation was allowed. All deviations from the required criterion were documented with explanatory memos.

Another departure was in the number of duplicates and standards that had to be in compliance. In order to accept the results of a DCD, $80 \%$ of the duplicate pairs and $100 \%$ of the standards are required to be in compliance with the QC criteria. When the number of duplicate pairs sent in a DCD did not permit exactly $80 \%$ compliance (for example, 3 of 4 pairs yield $75 \%$ compliance), the criterion was relaxed to allow for less than $80 \%$ to be considered acceptable. The $100 \%$ compliance criterion on standards was occasionally eased if the radiochemical analysis reported for the standard was close to the accepted activity and if the laboratory had 
previously established a record of accurate radiochemical analysis on other aliquots of the same standard.

The methods used to prepare the duplicate and standard samples are presented in Appendices $A$ and $B$, respectively. The certification process for the standards is described in Appendix C.

\section{Evaluation of Data}

In evaluating the data produced by the participating laboratories as part of the PNMIRS, the following procedure was established for the review of the QC sample results. Participating laboratories forwarded completed results for a given radionuclide and DCD to LLNL. Samples involved in the QC program (duplicate pairs and standards) were then collated and compared and a summary submitted to our independent reviewer, Dr. C. D. Jennings of WOSC and later Eckerd College. QC sample results (for each isotope analysis requested) that met the three criteria requirements described earlier in the text provided a basis of acceptance for the entire set of samples contained in the DCD and would be recommended by Dr. Jennings for inclusion into the PNMIRS data base. In the event that QC sample results for a given radionuclide and $D C D$ were unacceptable, the participating laboratory was required to initially revalidate all numerical calculations and analytical procedures for the analyses in question. Should this effort fail to correct the deficiencies, the participating laboratory was then required to re-analyze a selected number of samples from the DCD, some of which were $Q C$, for the given radionuclide. If these re-analyses failed to correct the deficiencies, the results for that radionuclide and DCD were rejected by Dr. Jennings and excluded from the PNMIRS data base. This procedure continued for several years. Ultimately, when Dr. Jennings was no longer available to continue as our independent reviewer, the decision was made to terminate the use of an independent reviewer and to place that responsibility in the hands of the LLNL Marshall Island Program Quality Assurance personnel. Furthermore, the decision centered on the fact that our QC process had been operating successfully for many years and the Bikini Atoll Rehabilitation Committee, in its review of our Marshall Islands program, had found our QC program to be well established.

\section{Summary of the Post Northern Marshall Islands Radiological Survey Quality Control Results}

Our results indicate that a high degree of compliance with respect to $\mathrm{QC}$ criteria was achieved during this project. Over $90 \%$ of the samples analyzed were found acceptable for dose calculations. As shown in Table 2, 89\% of the 4758 analyses requested of NCSU, $93 \%$ of the 2792 analyses requested of TMA, $87 \%$ of the 2261 analyses requested of LRE, and $90 \%$ of the 515 analyses requested of LLNL were accepted. The reproducibility of the analyses is particularly apparent in Figures 1 to 
Table 2. Summary of the Post Northern Marshall Islands Radiological Survey radiochemical and gamma spectroscopy analyses.

\begin{tabular}{llcc}
\hline Laboratory & Analysis method & Number requested & Number accepted $^{\mathrm{a}}$ \\
\hline LRE & $\begin{array}{l}\text { Gamma } \\
\text { spectroscopy } \\
\text { Radiochemistry }\end{array}$ & 871 & $772^{\mathrm{b}}$ \\
& & 1,390 & 1,203
\end{tabular}

LLNL

Radiochemistry

515

$465^{c}$

NCSU

$\begin{array}{lrr}\text { Gamma } & 4,566 & 4,023^{d} \\ \text { spectroscopy } & 192 & 192 \\ \text { Radiochemistry } & 192\end{array}$

TMA
Radiochemistry
2792
2,595

TOTAL

10,326

9,250

a Includes duplicates and standards.

b Number does not include 3 additional ${ }^{60} \mathrm{Co}$ or 107 additional $40 \mathrm{~K}$ values received but not requested.

c Number does not include 8 additional 238Pu values received but not requested.

d Number does not include 435 additional 60 Co values received but not requested.

16 which show most of the data clustered about an ideal line. In the event that the results for a DCD do not meet the quality control criteria established in the contract, the laboratory performing the analyses is required to analyze a second set of samples that are duplicates of the original samples. DCDs still found unacceptable do not meet the QA guidelines and are excluded from the dose assessment.

\section{Summary Performance on the Duplicates and Standards of Participating Laboratories}

The radionuclides most often measured in the program are ${ }^{90} \mathrm{Sr}$ (beta counting), ${ }^{137} \mathrm{Cs}$ (beta and gamma-ray spectroscopy), $239+240 \mathrm{Pu}$ and $238 \mathrm{Pu}$ (alpha pulse-height analysis), and ${ }^{241} \mathrm{Am}$ (alpha pulse-height analysis and gamma-ray spectroscopy). There were 10,326 total analyses, including the duplicate and standard samples of the QC program, requested of the four participating laboratories. The largest fraction of the analyses was performed by NCSU at $46 \%$ followed by TMA at $27 \%$, LRE at $22 \%$, and LLNL at $5 \%$. 
Table 3 summarizes the number of duplicate and standard analyses associated with the 10,326 total analyses performed on soil, vegetation, terrestrial animal, and marine organism samples evaluated as part of the PNMIRS QC program. The number of duplicates and standards presented for each individual sample matrix are representative of the total number of those sample types sent for analysis. Since the majority of samples sent for analysis were soils, more duplicate pairs and soil standards of this matrix are reported. Conversely, since very few marine organisms were sent for analysis, only a small number of duplicates and standards of that matrix were sent. Of the 10,326 analyses evaluated herein, $18 \%$ were associated with the QC program. On an individual laboratory basis, QC program analyses accounted for $17 \%$ of NCSU's, $22 \%$ of TMA's, $14 \%$ of LRE's, and $20 \%$ of LLNL's total required analyses.

While not necessary to the QA program, three laboratories, NCSU, LRE and LLNL reported additional results for isotopes measured, but not required. NCSU reported $531{ }^{60} \mathrm{Co}$ values, LRE reported $3{ }^{60} \mathrm{Co}$ values and $107{ }^{40} \mathrm{~K}$ values, and LLNL reported $8{ }^{238} \mathrm{Pu}$ analyses (all except $238 \mathrm{Pu}$ obtained by gamma spectroscopy). When a laboratory reports isotopes that, while not required by the contract are included with the reported data, approval is based on the following: if the additional isotope is covered by the QA guidelines, acceptance is based on the limits imposed by the contract. On isotopes not covered by the QA guidelines, acceptance is based on whether the attending standards and duplicates are approved.

\section{Detailed Quality Control Results}

In the graphic representation of duplicate sample measurements, the results for the two samples (A \& B) are plotted on the $X$ and $Y$ axis respectively. In these figures, the broken line represents duplicates that are in perfect agreement and is not a fit to the data. Solid symbols depict duplicates that overlap at $2 \sigma$; open symbols depict duplicates that do not overlap at $2 \sigma$.

The standard sample measurement results are plotted against the certified value. In these figures, the different standard types (different activity levels) have been normalized by dividing the reported activity by the certified activity of the corresponding standard. The horizontal lines represent the certified value normalized to itself, plus and minus $1 \sigma$. Solid symbols depict standards that overlap the certified value at $1 \sigma$; open symbols depict standards that do not overlap the certified value at $1 \sigma$.

In the graphic representations of gamma spectroscopy to gamma spectroscopy and radiochemistry to gamma spectroscopy results, a broken line is also used to represent measurement results that are in perfect agreement and is not a fit to the data. 
Table 3. Summary of the duplicate and standard analyses evaluated for each participating laboratory as part of the quality control program for the Post Northern Marshall Islands Radiological Survey.

Laboratory

LRE

SUBTOTAL

LLNL

SUBTOTAL

NCSU

SUBTOTAL

TMA

SUBTOTAL GRAND TOTAL
Sample type $\quad 90 \mathrm{Sr}$ Soil

Duplicate

Standard

Vegetation

Duplicate

Standard

Marine

organism

Duplicate

Standard

Soil

Duplicate

Standard

Vegetation

Duplicate

Standard

Soil

Duplicate

Standard

Vegetation

Duplicate

Standard

Soil

Duplicate

Standard

Vegetation

Duplicate

Standard

Terrestrial

animal

Duplicate

Standard

28
9

14

11

\section{1}

65

$\begin{array}{rr}- & - \\ - & \\ 9 & 9 \\ 8 & 8 \\ 17 & 17\end{array}$

-
-
9
8
17

16

15

36

16

${ }^{137} \mathrm{Cs}$

$239+240 \mathrm{Pu}$

${ }^{241} \mathrm{Am}$

Total

$\begin{array}{ll}8 & 36 \\ 9 & 16\end{array}$

28

9

14

11

26

46

16

138

50

70

52 
Taken as a group, the acceptable gamma spectroscopy and radiochemical analyses of soil and vegetation and the radiochemical analyses of terrestrial animals and marine organisms have a high degree of compliance with the QC criteria, and thus we are confident that these measurements accurately reflect the radionuclide concentrations of the locations sampled.

\section{Gamma Spectroscopy Analysis - Soil and Vegetation Samples}

Results for acceptable gamma spectroscopy analysis of soil and vegetation samples are summarized in Table 4 (LRE) and Table 5 (NCSU). Overall, the success rate for gamma spectroscopy analysis of soil duplicate and standard samples was $81 \%$ and $100 \%$, respectively, for LRE and $93 \%$ and $97 \%$, respectively, for NCSU. The success rate for gamma spectroscopy analyses of vegetation duplicate and standard samples was $96 \%$ and $100 \%$, respectively, for LRE and $100 \%$ and $93 \%$, respectively, for NCSU.

Figure 1 and Figure 3 present a graphic representation of the duplicate sample measurements for ${ }^{137} \mathrm{Cs}$ and ${ }^{241} \mathrm{Am}$ measured in soil and vegetation by LRE and NCSU. In the figures, the broken line represents perfect agreement and is not a fit to the data. The range of duplicate soil sample activities measured was 0.020 to 300 $\mathrm{pCi} / \mathrm{g}$ for ${ }^{137} \mathrm{Cs}$ and 0.063 to $48 \mathrm{pCi} / \mathrm{g}$ for ${ }^{241} \mathrm{Am}$. The range of duplicate vegetation sample ${ }^{137} \mathrm{Cs}$ activities measured was 3.2 to $586 \mathrm{pCi} / \mathrm{g}$.

Figure 2 presents a graphic representation of the standard sample measurements for ${ }^{137} \mathrm{Cs}$ and ${ }^{241} \mathrm{Am}$ measured in soil and vegetation by LRE and NCSU. In this figure the standards, ranging in activities, were normalized by dividing the reported activity by the certified activity (both in $\mathrm{dpm} / \mathrm{g}$ ) with the resultant values plotted. In this figure ${ }^{241} \mathrm{Am}$ is shown above ${ }^{137} \mathrm{Cs}$. The horizontal lines represent the certified values normalized to itself, plus and minus $10 \%$.

As expected, the lowest activity level samples showed the greatest differences when compared as duplicates. Because these samples were low in activity, they have less stringent error requirements, as shown in Table 1. Consequently, the accepted values for low-activity samples deviates further from the ideal line than for highactivity samples. Vegetation and soil analyses showed the greatest difference when the samples were low in activity.

Vegetation, more than any other matrix, approached the limits of detection for many of the contracting laboratories with a larger discrepancy in the results when compared as duplicates. In analyzing vegetation samples collected from the Marshall Islands, measuring ${ }^{137} \mathrm{Cs}$ activity generally presented no problem. ${ }^{241} \mathrm{Am}$, on the other hand, generally cannot be found in vegetation in high enough concentrations to accurately measure by non-destructive means. While the contracting laboratory measurements had to meet the second criterion as stated in the contract, results for ${ }^{241} \mathrm{Am}$ in duplicates generally were at or below detection levels and so were not plotted. While this may limit the amount of information collected for ${ }^{241} \mathrm{Am}$ in vegetation to that gathered by radiochemical means, it poses 
Table 4. Acceptable gamma spectroscopy quality control results for duplicate pairs and standard samples analyzed in soil and vegetation by Laboratory of Radiation Ecology.

\begin{tabular}{lccc}
\hline \multicolumn{2}{c}{$\begin{array}{c}\text { Delivery control } \\
\text { Document number total }\end{array}$} & $\begin{array}{c}\text { Soil } \\
\text { Duplicate pairs }\end{array}$ & $\begin{array}{c}\text { Soil } \\
\text { Standard samples }\end{array}$ \\
\hline Total of 4 & ${ }^{137} \mathrm{Cs}$ & 14 of $18(78 \%)$ & 6 of $6(100 \%)$ \\
Total of 4 & ${ }^{241} \mathrm{Am}$ & 15 of $18(83 \%)$ & 6 of $6(100 \%)$ \\
$\begin{array}{c}\text { Delivery control } \\
\text { Document number total }\end{array}$ & $\begin{array}{c}\text { Vegetation } \\
\text { Duplicate pairs }\end{array}$ & $\begin{array}{c}\text { Vegetation } \\
\text { Standard samples }\end{array}$ \\
\hline Total of 3 & ${ }^{137} \mathrm{Cs}$ & 12 of $12(100 \%)$ & 4 of $4(100 \%)$ \\
Total of 3 & ${ }^{241} \mathrm{Am}$ & 11 of $12(92 \%)$ & 4 of $4(100 \%)$ \\
\hline
\end{tabular}

Table 5. Acceptable gamma spectroscopy quality control results for duplicate pairs and standard samples analyzed in soil and vegetation by Nuclear Energy Services, North Carolina State University.

\begin{tabular}{llcc}
\hline \multicolumn{2}{c}{ Delivery control } & Soil \\
Document number total & Duplicate pairs & $\begin{array}{c}\text { Soil } \\
\text { Standard samples }\end{array}$ \\
\hline Total of 22 & ${ }^{137} \mathrm{Cs}$ & 214 of $223(96 \%)$ & 155 of $155(100 \%)$ \\
Total of 22 & ${ }^{241} \mathrm{Am}$ & 200 of $223(90 \%)$ & 103 of $110(94 \%)$ \\
$\begin{array}{c}\text { Delivery control } \\
\text { Document number total }\end{array}$ & $\begin{array}{c}\text { Vegetation } \\
\text { Duplicate pairs }\end{array}$ & $\begin{array}{c}\text { Vegetation } \\
\text { Standard samples }\end{array}$ \\
\hline Total of 1 & ${ }^{137} \mathrm{Cs}$ & 9 of $9(100 \%)$ & 18 of $21(86 \%)$ \\
Total of 1 & ${ }^{241} \mathrm{Am}$ & 9 of $9(100 \%)$ & 21 of $21(100 \%)$ \\
\hline
\end{tabular}

no limitation in establishing a database for ${ }^{137} \mathrm{Cs}$, which has been found to contribute more to the radiation dose than $241 \mathrm{Am}$. The accepted gamma spectroscopy analyses for ${ }^{137} \mathrm{Cs}$ and ${ }^{241} \mathrm{Am}$ in soil and vegetation have a high degree of compliance with the QC criteria. 


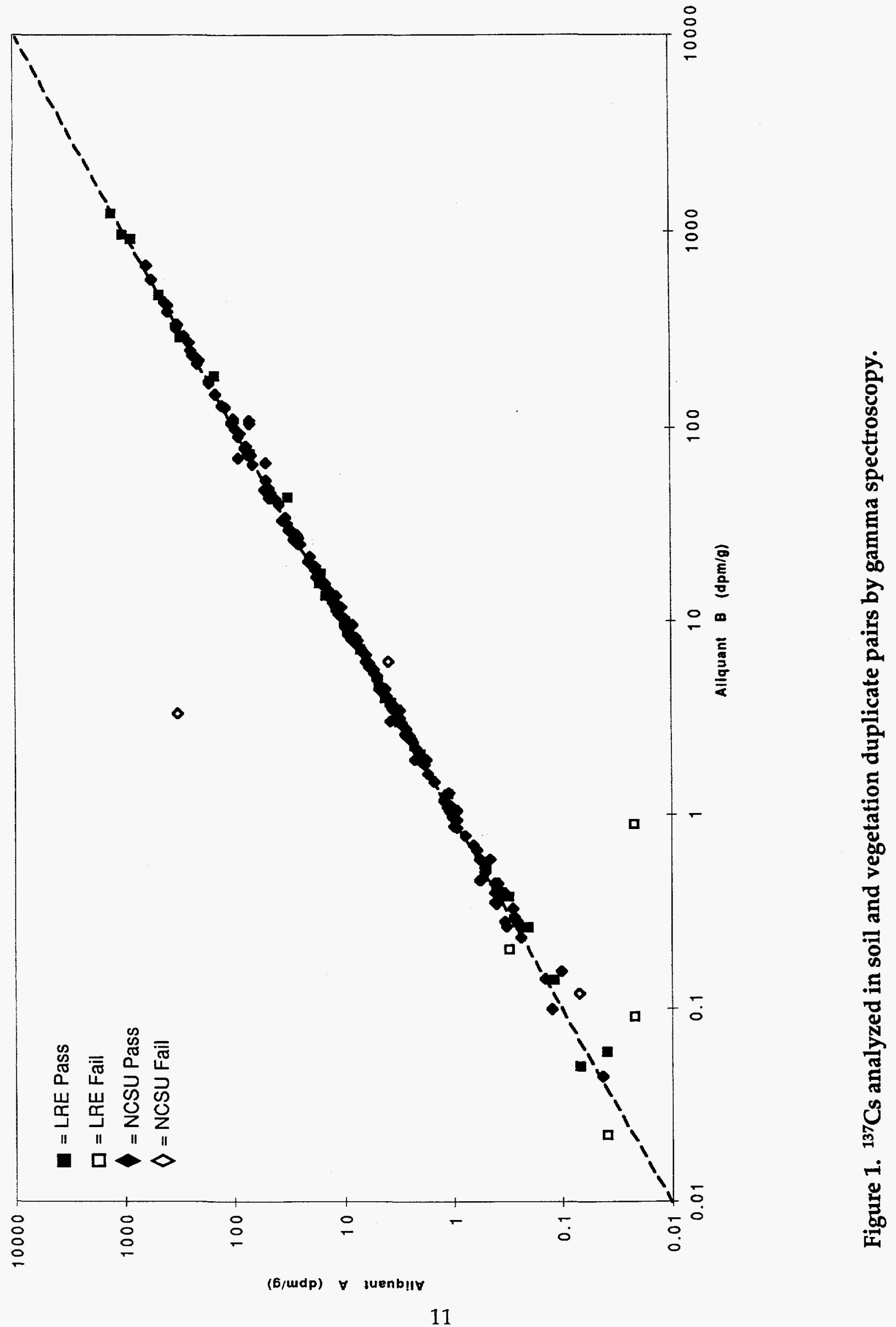




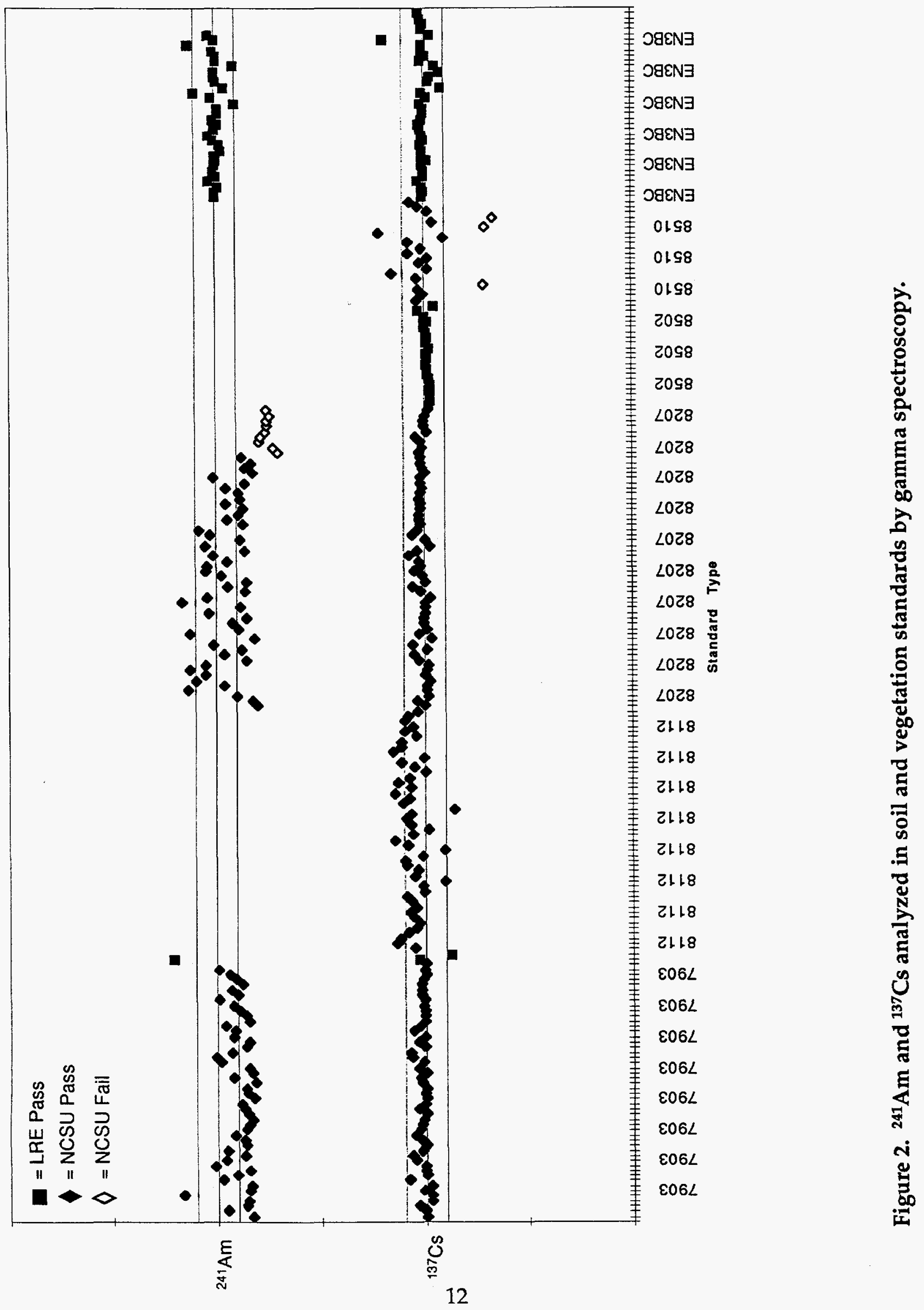




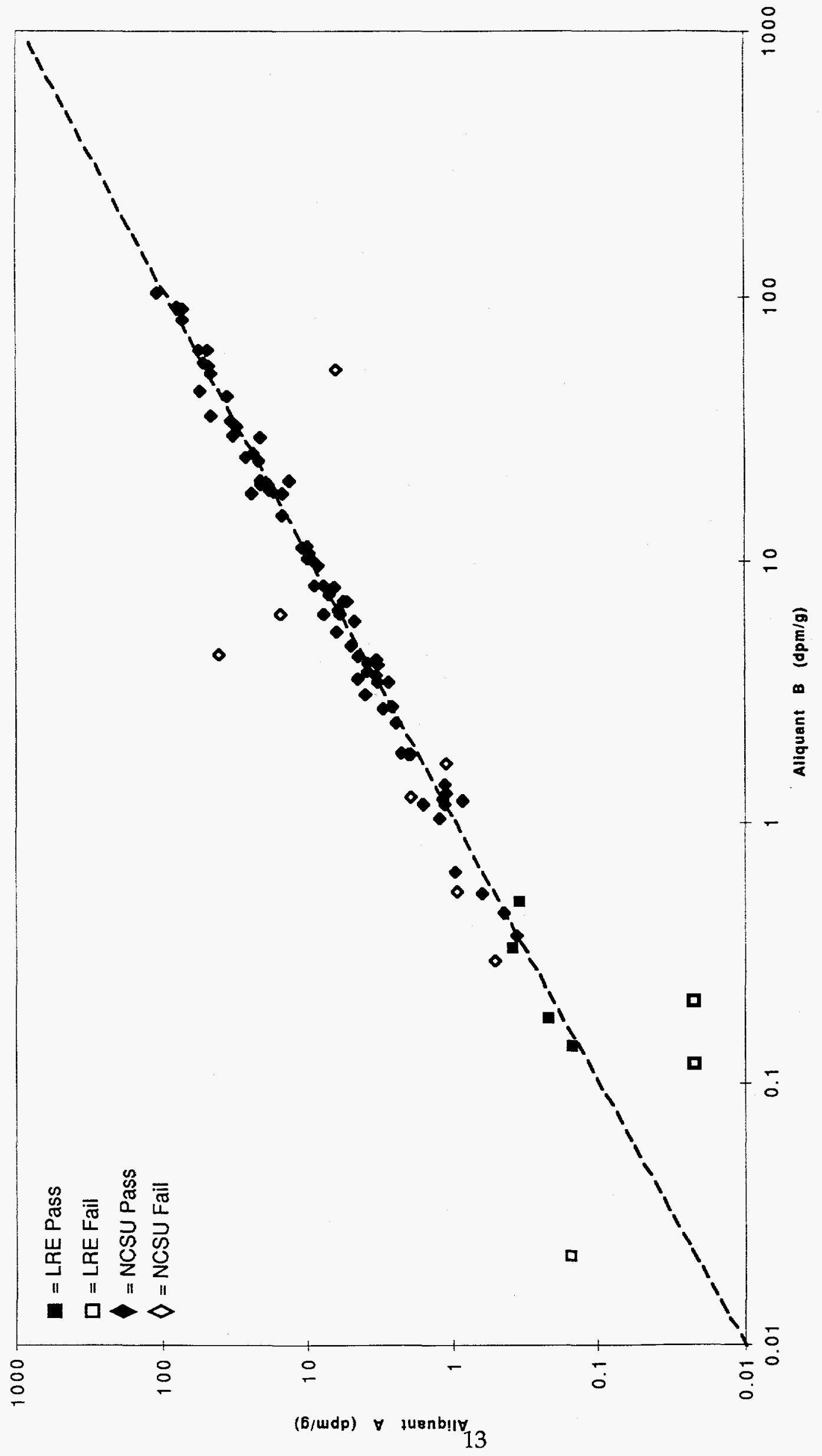

总 
${ }^{137} \mathrm{Cs}$ in Soil and Vegetation Duplicate Samples by Gamma Spectroscopy

The graphic representation of sample comparisons for ${ }^{137} \mathrm{Cs}$ measured in soil and vegetation duplicates by gamma spectroscopy appears in Figure 1 . The range of ${ }^{137} \mathrm{Cs}$ activities measured in soil duplicates was 0.054 to $1.9 \mathrm{pCi} / \mathrm{g}$ for LRE and 0.020 to 300 $\mathrm{pCi} / \mathrm{g}$ for NCSU. Overall, the accepted mean value of the ratio of the sample A activity to sample $\mathrm{B}$ activity for ${ }^{137} \mathrm{Cs}$ measured in soil duplicates by gamma spectroscopy was $0.93 \pm 9.6 \%$ for LRE and $1.0 \pm 7.2 \%$ for NCSU. The range of ${ }^{137} \mathrm{Cs}$ activities measured in vegetation duplicates was 3.2 to $586 \mathrm{pCi} / \mathrm{g}$ for LRE and 4.2 to $48 \mathrm{pCi} / \mathrm{g}$ for NCSU. Overall, the accepted mean of the ratio of the sample A activity to sample $\mathrm{B}$ activity for ${ }^{137} \mathrm{Cs}$ measured in vegetation duplicates by gamma spectroscopy was $0.96 \pm 11 \%$ for LRE and $0.99 \pm 21 \%$ for NCSU.

\section{${ }^{137} \mathrm{Cs}$ in Soil and Vegetation Standard Samples by Gamma Spectroscopy}

The graphic representation of sample comparisons for ${ }^{137} \mathrm{Cs}$ measured in soil and vegetation standards by gamma spectroscopy appear as the lower group in Figure 2. Overall, the accepted mean value of ratio of the measured activity to certified activity for ${ }^{137} \mathrm{Cs}$ measured in soil standards by gamma spectroscopy was $1.0 \pm 4.1 \%$ (EN3BC) for LRE and $1.0 \pm 2.4 \%$ (7903), $1.1 \pm 5.6 \%$ (8112), and $1.0 \pm 2.4 \%$ (8207) for NCSU. For vegetation, the overall accepted mean value of the ratio of the measured activity to certified activity for ${ }^{137} \mathrm{Cs}$ measured in vegetation standards by gamma spectroscopy was $0.98 \pm 1.0 \%$ (8502) and $0.99 \pm 3.2 \%$ (8510) for LRE and $1.0 \pm$ $6.7 \%$ (8510) for NCSU. In reporting the ratios, the standard type is enclosed in parenthesis.

\section{${ }^{241} \mathrm{Am}$ in Duplicate Soil Samples by Gamma Spectroscopy}

The graphic representation of duplicate sample comparisons for ${ }^{241} \mathrm{Am}$ measured in soil by gamma spectroscopy appear in Figure 3. The range of $241 \mathrm{Am}$ activities measured was 0.063 to $0.23 \mathrm{pCi} / \mathrm{g}$ for LRE and 0.16 to $48 \mathrm{pCi} / \mathrm{g}$ for NCSU. Overall, the accepted mean value of the ratio of sample A activity to sample B activity for ${ }^{241} \mathrm{Am}$ measured in soil duplicates by gamma spectroscopy was $1.0 \pm 23 \%$ for LRE and $0.99 \pm 17 \%$ for NCSU.

\section{${ }^{241} \mathrm{Am}$ in Soil Standard Samples by Gamma Spectroscopy}

The graphic representation of standard sample measurements for ${ }^{241} \mathrm{Am}$ measured in soil by gamma spectroscopy appear as the upper group in Figure 2. In this figure the standards, ranging in activities, were normalized by dividing the reported activity by the certified activity (both in $\mathrm{dpm} / \mathrm{g}$ ) with the resultant values plotted. The horizontal lines represent the certified value normalized to itself, plus and minus $10 \%$. Overall, the accepted mean value of the ratio of the measured activity to certified activity for $241 \mathrm{Am}$ in soil standards was $1.0 \pm 4.1 \%$ (EN3BC) for LRE and $0.90 \pm 7.3 \%(7903)$ and $0.95 \pm 10 \%$ (8207) for NCSU. In reporting the ratios, the standard type is enclosed in parenthesis. 


\section{Radiochemistry Analysis - Soil and Vegetation Samples}

Results for acceptable radiochemical analyses of soil and vegetation samples are summarized in Table 6 (LRE), Table 7 (LLNL), Table 8 (NCSU), and Table 9 (TMA). Overall, the success rate for radiochemical analyses of soil duplicate and standard samples was $95 \%$ and $87 \%$, respectively, for LRE; $95 \%$ and $88 \%$, respectively, for LLNL; $100 \%$ and $100 \%$, respectively, for NCSU; and $95 \%$ and $95 \%$, respectively, for TMA. The success rate for radiochemical analyses of vegetation duplicate and standard samples was $89 \%$ and $100 \%$, respectively, for LRE; $100 \%$ and $88 \%$, respectively, for LLNL; $100 \%$ and $100 \%$, respectively, for NCSU; and $98 \%$ and $98 \%$, respectively, for TMA.

Figures 4 through 8 present a graphic representation of the duplicate and standard sample results for ${ }^{90} \mathrm{Sr},{ }^{137} \mathrm{Cs}, 239+240 \mathrm{Pu}$, and ${ }^{241} \mathrm{Am}$ measured in soil and vegetation by LRE, LLNL, NCSU, and TMA. The range of duplicate soil sample activities measured radiochemically was 0.0063 to $185 \mathrm{pCi} / \mathrm{g}$ for $90 \mathrm{Sr}, 0.041$ to $150 \mathrm{pCi} / \mathrm{g}$ for ${ }^{137} \mathrm{Cs}, 0.0014$ to $57 \mathrm{pCi} / \mathrm{g}$ for $239+240 \mathrm{Pu}$, and 0.00046 to $32 \mathrm{pCi} / \mathrm{g}$ for ${ }^{241} \mathrm{Am}$. The range of duplicate vegetation sample activities measured radiochemically was 0.0014 to 11 $\mathrm{pCi} / \mathrm{g}$ for ${ }^{90} \mathrm{Sr}, 0.75$ to $385 \mathrm{pCi} / \mathrm{g}$ for ${ }^{137} \mathrm{Cs}, 0.0000060$ to 0.026 to $\mathrm{pCi} / \mathrm{g}$ for $239+240 \mathrm{Pu}$, and 0.00013 to $0.020 \mathrm{pCi} / \mathrm{g}$ for ${ }^{241} \mathrm{Am}$.

The trends discussed with respect to the gamma spectroscopy analyses of low activity level soil and vegetation samples is also apparent in the radiochemical analyses: analytical results approached the limits of detection for many of the participating laboratories with a larger discrepancy in the results when compared as duplicates. This was particularly apparent in vegetation where $239+240 \mathrm{Pu}$ and $241 \mathrm{Am}$ concentration levels in vegetation samples were often at or near detection limits for some of the participating laboratories. Once again, because these samples were low in activity, they have a less stringent error requirement. While detection limits were accepted they were not plotted nor were they included in the overall ranges, means, and standard deviation percentages. Despite some scatter that arose from the low activity levels, the radiochemical analyses of ${ }^{90} \mathrm{Sr}, 137 \mathrm{Cs}, 239+240 \mathrm{Pu}$, and ${ }^{241} \mathrm{Am}$ in soil and vegetation yielded an acceptable data base. This is especially true for ${ }^{90} \mathrm{Sr}$ and ${ }^{137} \mathrm{Cs}$, which have been found to contribute the most to the radiation dose. The accepted radiochemical analyses for ${ }^{90} \mathrm{Sr},{ }^{137} \mathrm{Cs}, 239+240 \mathrm{Pu}$, and ${ }^{241} \mathrm{Am}$ in soil and vegetation have a high degree of compliance with the QC criteria. 
Table 6. Acceptable radiochemistry quality control results for duplicate pairs and standard samples analyzed in soil and vegetation by the Laboratory of Radiation Ecology.

\begin{tabular}{|c|c|c|c|}
\hline \multicolumn{2}{|c|}{$\begin{array}{c}\text { Delivery control } \\
\text { Document number total }\end{array}$} & \multirow{2}{*}{$\begin{array}{c}\text { Soil } \\
\text { Duplicate pairs } \\
27 \text { of } 28(96 \%)\end{array}$} & \multirow{2}{*}{$\begin{array}{c}\text { Soil } \\
\text { Standard samples } \\
8 \text { of } 9(89 \%)\end{array}$} \\
\hline Total of 4 & ${ }^{90} \mathrm{Sr}$ & & \\
\hline Total of 5 & ${ }^{137} \mathrm{Cs}$ & 18 of $18(100 \%)$ & 8 of $10(80 \%)$ \\
\hline Total of 4 & $239+240 \mathrm{Pu}$ & 26 of $28(93 \%)$ & 9 of $9(100 \%)$ \\
\hline Total of 5 & ${ }^{241} \mathrm{Am}$ & 26 of $28(93 \%)$ & 8 of $10(80 \%)$ \\
\hline \multicolumn{2}{|c|}{$\begin{array}{c}\text { Delivery control } \\
\text { Document number total }\end{array}$} & $\begin{array}{c}\text { Vegetation } \\
\text { Duplicate pairs }\end{array}$ & $\begin{array}{c}\text { Vegetation } \\
\text { Standard samples }\end{array}$ \\
\hline Total of 4 & ${ }^{90} \mathrm{Sr}$ & 10 of $14(71 \%)$ & 11 of $11(100 \%)$ \\
\hline Total of 4 & ${ }^{137} \mathrm{Cs}$ & 4 of $4(100 \%)$ & 11 of $11(100 \%)$ \\
\hline Total of 4 & $239+240 \mathrm{Pu}$ & 14 of $14(100 \%)$ & 11 of $11(100 \%)^{\mathrm{a}}$ \\
\hline Total of 4 & ${ }^{241} \mathrm{Am}$ & 13 of $14(93 \%)$ & 11 of $11(100 \%)$ \\
\hline
\end{tabular}

a One approved at $12 \%$.

Table 7. Acceptable radiochemistry quality control results for duplicate pairs and standard samples analyzed in soil and vegetation by Lawrence Livermore National Laboratory.

Delivery control Soil Soil Document number total Duplicate pairs Standard samples

Total of $4 \quad 239+240 \mathrm{Pu}$ 21 of $22(95 \%)$ 18 of $21(86 \%)$

Total of $1 \quad{ }^{241} \mathrm{Am}$ - $\quad 5$ of $5(100 \%)$

Delivery control Vegetation Document number total Duplicate pairs Vegetation

\begin{tabular}{|c|c|c|c|}
\hline \multicolumn{2}{|c|}{ Document number tota } & Duplicate pairs & Standard samples \\
\hline Total of 2 & ${ }^{90} \mathrm{Sr}$ & 9 of $9(100 \%)$ & 8 of $8(100 \%)$ \\
\hline Total of 2 & ${ }^{137} \mathrm{Cs}$ & 9 of $9(100 \%)$ & 7 of $8(88 \%)$ \\
\hline Total of 3 & $239+240 \mathrm{Pu}$ & 9 of $9(100 \%)$ & 7 of $9(78 \%) a$ \\
\hline Total of 1 & ${ }^{241} \mathrm{Am}$ & --- & 1 of $1(100 \%)$ \\
\hline
\end{tabular}

a One approved at $13 \%$. 
Table 8. Acceptable radiochemistry quality control results for duplicate pairs and standard samples analyzed in soil and vegetation by Nuclear Energy Services, North Carolina State University.

Delivery control

\begin{tabular}{|c|c|c|c|}
\hline \multicolumn{2}{|c|}{ document number total } & Duplicate samples & Standard samples \\
\hline Total of 1 & $90 \mathrm{Sr}$ & 7 of $7(100 \%)$ & 4 of $4(100 \%)$ \\
\hline Total of 1 & ${ }^{137} \mathrm{Cs}$ & 7 of $7(100 \%)$ & 4 of $4(100 \%)$ \\
\hline Total of 1 & $239+240 \mathrm{Pu}$ & 7 of $7(100 \%)$ & 4 of $4(100 \%)$ \\
\hline \multicolumn{2}{|c|}{$\begin{array}{c}\text { Delivery control } \\
\text { document number total }\end{array}$} & $\begin{array}{l}\text { Vegetation } \\
\text { Duplicate pairs }\end{array}$ & $\begin{array}{c}\text { Vegetation } \\
\text { Standard samples }\end{array}$ \\
\hline Total of & ${ }^{90} \mathrm{Sr}$ & 2 of $2(100 \%)$ & 2 of $2(100 \%)$ \\
\hline Total of 1 & $239+240 \mathrm{Pu}$ & 2 of $2(100 \%)$ & 2 of $2(100 \%) a$ \\
\hline
\end{tabular}

a One standard approved at $13 \%$.

Table 9. Acceptable radiochemistry quality control results for duplicate pairs and standard samples analyzed in soil and vegetation by Thermo Analytical Norcal.

Delivery control

\begin{tabular}{|c|c|c|c|}
\hline \multicolumn{2}{|c|}{ Document number total } & Duplicate pairs & Standard samples \\
\hline Total of 12 & ${ }^{90} \mathrm{Sr}$ & 49 of $52(94 \%)$ & 44 of $48(92 \%)$ \\
\hline Total of 12 & ${ }^{37} \mathrm{Cs}$ & 13 of $13(100 \%)$ & 38 of $41(93 \%)^{a, b}$ \\
\hline Total of 12 & $239+240 \mathrm{Pu}$ & 49 of $52(94 \%)$ & 40 of $42(95 \%)$ \\
\hline Total of 12 & ${ }^{241} \mathrm{Am}$ & 50 of $52(96 \%)$ & 42 of $42(100 \%) c$ \\
\hline \multicolumn{2}{|c|}{$\begin{array}{l}\text { Delivery control } \\
\text { document number total }\end{array}$} & $\begin{array}{l}\text { Vegetation } \\
\text { Duplicate pairs }\end{array}$ & $\begin{array}{c}\text { Vegetation } \\
\text { Standard samples }\end{array}$ \\
\hline Total of 13 & $90 \mathrm{Sr}$ & 38 of $40(95 \%)$ & 30 of $30(100 \%)^{d}$ \\
\hline Total of 11 & ${ }^{137} \mathrm{Cs}$ & 25 of $25(100 \%)$ & 27 of $28(96 \%)$ \\
\hline Total of 13 & $239+240 \mathrm{Pu}$ & 40 of $40(100 \%)$ & 30 of $30(100 \%) e$ \\
\hline Total of 13 & ${ }^{241} \mathrm{Am}$ & 39 of $40(98 \%)$ & 31 of $33(94 \%)^{f, g}$ \\
\hline
\end{tabular}

a One DCD approved at $14 \%$.

b One DCD approved at $12 \%$.

c One DCD approved at $13 \%$.

d One DCD approved at $11 \%$.

e One DCD approved at $13 \%$.

f One DCD had three new standards run at a later time. Results were 2 for 3 at $20 \%$. Cleared for payment by WLR.

g One DCD approved at $14 \%$. 


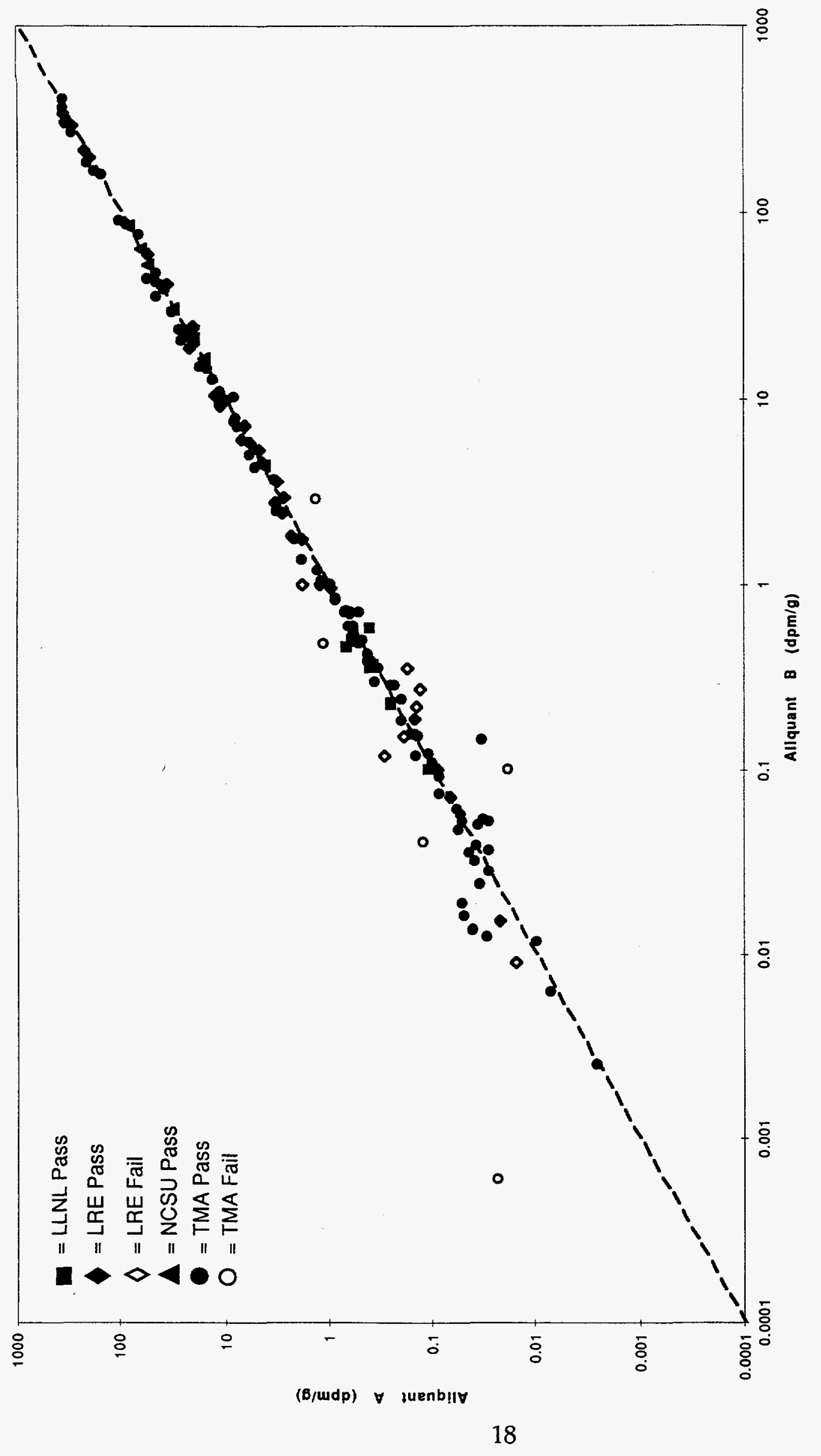

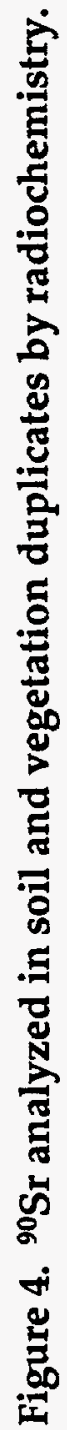




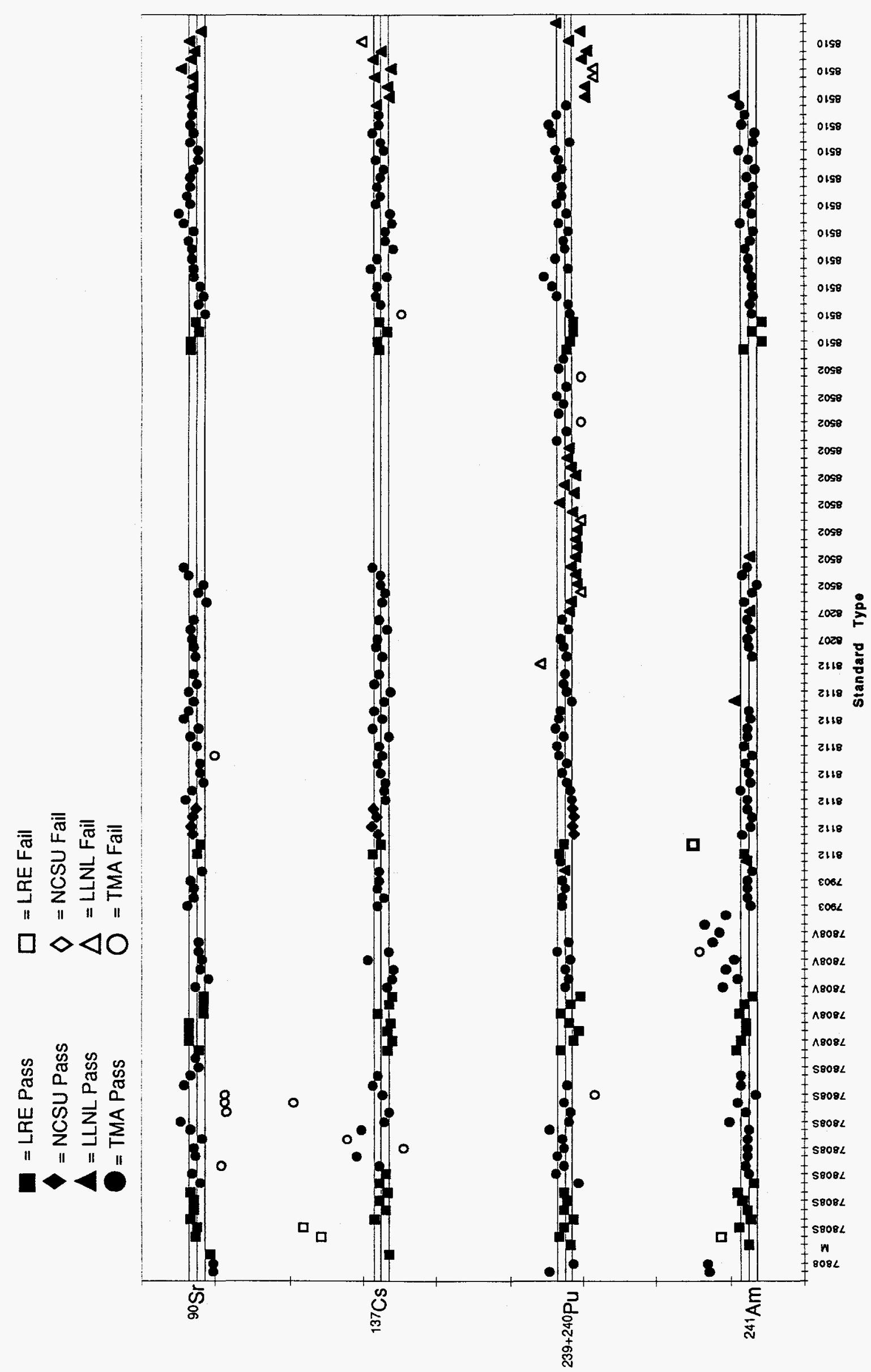

폴. 


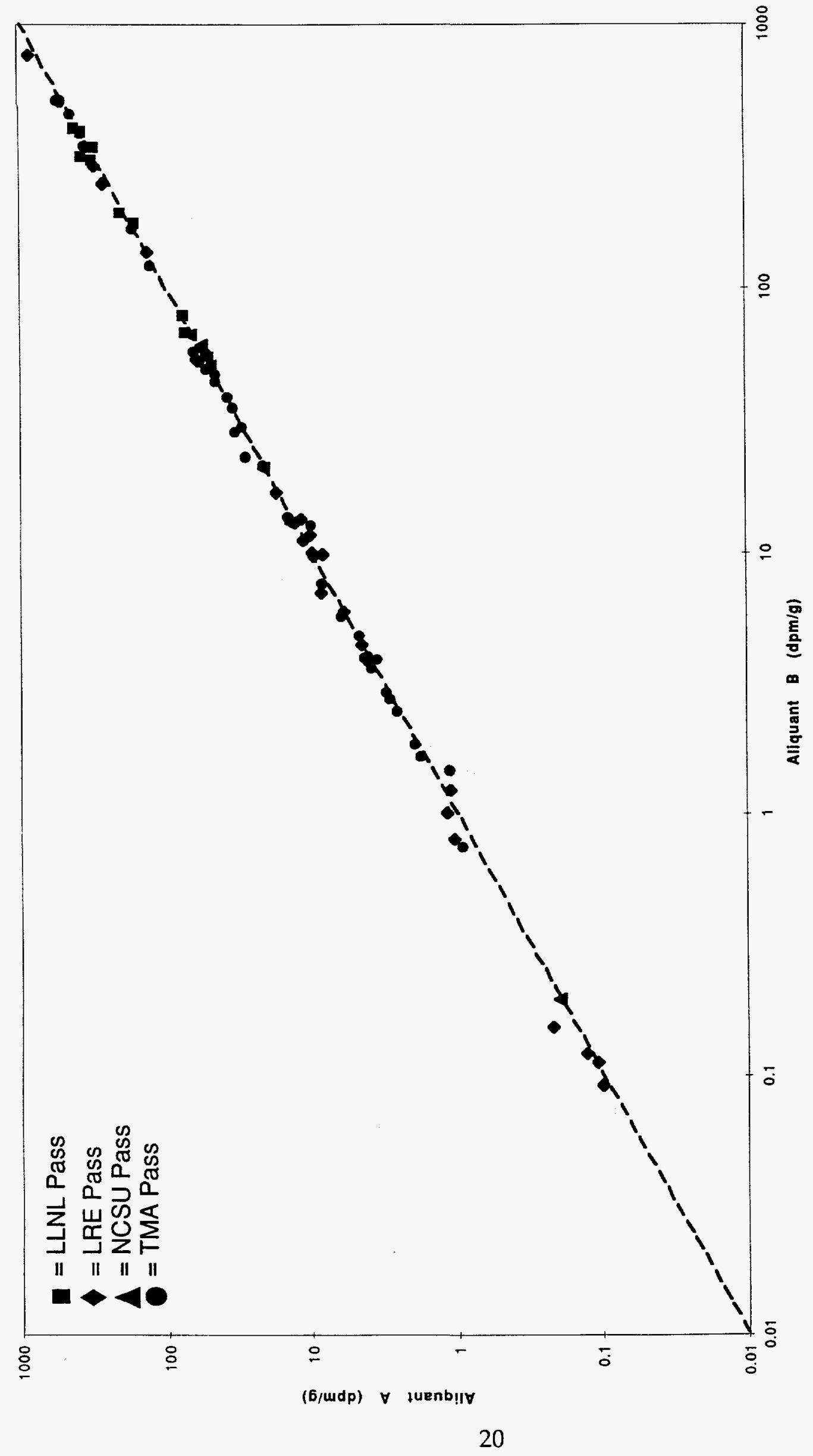

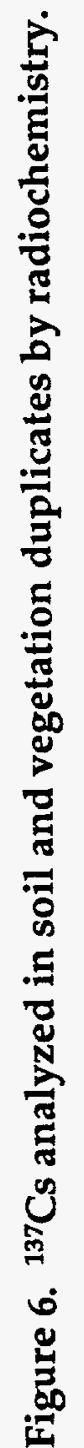




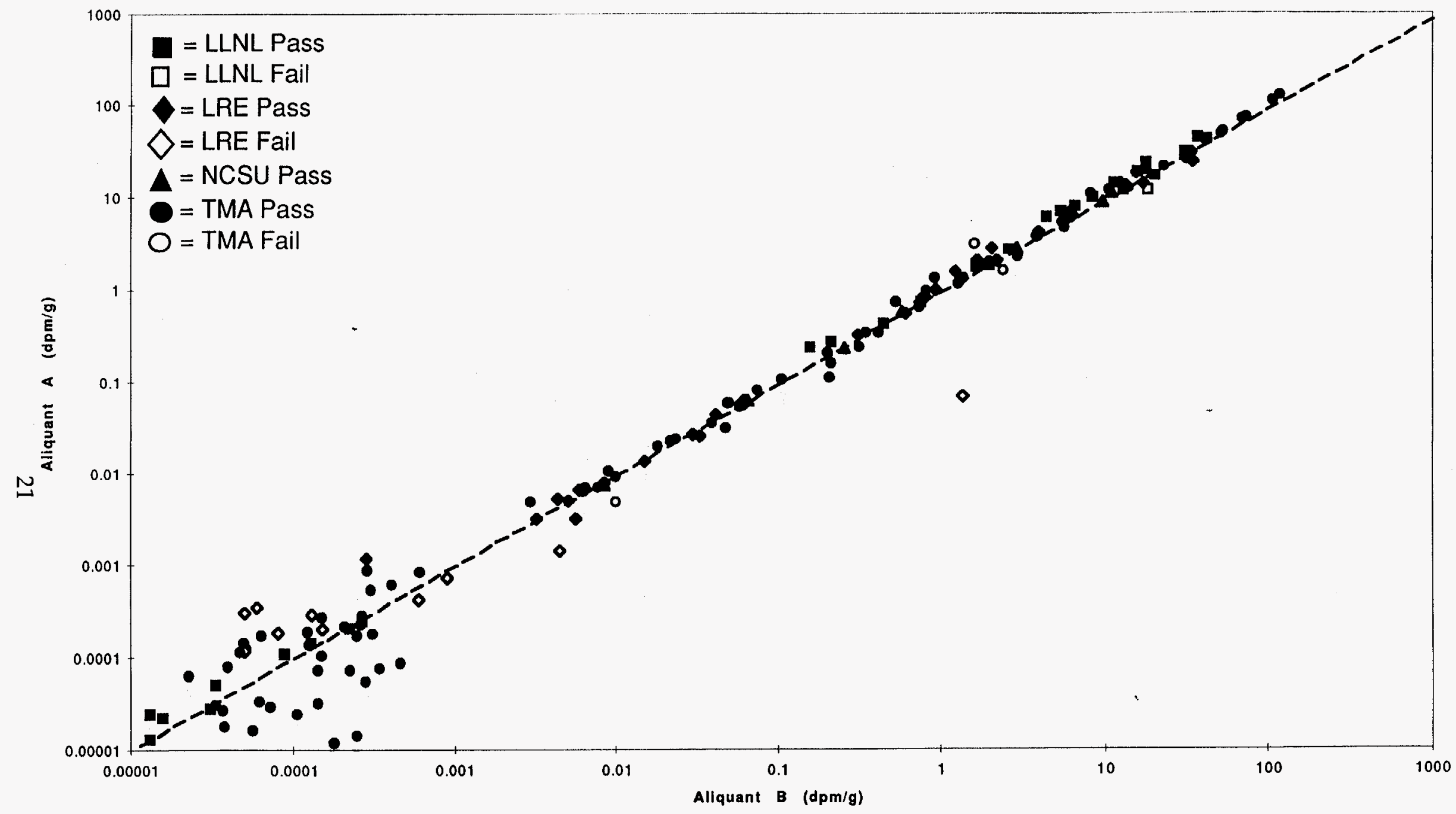

Figure 7. ${ }^{239+240} \mathrm{Pu}$ analyzed in soil and vegetation duplicates by radiochemistry. 


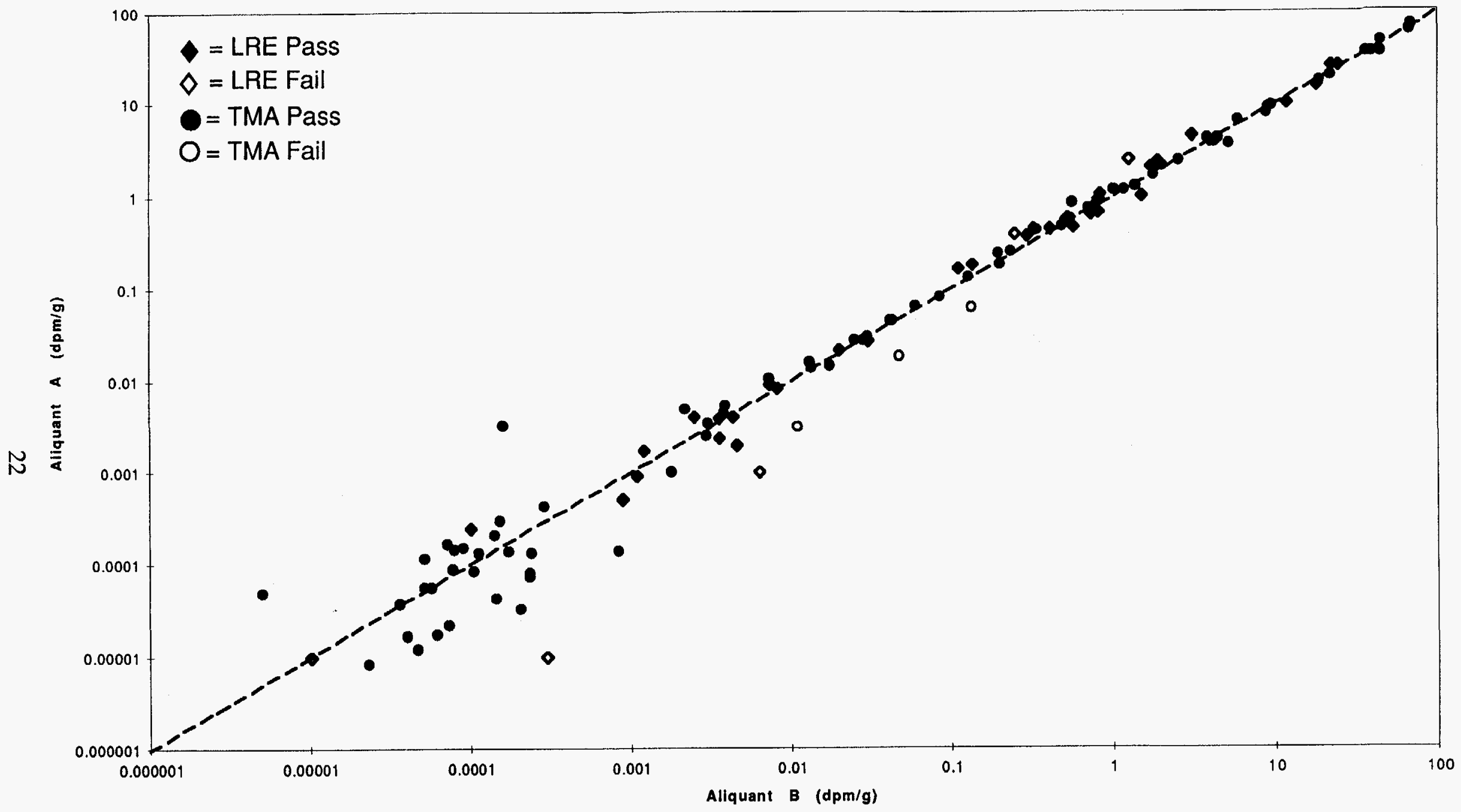

Figure 8. ${ }^{241} \mathrm{Am}$ analyzed in soil and vegetation duplicates by radiochemistry. 
90Sr in Soil and Vegetation Duplicate Samples by Radiochemistry

The graphic representation of comparative results for ${ }^{90} \mathrm{Sr}$ measured in soil and vegetation duplicate samples by radiochemistry appear in Figure 4 . The range of ${ }^{90} \mathrm{Sr}$ activities measured in soil was 0.18 to $160 \mathrm{pCi} / \mathrm{g}$ for LRE, 1.8 to $38 \mathrm{pCi} / \mathrm{g}$ for $\mathrm{NCSU}$, and 0.0063 to $185 \mathrm{pCi} / \mathrm{g}$ for TMA. The range of ${ }^{90} \mathrm{Sr}$ activities measured in vegetation was 0.0068 to $11 \mathrm{pCi} / \mathrm{g}$ for LRE, 0.046 to $0.3 \mathrm{pCi} / \mathrm{g}$ for LLNL, and 0.0014 to $9.9 \mathrm{pCi} / \mathrm{g}$ for TMA. Overall, the accepted mean value of the ratio of the sample A activity to sample B activity for ${ }^{90} \mathrm{Sr}$ measured in soil duplicates by radiochemistry was $0.98 \pm 12 \%$ for LRE, $0.98 \pm 3.4 \%$ for NCSU, and $1.2 \pm 39.4 \%$ for TMA. The accepted mean value of the ratio of the sample A activity to sample B activity for ${ }^{90} \mathrm{Sr}$ measured in vegetation duplicates by radiochemistry was $1.0 \pm 17 \%$ for LRE, 1.1 $\pm 18 \%$ for $L L N L$, and $0.93 \pm 22 \%$ for TMA.

\section{${ }^{90} \mathrm{Sr}$ in Soil and Vegetation Standard Samples by Radiochemistry}

The graphic representation of comparative results for ${ }^{90} \mathrm{Sr}$ measured in soil and vegetation standard samples by radiochemistry appear as the uppermost group in Figure 5. Overall, the accepted mean value of the ratio of the measured activity to certified activity for ${ }^{90} \mathrm{Sr}$ in soil standards (standard type listed in brackets) by radiochemistry was $1.1 \pm 3.2 \%$ (7808S) and $0.95 \pm 1.9 \%$ (8112) for LRE, $1.1 \pm 1.8 \%$ for NCSU, and $1.1 \pm 7.9 \%$ (7808S), $1.0 \pm 6.4 \%$ (7903), $1.0 \pm 4.0 \%$ (8112), $1.1 \pm 1.9 \%$ (8207), and $1.0 \pm 11.6 \%(8502)$ for TMA. The accepted mean value of the ratio of the measured activity to the certified activity for ${ }^{90} \mathrm{Sr}$ measured in vegetation standards by radiochemistry was $1.0 \pm 9.9 \%(7808 \mathrm{~V})$ and $1.0 \pm 4.6 \%$ (8510) for LRE, $1.1 \pm 6.5 \%$ (8510) for LLNL, and $1.0 \pm 5.7 \%(7808 \mathrm{~V})$ and $1.1 \pm 7.2 \%(8510)$ for TMA.

\section{${ }^{137}$ Cs in Soil and Vegetation Duplicate Samples by Radiochemistry}

The graphic representation of comparative results for ${ }^{137} \mathrm{Cs}$ measured in soil and vegetation duplicate samples by radiochemistry appear in Figure 6 . The range of ${ }^{137} \mathrm{Cs}$ activities measured in soil was 0.041 to $120 \mathrm{pCi} / \mathrm{g}$ for LRE, 0.086 to $30 \mathrm{pCi} / \mathrm{g}$ for $\mathrm{NCSU}$, and 0.34 to $150 \mathrm{pCi} / \mathrm{g}$ for TMA. The range of ${ }^{137} \mathrm{Cs}$ activities measured in vegetation was 5.0 to $385 \mathrm{pCi} / \mathrm{g}$ for LRE, 31 to $190 \mathrm{pCi} / \mathrm{g}$ for LLNL, and 0.75 to 240 $\mathrm{pCi} / \mathrm{g}$ for TMA. Overall, the accepted mean value of the ratio of sample A activity to sample B activity for ${ }^{137} \mathrm{Cs}$ measured in soil duplicates by radiochemistry was 0.96 $\pm 13 \%$ for LRE, $0.99 \pm 5 \%$ for NCSU, and $1.0 \pm 11 \%$ for TMA. The accepted mean value of the ratio of the sample A activity to sample $B$ activity for ${ }^{137} \mathrm{Cs}$ measured in vegetation duplicates by radiochemistry was $1.0 \pm 9.9 \%$ for LRE, $1.0 \pm 8.4 \%$ for LLNL, and $1.0 \pm 7.5 \%$ for TMA.

${ }^{137} \mathrm{Cs}$ in Soil and Vegetation Standard Samples by Radiochemistry

The graphic representation of comparative results for ${ }^{137} \mathrm{Cs}$ measured in soil and vegetation standards by radiochemistry appear as the second group from the top of Figure 5. Overall, the accepted mean value of the ratio of measured activity to 
certified activity for ${ }^{137} \mathrm{Cs}$ in soil standards (standard type shown in brackets) by radiochemistry was $0.99 \pm 6.4 \%$ (7808S) and $1.1 \pm 4.6 \%$ (8112) for LRE, $1.1 \pm 2.5 \%$ for NCSU, and $1.1 \pm 13 \%$ (7808S), $1.03 .1 \%$ (7903), $1.0 \pm 0.8 \%$ (8112), $1.0 \pm 5.2 \%$ (8207), and $1.0 \pm 5.6 \%(8502)$ for TMA. The accepted mean value of the ratio of the measured activity to certified activity for ${ }^{137} \mathrm{Cs}$ measured in vegetation standards by radiochemistry was $0.91 \pm 6.6 \%(7808 \mathrm{~V})$ and $1.0 \pm 4.9 \%$ (8510) for LRE, $1.0 \pm 9.3 \%$ (8510) for LLNL, and $0.94 \pm 13 \%$ (7808V) and $1.0 \pm 8.2 \%$ (8510) for TMA.

\section{${ }^{239+240} \mathrm{Pu}$ in Soil and Vegetation Duplicate Samples by Radiochemistry}

The graphic representation of comparative results for $239+240 \mathrm{Pu}$ measured in soil and vegetation duplicate samples by radiochemistry appear in Figure 7 . The range of $239+240 \mathrm{Pu}$ activities measured in soil was 0.0014 to $16 \mathrm{pCi} / \mathrm{g}$ for LRE, 0.070 to 20 $\mathrm{pCi} / \mathrm{g}$ for LLNL, 0.0036 to $5.2 \mathrm{pCi} / \mathrm{g}$ for NCSU, and 0.0014 to $57 \mathrm{pCi} / \mathrm{g}$ for TMA. The range of $239+240 \mathrm{Pu}$ activities measured in vegetation was 0.00013 to $0.013 \mathrm{pCi} / \mathrm{g}$ for LRE, 0.0000060 to $0.00012 \mathrm{pCi} / \mathrm{g}$ for LLNL, and 0.00012 to $0.026 \mathrm{pCi} / \mathrm{g}$ for TMA. Overall, the accepted mean value of the ratio of the sample A activity to sample $B$ activity for $239+240 \mathrm{Pu}$ measured in soil duplicates by radiochemistry was $0.98 \pm 15 \%$ for LRE, $1.1 \pm 15 \%$ for LLNL, $0.98 \pm 5.0 \%$ for NCSU, and $0.99 \pm 19 \%$ for TMA. The accepted mean value of the ratio of the sample A activity to sample B activity for $239+240 \mathrm{Pu}$ measured in vegetation duplicates by radiochemistry was $1.0 \pm 44 \%$ for LRE, $1.2 \pm 25 \%$ for LLNL, and $1.3 \pm 53 \%$ for TMA.

\section{9+240 $\mathrm{Pu}$ in Soil and Vegetation Standard Samples by Radiochemistry}

The graphic representation of comparative results for $239+240 \mathrm{Pu}$ measured in soil and vegetation standards by radiochemistry appear as the third from the top group in Figure 5. Overall, the accepted mean value of the ratio of the measured activity to the certified activity for $239+240 \mathrm{Pu}$ soil standards by radiochemistry (standard type listed in brackets) was $0.99 \pm 6.2 \%$ (7808S) and $1.0 \pm 2.6 \%$ (8112) for LRE, $0.91 \pm 7.4 \%$ for LLNL, $0.89 \pm 0.4 \%$ for NCSU, and $1.0 \pm 9.9 \%$ (7808S), $1.0 \pm 1.5 \%$ (7903), $1.0 \pm 1.8 \%$ (8112), $1.0 \pm 3.6 \%$ (8207), and $1.0 \pm 5.6 \%$ (8502) for TMA. The accepted mean value of the ratio of the measured activity to certified activity for $239+240 \mathrm{Pu}$ measured in vegetation standards by radiochemistry was $0.93 \pm 11 \%(7808 \mathrm{~V})$ and $0.92 \pm 3.8 \%$ (8510) for LRE, $0.83 \pm 16.7 \%$ (8510) for LLNL, and $0.98 \pm 5.7 \%$ (7808V) and $1.1 \pm 8.8 \%$ (8510) for TMA.

\section{${ }^{241} \mathrm{Am}$ in Soil and Vegetation Duplicate Samples by Radiochemistry}

The graphic representation of comparative results for ${ }^{241} \mathrm{Am}$ measured in soil and vegetation duplicate samples by radiochemistry appear in Figure 8 . The range of ${ }^{241} \mathrm{Am}$ activities measured in soil was 0.0018 to $12 \mathrm{pCi} / \mathrm{g}$ for LRE and 0.00046 to 32 $\mathrm{pCi} / \mathrm{g}$ for TMA. The range of $241 \mathrm{Am}$ activities measured in vegetation was 0.000045 to $0.0041 \mathrm{pCi} / \mathrm{g}$ for LRE and 0.00013 to $0.020 \mathrm{pCi} / \mathrm{g}$ for TMA. Overall, the accepted mean value of the ratio of the sample $A$ activity to sample $B$ activity for $241 \mathrm{Am}$ measured in soil duplicates by radiochemistry was $1.1 \pm 19 \%$ for LRE and $1.0 \pm 23 \%$ for TMA. The accepted mean value of the ratio of the sample A activity to sample B 
activity for ${ }^{241} \mathrm{Am}$ measured in vegetation duplicates by radiochemistry was $1.0 \pm$ $54 \%$ for LRE and $1.0 \pm 20 \%$ for TMA.

${ }^{241} \mathrm{Am}$ in Soil and Vegetation Standard Samples by Radiochemistry

The graphic representation of comparative results for ${ }^{241} \mathrm{Am}$ measured in soil and vegetation standards by radiochemistry appear as the fourth group from the top in Figure 5. Overall, the accepted mean value of the ratio of the measured activity to certified activity for $241 \mathrm{Am}$ in soil standards (standard type in brackets) by radiochemistry was $1.0 \pm 6.7 \%$ (7808S) for LRE and $1.1 \pm 8.5 \%$ (7808S), $1.0 \pm 2.7 \%$ (7903), $1.0 \pm 6.0 \%$ (8112), $1.0 \pm 2.3 \%$ (8207), and $1.0 \pm 7.1 \%$ (8502) for TMA. The accepted mean value of the ratio of the measured activity to certified activity for ${ }^{241} \mathrm{Am}$ measured in vegetation standards by radiochemistry was $1.1 \pm 5.8 \%$ (7808V) and $0.92 \pm 11 \%$ (8510) for LRE and $1.4 \pm 9.8 \%$ (7808V) and $0.99 \pm 6.3 \%$ (8510) for TMA.

\section{Radiochemistry Analysis - Terrestrial Animals}

Results for acceptable radiochemical analyses of terrestrial animal samples, all performed by TMA, are presented in Table 10. Since only a small number of terrestrial animal samples were sent for analysis (24 total samples), only two standards were included. The graphic representation of terrestrial animal standard $(7808 \mathrm{~A})$ is presented in figure 5 for ${ }^{90} \mathrm{Sr},{ }^{239}+240 \mathrm{Pu}$, and ${ }^{241} \mathrm{Am}$ respectively. Overall, the success rate for radiochemical analyses of terrestrial animal standard samples was $100 \%$. All samples contained only small amounts of activity and met the QC criteria.

Table 10. Acceptable radiochemistry quality control results for duplicate pairs and standard samples analyzed in terrestrial animals by Thermo Analytical Norcal.

Delivery control

document number total

Duplicate pairs

Standard Samples

$\begin{array}{llll}\text { Total of } 1 & 90 \mathrm{Sr} & - & 2 \text { of } 2(100 \%)\end{array}$

${ }^{137} \mathrm{Cs}^{\mathrm{a}}$

$\begin{array}{lll}\text { Total of } 1 & 239+240 \mathrm{Pu} & -\end{array}$

$\begin{array}{llll}\text { Total of } 1 & 241 \mathrm{Am} & - & 2 \text { of } 2(100 \%)\end{array}$

a Chemistry values for ${ }^{137 C s}$ were lost when an ashing oven malfunctioned. Radiochemistry Analysis - Marine Organisms

Results for acceptable radiochemical analyses of marine organism samples, all performed by LRE, are presented in Table 11. Since only a small number of marine 
organism samples were sent for analysis (11 total samples), only two duplicate pairs and one marine organism standard were included. Overall, the success rate for radiochemical analyses of marine organism duplicate and standard samples was $75 \%$ and $100 \%$, respectively. Figures 4,5, and 6 present a graphic representation of the duplicate and standard (standard is listed as $7808 \mathrm{M}$ ) sample results for $90 \mathrm{Sr}$ and ${ }^{137} \mathrm{Cs}$ measured in marine organism samples. Overall, all samples contained only small amounts of activity and met the QC criteria.

\section{Gamma to Gamma Cross-Counts Between Laboratories}

Figures 9 and 10 present a graphical representation of the gamma to gamma crosscount comparisons for ${ }^{137} \mathrm{Cs}$ and ${ }^{241} \mathrm{Am}$ measured in soil and vegetation by LRE and NCSU to LLNL gamma spectroscopy. LLNL gamma spectroscopy results were at or below detection limits for ${ }^{241} \mathrm{Am}$ in the vegetation, do to the low activity levels, and so were not compared. The ranges of gamma to gamma cross-count comparisons in soil and vegetation sample activities was 0.018 to $246 \mathrm{pCi} / \mathrm{g}$ for ${ }^{137} \mathrm{Cs}$ in soil, 0.090 to $38 \mathrm{pCi} / \mathrm{g}$ for ${ }^{241} \mathrm{Am}$ in soil, and 1.1 to $410 \mathrm{pCi} / \mathrm{g}$ for ${ }^{137} \mathrm{Cs}$ in vegetation. As expected, samples that exhibited the lowest activity level had the greatest differences when compared to the measurements of LLNL.

When a DCD returns from the analyzing laboratory, roughly $10 \%$ of the samples are randomly selected for cross-count analysis. This allows a comparison between the participating laboratory and our own gamma spectroscopy facility. Used as a spot check, any discrepancies between counts could indicate an error by either analyst or analytical hardware. While duplicates sent with the DCD performed the same function, the advantage of this comparison is that it allows for a cross-check over a variety of samples instead of just the duplicate samples sent. This system works well within a broad range of values, but it does have limitations. If the sample activity is sufficiently low, the gamma measurements will approach detection limits

Table 11. Acceptable radiochemistry quality control results for duplicate pairs and standard samples analyzed in marine organisms by the Laboratory of Radiation Ecology.

\begin{tabular}{lcc}
\hline \multicolumn{2}{c}{ Delivery control } \\
Document number total & Duplicate pairs & Standard samples \\
\hline Total of $1 \quad 90 \mathrm{Sr}$ & 2 of $2(100 \%)$ & 1 of $1(100 \%)$ \\
Total of $1 \quad 137 \mathrm{Cs}$ & 1 of $2(50 \%)$ & 1 of $1(100 \%)$ \\
\hline
\end{tabular}


and will yield unacceptable comparisons. Therefore, a method to determine acceptable gamma to gamma spectroscopy results was required.

The method developed, utilized a 3 sigma test. Any comparison failing a 3 sigma test is not significantly similar and so, should be excluded from calculations determining ranges, means, or fractional standard deviations. The 3 sigma test generates ranges by adding plus and minus 3 times the counting error to each of the corresponding values. Considered similar if the ranges overlapped and dissimilar if they did not, only similar values were used for calculations. All gamma to gamma cross-count comparisons were plotted and took this 3 sigma test.

\section{${ }^{137} \mathrm{Cs}$ in Soil and Vegetation}

The graphic representation of gamma spectroscopy to gamma spectroscopy measurements for ${ }^{137} \mathrm{Cs}$ measured in soil and vegetation appear in Figure 9. The range of ${ }^{137} \mathrm{Cs}$ activities compared in soil was 0.034 to $150 \mathrm{pCi} / \mathrm{g}$ for LRE and 0.018 to $246 \mathrm{pCi} / \mathrm{g}$ for NCSU. The range of ${ }^{137} \mathrm{Cs}$ activities compared in vegetation was 1.1 to $410 \mathrm{pCi} / \mathrm{g}$ for LRE and 4.3 to $107 \mathrm{pCi} / \mathrm{g}$ for NCSU. Overall, the accepted mean value of the ratio of the participating laboratory activity to LLNL activity for ${ }^{137} \mathrm{Cs}$ measured in soil samples by gamma spectroscopy was $1.0 \pm 10 \%$ for LRE and $1.0 \pm$ $16 \%$ for NCSU. The accepted mean of the ratio of the participating laboratory activity to LLNL activity for ${ }^{137} \mathrm{Cs}$ measured in vegetation samples by gamma spectroscopy was $1.0 \pm 12 \%$ for LRE and $0.98 \pm 5 \%$ for NCSU.

\section{${ }^{241} \mathrm{Am}$ in Soil}

The graphic representation of gamma spectroscopy to gamma spectroscopy comparisons for ${ }^{241} \mathrm{Am}$ measured in soil appear in Figure 10. The range of ${ }^{241} \mathrm{Am}$ activities compared was 0.090 to $15 \mathrm{pCi} / \mathrm{g}$ for LRE and 0.12 to $38 \mathrm{pCi} / \mathrm{g}$ for NCSU. Overall, the accepted mean value of the ratio of the participating laboratory activity to LLNL activity for ${ }^{241} \mathrm{Am}$ measured in soil samples by gamma spectroscopy was $0.87 \pm 30 \%$ for LRE and $1.1 \pm 41 \%$ for NCSU.

\section{Radiochemistry Analysis Versus Gamma-Spectroscopy Analysis}

Figures 11 and 12 present a graphical representation of the radiochemical analysis to gamma spectroscopy comparisons for ${ }^{137} \mathrm{Cs}$ and ${ }^{241} \mathrm{Am}$ measured radiochemically in soil and vegetation by LRE and TMA to LLNL gamma spectroscopy. The ranges of radiochemical analyses to gamma spectroscopy analyses in soil and vegetation sample activities was 150 to $0.0009 \mathrm{pCi} / \mathrm{g}$ for ${ }^{137} \mathrm{Cs}$ in soil, 63 to $0.033 \mathrm{pCi} / \mathrm{g}$ for ${ }^{241} \mathrm{Am}$ in soil, and 0.28 to $385 \mathrm{pCi} / \mathrm{g}$ for ${ }^{137} \mathrm{Cs}$ in vegetation. As expected, samples that exhibited the lowest activity level had the greatest differences when compared to the measurements of LLNL.

Since all samples are measured by gamma spectroscopy by LLNL prior to radiochemical analysis, a comparison between the results of gamma spectroscopy and radiochemistry is easily made. Any discrepancy indicates a potential error by 


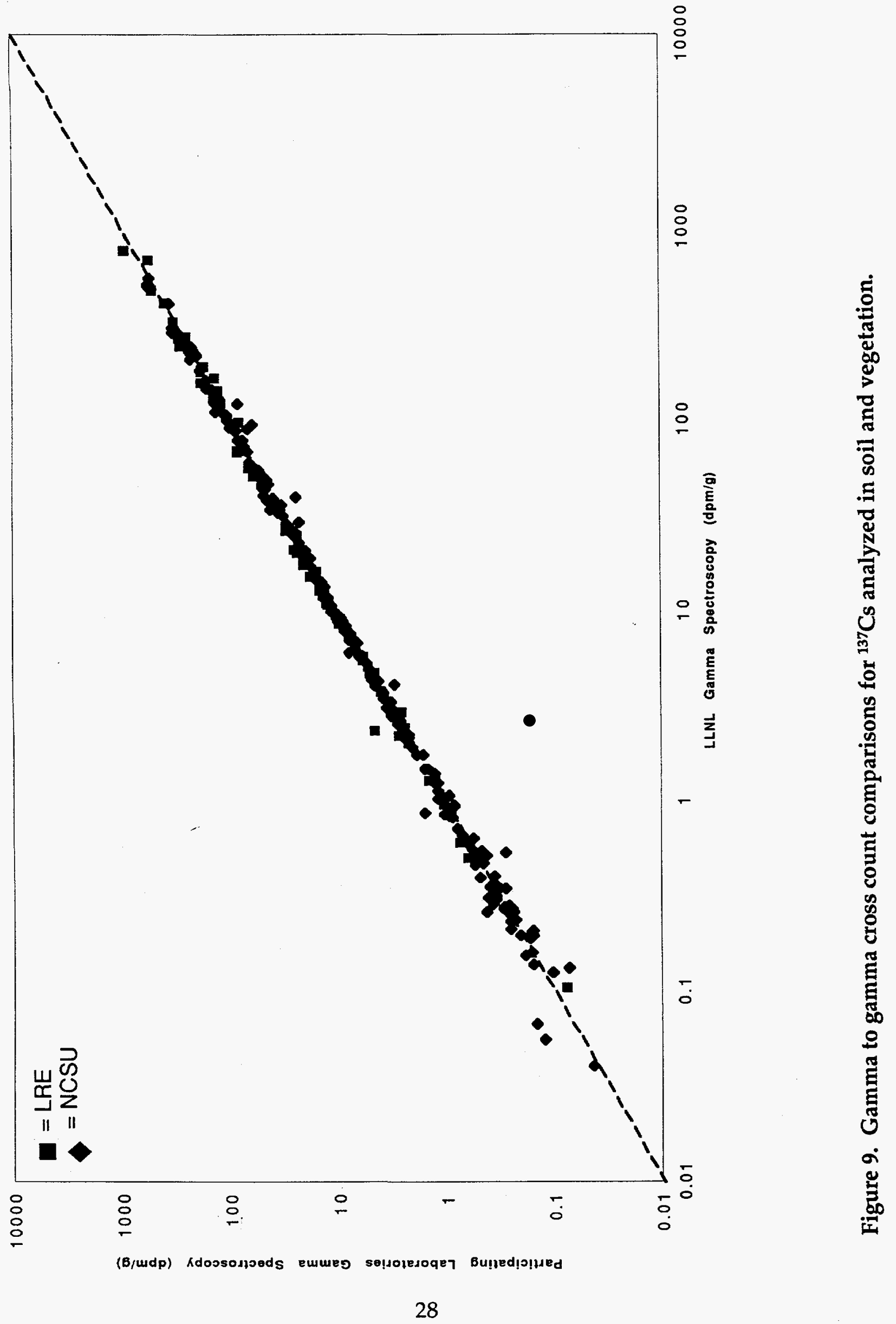


Participating Laboratories Gamma Spectroscopy (dpm/g)

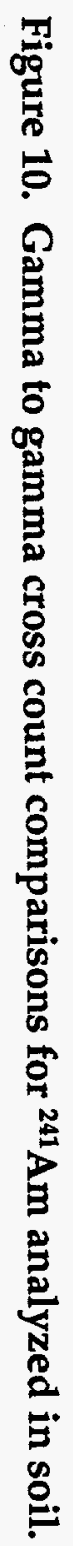

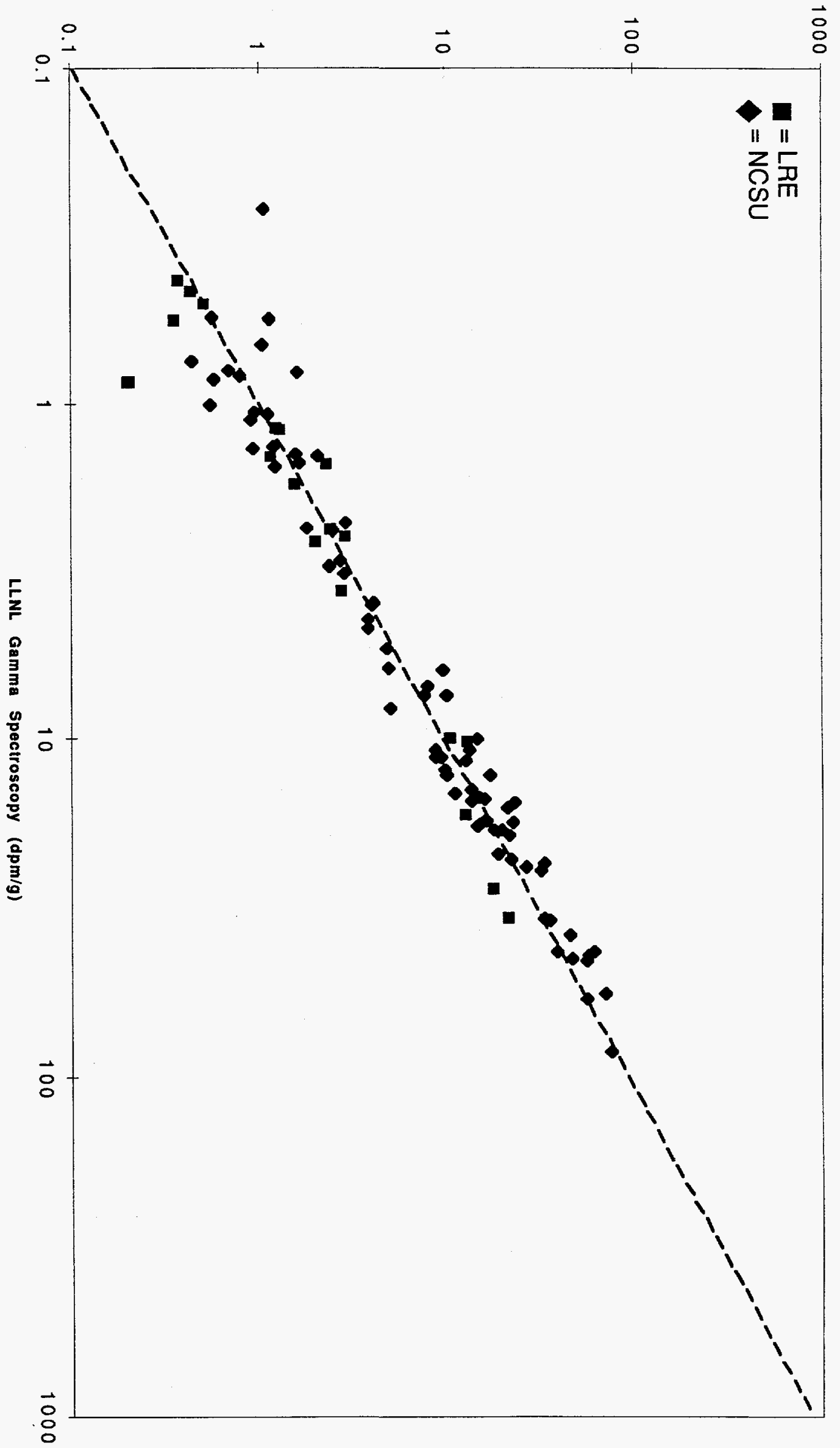


either the analyst or a systematic error in the analytical procedures used. While standards sent with the DCD performed the same function, an advantage of this comparison is that it allows for a cross-check of each sample sent. This system works well within a broad range of values but it does have some limitations. Since radiochemical analysis is more sensitive than gamma spectroscopy, the counting error associated with gamma spectroscopy tends to approach detection limits faster than the same sample analyzed radiochemically. If the sample is sufficiently low in activity, the gamma measurement will approach detection limits and yield an unacceptable comparison. Therefore, a method was required to determine acceptable radiochemistry to gamma spectroscopy comparisons.

Since a similar problem was faced during the gamma to gamma cross-count comparison, the same solution was used to determine acceptable radiochemistry to gamma spectroscopy comparisons. Any radiochemical to gamma spectroscopy analysis comparison which failed a 3 sigma test was determined not significantly similar and would not be used in determining ranges, means or fractional standard deviations. All samples compared radiochemically to gamma spectroscopy were evaluated by this test. It was during the application to all samples that an additional limitation was discovered. Though to a lesser extent, samples high in activity were failing the 3 sigma test as well. These samples had such small errors associated with the count that when the 3 sigma test was applied, they did not overlap. These samples were treated in the same manner as those with small activities and large errors, i.e., plotted but not used in the calculations.

\section{${ }^{137} \mathrm{Cs}$ in Soil and Vegetation}

The graphic representation of radiochemistry to gamma spectroscopy comparisons for ${ }^{137} \mathrm{Cs}$ measured in soil and vegetation appear in Figure 11 . The range of ${ }^{137} \mathrm{Cs}$ activities compared in soil was 0.0009 to $135 \mathrm{pCi} / \mathrm{g}$ for LRE and 0.025 to $150 \mathrm{pCi} / \mathrm{g}$ for TMA. The range of ${ }^{137} \mathrm{Cs}$ activities compared in vegetation was 2.0 to $385 \mathrm{pCi} / \mathrm{g}$ for $\mathrm{LRE}, 2.0$ to $204 \mathrm{pCi} / \mathrm{g}$ for LLNL, and 0.28 to $344 \mathrm{pCi} / \mathrm{g}$ for TMA. Overall, the accepted mean value for the ratio of the participating laboratory radiochemistry activity to LLNL gamma spectroscopy activity for ${ }^{137} \mathrm{Cs}$ measured in soil samples was $0.95 \pm$ $31 \%$ for LRE and $1.0 \pm 9.7 \%$ for TMA. The accepted mean of the ratio of the participating laboratory radiochemistry activity to LLNL gamma spectroscopy activity for ${ }^{137} \mathrm{Cs}$ measured in vegetation samples was $1.0 \pm 6.2 \%$ for LRE, $0.93 \pm 6.0 \%$ for LLNL, and $0.96 \pm 6.8 \%$ for TMA. 


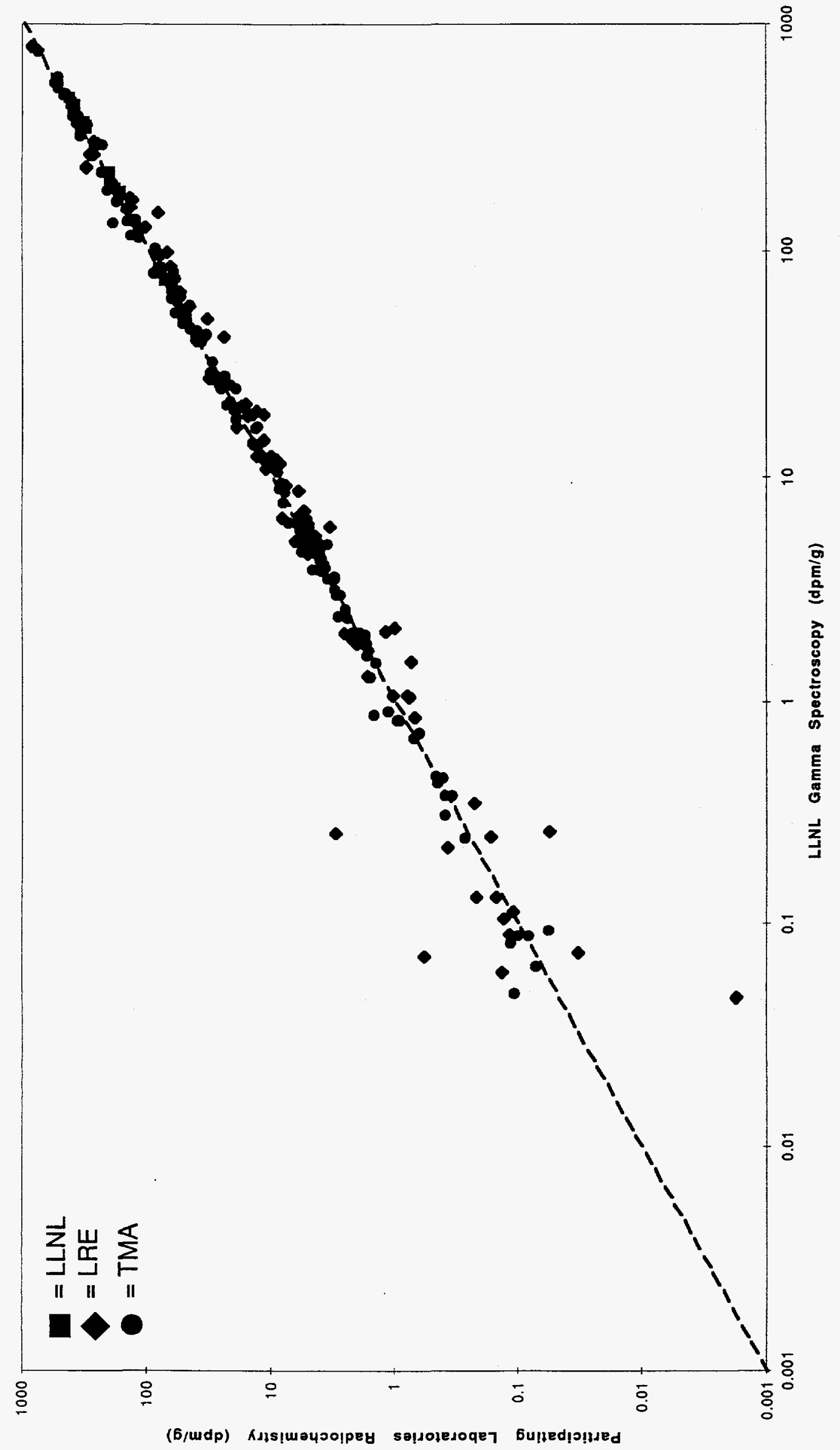

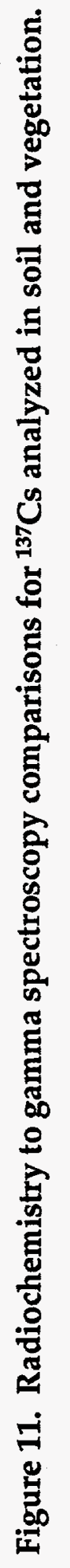


The graphic representation of radiochemistry to gamma spectroscopy results for ${ }^{241} \mathrm{Am}$ measured in soil appear in Figure 12. The range of ${ }^{241} \mathrm{Am}$ activities compared was 0.033 to $16 \mathrm{pCi} / \mathrm{g}$ for LRE and 0.087 to $63 \mathrm{pCi} / \mathrm{g}$ for TMA. Overall, the accepted mean of the ratio of the participating laboratory radiochemistry activity to LLNL gamma spectroscopy activity for ${ }^{241} \mathrm{Am}$ measured in soil samples was $1.0 \pm$ $24 \%$ for LRE and $1.1 \pm 14 \%$ for TMA.

\title{
Intercalibration and Split Sample Analyses for LLNL Health and Ecological Assessment Division Analytical Facilities
}

In addition to our internal LLNL calibration and quality control (QC) program described above we participate in international QC programs with a variety of agencies and institutions. We have participated in standard certification excerises, interlaboratory comparisons, and/or split-sample analyses with the following:

\author{
International Atomic Energy Agency (IAEA) - Monaco \\ French Atomic Energy Commission - Paris, France \\ GSF Institute - Munich, Germany \\ 100 worldwide laboratories through IAEA \\ Department of Public Health - Hamburg, Germany \\ Environmental Measurement Laboratory (EML) - New York, New \\ York \\ University of North Carolina - Raleigh, North Carolina \\ University of Washington - Seattle, Washington \\ TMA Norcal - Richmond, California \\ Marshall Islands Nationwide Survey - Majaro, Marshall Islands
}

We have also completed split-sample comparisons with other groups that have been retained by the Enewetak community, Bikini community, Republic of the Marshall Islands Government, and United States Congress to review our program. These intercomparisons were conducted on samples that these organizations were in charge of collecting. These groups are:

Epidemiological Research Inc.

This group was hired by the Enewetak people to review our program. The people were Nancy Dryer, an epidemiologist; Dr. Henry Kohn of Harvard University; and, Dr. John Harley of the U.S. DOE Environmental Measurements Laboratory. 



\section{Bikini Atoll Rehabilitation Committee (BARC)}

Formed by the U.S. Congress to review our program (plus resettlement issue in general) for the Bikini people. The members were:

Dr. Henry Kohn, Chairman (Harvard - retired)

Dr. Frank Peterson, University of Hawaii

Dr. Earl Stone, University of Florida

Dr. Arthur Kubo, BDM Corporation

\section{Rongelap Reassessment Programs \\ Dr. Paretzke - GSF Institute, Munich, Germany \\ Dr. Boikat - Department of Public Health, Hamburg, Germany \\ International Atomic Energy Agency - Monaco}

The following discussion and data represent some of our past and most recent quality assurance activities. In Table 12 are listed the results of an ongoing intercalibration with IAEA beginning in 1972 up through 1991. More recent results on IAEA intercalibration samples are listed in Tables 13 through 16 and Figures 13 through 15. Our results have always been in excellent agreement with the adopted IAEA value for their intercalibration standards.

\section{Intercalibration on Standards}

In 1991 the French Atomic Energy Commission requested that an analytical validation of radionuclide concentrations in water and plankton samples from Mururoa Atoll be run through IAEA, Monaco. We were asked to participate by the French and IAEA. The results for the three laboratories are shown in Tables 17 and 18 and demonstrate excellent agreement between the laboratories on nearly a dozen radionuclides.

The results given by the three laboratories are in full agreement for all radionuclides analyzed. The activity concentrations measured in March 1991 confirm values given for previous years. In seawater sample $\mathrm{n} 2$, a trace pf $239+240 \mathrm{Pu}$ (three times oceanic background noise), coming from lagoons, is measured. On the other hand, no trace of ${ }^{60} \mathrm{Co}$ or ${ }^{137} \mathrm{Cs}$ has been detected, in spite of particularly low detection limits $\left(<10^{-1} \mathrm{~Bq} / \mathrm{m}^{3}\right)$.

A second intercalibration exercise on fish, invertebrates, water, and sediment samples collected from Mururoa Atoll by the French scientists, with participation from the United States and IAEA Monaco, was conducted in 1994. The results, completed in 1995, from several laboratories are listed in Tables 19 and 20. Our results are in excellent agreement with the mean values from the participating laboratories. 
Table 12. Pu-239+240 Activity Ratio (x/median value).

Participant ID and activity ratios

\begin{tabular}{|c|c|c|c|c|c|c|c|c|c|c|c|c|c|}
\hline \multirow[b]{2}{*}{ Sample ID } & \multirow[b]{2}{*}{ Type } & & & & & & & & & & & & \multirow[b]{2}{*}{$\begin{array}{c}\text { Median } \\
\left(\mathrm{Bq} \mathrm{kg}^{-1}\right)\end{array}$} \\
\hline & & Year & $\mathrm{A}$ & B & $C$ & $\mathrm{D}$ & $\mathrm{F}$ & $\mathrm{G}$ & $\mathrm{H}$ & I & $L^{* * *}$ & $\mathrm{M}$ & \\
\hline IAEA-367 & sediment & 91 & 0.99 & - & 1.14 & - & 1.27 & 0.90 & 1.10 & 0.87 & 1.02 & 0.75 & 38 \\
\hline IAEA-368 & sediment & 91 & 0.98 & - & 1.00 & - & 1.17 & 0.74 & 1.03 & 0.87 & 0.94 & 0.85 & 31 \\
\hline IAEA-306 & sediment & 89 & 1.00 & 0.47 & 1.16 & 0.98 & 0.89 & 1.00 & 1.00 & 0.96 & - & 0.91 & 5.7 \\
\hline IAEA-307 & biota & 89 & 1.06 & 0.81 & 1.17 & 1.07 & - & 1.10 & 1.14 & 0.94 & - & 0.97 & 0.72 \\
\hline IAEA-308 & biota & 89 & 1.06 & 1.10 & 1.04 & 0.96 & - & 1.00 & 0.94 & 0.86 & - & 0.88 & 0.50 \\
\hline SD-N-2 & sediment & 86 & 0.74 & 0.68 & - & 0.94 & - & 0.68 & 0.97 & 0.77 & 1.07 & - & $8.8^{*}$ \\
\hline AG-B-1 & biota & 85 & 1.06 & - & - & - & 1.00 & 0.50 & 0.92 & 0.79 & 1.00 & - & 0.066 \\
\hline SW-N-2 & sea water & 85 & 1.09 & 0.54 & - & 1.01 & 0.90 & - & 0.97 & 0.77 & - & - & $0.124^{*}$ \\
\hline SD-N-1 & sediment & 84 & 0.95 & 0.75 & - & 0.98 & 1.04 & - & 1.05 & 0.91 & 1.00 & - & 0.56 \\
\hline SW-N-1 & sea water & 82 & 0.97 & 1.16 & 0.90 & - & 1.04 & - & 0.92 & 1.05 & - & - & $0.070^{*}$ \\
\hline SD-B-3 & sediment & 78 & 0.85 & - & 1.02 & 1.16 & - & - & 1.14 & 0.84 & - & - & 21.9 \\
\hline SW-A-1 & sea water & 76 & - & - & - & 1.09 & - & - & 0.82 & - & 1.36 & - & $0.041^{*}$ \\
\hline MA-B-1 & biota & 76 & 1.36 & - & - & 0.87 & - & - & 0.82 & - & - & - & 1.6 \\
\hline MA-B-2 & biota & 76 & 18.2 & - & - & 0.95 & - & - & 0.91 & - & - & - & 0.041 \\
\hline SW-I-3 & sea water & 76 & - & - & - & 1.15 & - & - & 1.14 & - & 1.10 & - & $3.81^{*}$ \\
\hline SD-B-1 & sediment & 73 & 1.05 & 0.97 & 1.06 & 0.93 & - & - & 0.98 & - & 1.02 & - & 35.5 \\
\hline AG-I-1 & biota & 73 & 0.77 & 1.03 & 0.85 & 1.11 & - & - & 0.89 & - & - & - & 999 \\
\hline SW-I-1 & sea water & 71 & 0.92 & 1.33 & 1.15 & 0.98 & - & - & 1.15 & - & - & - & $3.1^{*}$ \\
\hline SW-I-2 & sea water & 71 & 0.59 & 1.15 & 0.77 & 1.00 & - & - & 0.91 & - & - & - & $8.1^{*}$ \\
\hline Laboratory & & & & & & & & & & & & & \\
\hline $\begin{array}{l}\text { Mean ** } \\
\text { Standard }\end{array}$ & 0.99 & 0.91 & 1.02 & 1.01 & 1.04 & 0.84 & 0.99 & 0.87 & 1.06 & 0.87 & & & \\
\hline Deviation & 0.14 & 0.28 & 0.12 & 0.08 & 0.12 & 0.19 & 0.10 & 0.08 & 0.12 & 0.07 & & & \\
\hline
\end{tabular}

* Activity in $\mathrm{mBq} \mathrm{kg}^{-1}$.

** Outliers are not included.

*** Lawrence Livermore National Laboratory (LLNL) 
Table 13. Measurement of International Soil Standard No. 367.

\begin{tabular}{lcccc}
\hline \multirow{2}{*}{ Values or laboratory } & \multicolumn{4}{c}{ Concentration $(\mathrm{Bq} / \mathrm{kg})$} \\
\cline { 2 - 5 } & $90 \mathrm{Sr}$ & $137 \mathrm{Cs}$ & $239+240 \mathrm{Pu}$ & ${ }^{241} \mathrm{Am}$ \\
\hline Median of 68 international & 102 & 195 & 38 & 26 \\
$\quad$ laboratories & $(50-132)^{\mathrm{a}}$ & $(162-230)^{\mathrm{a}}$ & $(24-51)^{\mathrm{a}}$ & $(18-34)^{\mathrm{a}}$ \\
LLNL & $102 \pm 2$ & $194 \pm 2$ & $39 \pm 1$ & $25 \pm 3$ \\
IAEA & - & $192 \pm 6$ & $42 \pm 3$ & $27 \pm 2$ \\
France Atomic Energy & - & $196 \pm 10$ & $38 \pm 1.5$ & $28 \pm 2$ \\
$\quad$ Commission & - & $190 \pm 8$ & - & - \\
NISTc & - & & \\
\hline a Values in parenthesis represent the range of accepted means. \\
b International Atomic Energy Agency, Monaco. \\
c National Institute of Standards and Technology.
\end{tabular}

Table 14. Measurement of International Soil Standard No. 368.

\begin{tabular}{lccc}
\hline & \multicolumn{3}{c}{ Concentration $(\mathrm{Bq} / \mathrm{kg})$} \\
\hline & $90 \mathrm{Sr}$ & $239+240 \mathrm{Pu}$ & ${ }^{241} \mathrm{Am}$ \\
\cline { 2 - 4 } Median of 68 international & 1.8 & 32 & 1.3 \\
laboratories & $(0.18-8.6)^{\mathrm{a}}$ & $(18-39)^{\mathrm{a}}$ & $(0.8-1.9)^{\mathrm{a}}$ \\
LLNL & $1 \pm 2$ & $29 \pm 1$ & $0.9 \pm 0.8$ \\
\hline
\end{tabular}

a Values in parenthesis represent the range of reported values.

Table 15. Measurement of International Soil Standard No. 352.

\begin{tabular}{lccc}
\hline \multicolumn{1}{c}{ Values or laboratory } & \multicolumn{3}{c}{ Concentration $(\mathrm{Bq} / \mathrm{kg})$} \\
\hline & ${ }^{137} \mathrm{Cs}$ & $210 \mathrm{~Pb}$ & $210 \mathrm{Po}$ \\
\cline { 2 - 4 } IAEA $^{\mathrm{a}}$ & & & \\
$\quad$ Recommended value & 2.7 & 2.2 & 0.6 \\
LLNL & $2.8 \pm 0.7$ & $2.8 \pm 0.5$ & $0.6 \pm 0.3$ \\
\hline
\end{tabular}

a International Atomic Energy Agency, Monaco.

Table 16. Measurement of Lawrence Livermore National Laboratory vegetation standard 8510.

\begin{tabular}{lccc}
\hline Values or laboratory & \multicolumn{3}{c}{ Concentration $(\mathrm{Bq} / \mathrm{kg})$} \\
\hline LLNL & $40 \mathrm{~K}$ & $60 \mathrm{Co}$ & ${ }^{137} \mathrm{Cs}$ \\
$\quad$ Gamma Spectroscopy & $10.3 \pm 0.75$ & $0.39 \pm 0.037$ & $2.3 \pm 0.12$ \\
$\quad$ Radiochemistry & - & - & 2.2 \\
IAEA & $9.9 \pm 1.2$ & $0.34 \pm 0.066$ & $2.2 \pm 0.35$ \\
\hline
\end{tabular}

a International Atomic Energy Agency, Monaco. 


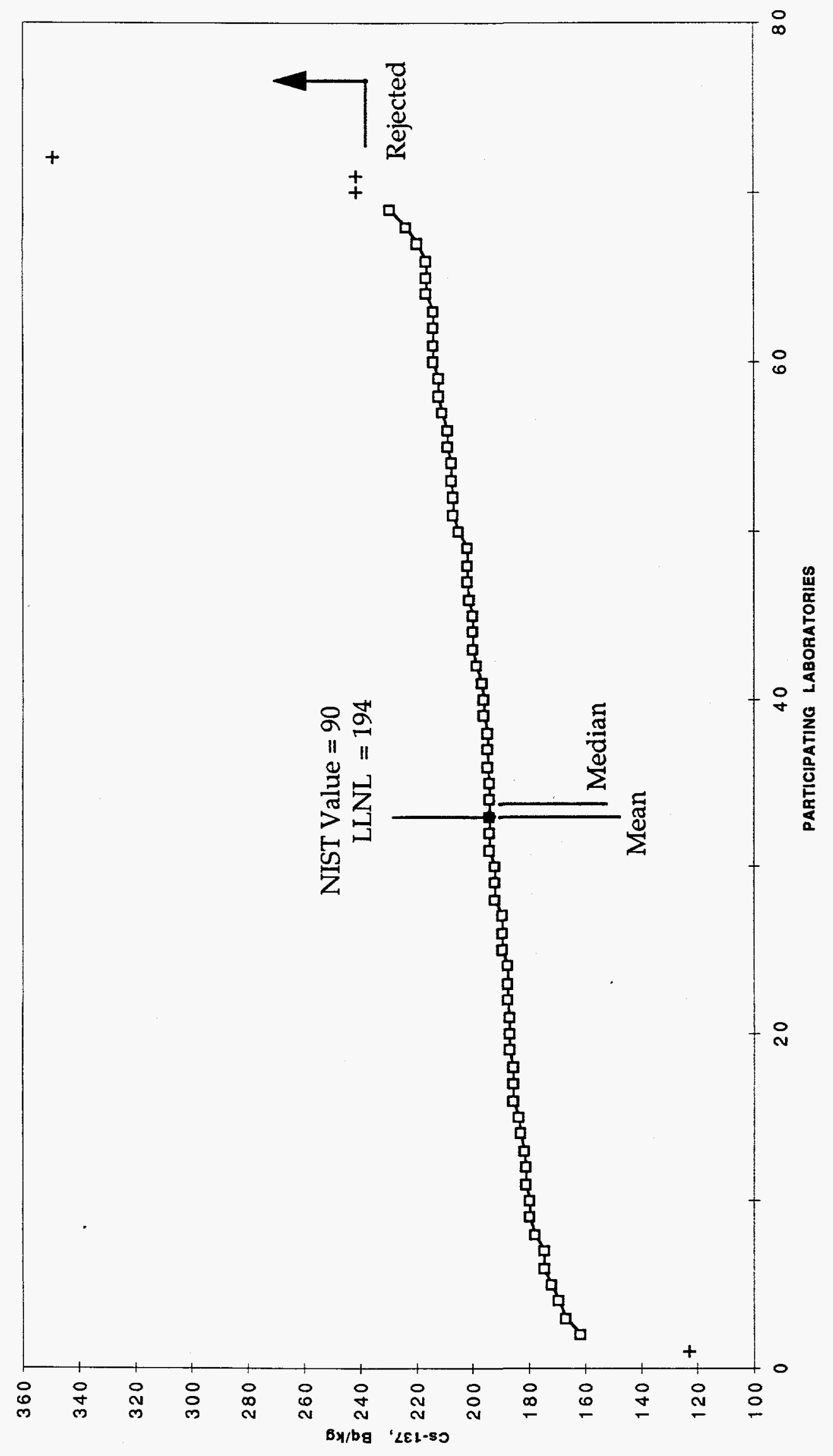

ปั. 
Table 17. Activity Concentration in Sea Water (in $\mathrm{Bq} / \mathrm{m}^{3}$ ).

\begin{tabular}{|c|c|c|c|c|c|c|c|c|c|}
\hline \multirow{2}{*}{$\begin{array}{l}\text { Samples } \\
\text { Laboratory }\end{array}$} & \multicolumn{3}{|c|}{ Water $\mathrm{n} 1$} & \multicolumn{3}{|c|}{ Water n 2} & \multicolumn{3}{|c|}{ Water $\mathrm{n} 3$} \\
\hline & AIEA & Livermore & SMSR & AIEA & Livermore & SMSR & AIEA & Livermore & SMSR \\
\hline${ }^{40} \mathrm{~K}$ & $12600 \pm 1300$ & - & $12500 \pm 500$ & $12300 \pm 1200$ & - & $11800 \pm 500$ & $11700 \pm 1200$ & - & $12506 \pm 500$ \\
\hline${ }^{234} U$ & $47.2 \pm 1.0$ & $45.0 \pm 5.1$ & $44.2 \pm 1.8$ & $48.0 \pm 3.0$ & $43.0 \pm 5.1$ & $45.6 \pm 1.6$ & $47.0 \pm 2.0$ & $43.0 \pm 5.1$ & $44.9 \pm 1.5$ \\
\hline${ }^{238} \mathrm{U}$ & $40.8 \pm 1.3$ & $37.0 \pm 1.9$ & $40.9 \pm 1.5$ & $41.2 \pm 2.8$ & $37.0 \pm 1.9$ & $41.4 \pm 1.5$ & $41.0 \pm 1.7$ & $36.0 \pm 1.8$ & $42.6 \pm 1.5$ \\
\hline${ }^{60} \mathrm{Co}$ & nd & nd & nd & nd & nd & nd & nd & nd & nd \\
\hline${ }^{90} \mathrm{Sr}$ & $1.33 \pm 0.10$ & $1.30 \pm 0.18$ & $1.37 \pm 0.08$ & $1.44 \pm 0.14$ & $1.50 \pm 0.21$ & $1.34 \pm 0.08$ & $1.26 \pm 0.14$ & $1.30 \pm 0.36$ & $1.35 \pm 0.08$ \\
\hline${ }^{134} \mathrm{Cs}$ & nd & nd & nd & nd & nd & nd & nd & nd & nd \\
\hline${ }^{137} \mathrm{Cs}$ & $2.42 \pm 0.34$ & $2.30 \pm 0.11$ & $2.29 \pm 0.08$ & $2.20 \pm 0.20$ & $2.50 \pm 0.12$ & $2.32 \pm 0.09$ & $2.30 \pm 0.20$ & $2.40 \pm 0.12$ & $2.31 \pm 0.09$ \\
\hline${ }^{238} \mathrm{Pu}$ & nd & $(0.4 \pm 0.2) \cdot 10^{-3}$ & nd & $(1.7 \pm 0.8) \cdot 10^{-3}$ & $(2.1 \pm 0.4) \cdot 10^{-3}$ & $(2.4 \pm 0.2) \cdot 10^{-3}$ & nd & nd & nd \\
\hline $239+240 \mathrm{Pu}$ & $(1.6 \pm 0.2) \cdot 10^{-3}$ & $(2.0 \pm 0.3) \cdot 10^{-3}$ & $(3.1 \pm 0.2) \cdot 10^{-3}$ & $(6.7 \pm 1.1) \cdot 10^{-3}$ & $(6.0 \pm 0.6) \cdot 10^{-3}$ & $(7.6 \pm 0.4) \cdot 10^{-3}$ & $(1.4 \pm 0.4) \cdot 10^{-3}$ & $(2.2 \pm 0.4) \cdot 10^{-3}$ & $(2.2 \pm) \cdot 10^{-3}$ \\
\hline
\end{tabular}

nd = no data 
Table 18. Activity Concentration in Plankton (in $\mathrm{Bg} / \mathrm{kg}$ wet).

\begin{tabular}{|c|l|l|l|l|l|l|}
\hline Samples & \multicolumn{3}{c|}{ Plankton n 2 } \\
\hline $\begin{array}{c}\text { Wet/Dry } \\
\text { weight } \\
\text { ratio }\end{array}$ & \multicolumn{5}{|c|}{ Plankton n 1 } & \multicolumn{3}{c|}{7.58} \\
\hline Laboratory & AIEA & Livermore & SMSR & AIEA & Livermore & SMSR \\
\hline${ }^{40} \mathrm{~K}$ & $30.3 \pm 1.5$ & $30.2 \pm 1.2$ & $37.7 \pm 1.4$ & $28.6 \pm 1.4$ & $38.3 \pm 3.9$ & $34.4 \pm 1.3$ \\
\hline${ }^{234} \mathrm{Th}$ & $322 \pm 32$ & $240 \pm 21$ & $295 \pm 10$ & $382 \pm 38$ & $412 \pm 78$ & $313 \pm 10$ \\
\hline${ }^{234} \mathrm{U}$ & $1.4 \pm 0.1$ & $1.58 \pm 0.08$ & $1.27 \pm 0.06$ & $1.4 \pm 0.1$ & $1.41 \pm 0.07$ & $1.18 \pm 0.06$ \\
\hline${ }^{238} \mathrm{U}$ & $1.37 \pm 0.04$ & $1.27 \pm 0.03$ & $1.14 \pm 0.06$ & $1.46 \pm 0.04$ & $1.14 \pm 0.02$ & $1.30 \pm 0.07$ \\
\hline${ }^{60} \mathrm{Co}$ & nd & nd & nd & nd & nd & nd \\
\hline${ }^{90} \mathrm{Sr}$ & nd & nd & nd & nd & nd & nd \\
\hline${ }^{134} \mathrm{Cs}$ & nd & nd & nd & nd & nd & nd \\
\hline${ }^{137} \mathrm{Cs}$ & nd & 0.0300 .009 & nd & nd & $0.035 \pm 0.008$ & nd \\
\hline${ }^{239+240} \mathrm{Pu}$ & $(9.1 \pm 1.0) .10^{-3}$ & $(7.4 \pm 1.7) .10^{-3}$ & $(9.5 \pm 1.2) .10^{-3}$ & $(6.4 \pm 1.3) .10^{-3}$ & $(7.9 \pm 1.1) .10^{-3}$ & $(6.2 \pm 1.1) .10^{-3}$ \\
\hline
\end{tabular}

nd: not detected, because under the detection limit of instrumentation.

Table 19. Mean Radionuclide concentrations from eight laboratories in biota samples collected inside, outside and on land of Mururoa Atoll (Bq kg-1 wet weight); $\pi$ LLNL values are in parentheses.

\begin{tabular}{lllll}
\multicolumn{1}{c}{ Sample } & \multicolumn{1}{c}{$40 \mathrm{~K}$} & \multicolumn{1}{c}{$60 \mathrm{Co}$} & \multicolumn{1}{c}{$90 \mathrm{Sr}$} & \multicolumn{1}{c}{${ }^{137 \mathrm{Cs}}$} \\
\hline Fish Rangiroa & $123 \pm 17(108 \pm 3)$ & $<0.033^{\circ}(<0.6)$ & $0.019 \pm 0.005(<0.022)$ & $0.24 \pm 0.03(0.26 \pm 0.03)$ \\
Fish Sector & $110 \pm 44(118 \pm 8)$ & $0.037 \pm 0.007(<0.4)$ & $<0.010^{\circ}(<0.012)$ & $0.31 \pm 0.02(0.32 \pm 0.04)$ \\
North & & & & \\
Fish Sector & $123 \pm 23(86 \pm 9)$ & $0.028 \pm 0.017(<0.5)$ & $<0.014^{\circ}(<0.016)$ & $0.30 \pm 0.02(0.29 \pm 0.06)$ \\
South & & & & \\
Fish Sector East & $123 \pm 18(109 \pm 4)$ & $0.030 \pm 0.004(<0.4)$ & $<0.021^{\circ}(<0.028)$ & $0.27 \pm 0.03(0.30 \pm 0.04)$ \\
Fish Sector West & $119 \pm 11(111 \pm 3)$ & $0.054 \pm 0.015(<0.4)$ & $<0.017^{\circ}(<0.012)$ & $0.35 \pm 0.03(0.31 \pm 0.05)$ \\
Clam & $73.7 \pm 9.1(68 \pm 3)$ & $3.19 \pm 0.40(3.10 .1)$ & $0.018 \pm 0.05(<0.011)$ & $0.032 \pm 0.014(0.02 \pm 0.01)$ \\
Turbo & $86.9 \pm 10.3(77 \pm 3)$ & $0.036 \pm 0.013(<0.7)$ & $<0.017^{\circ}(<0.016)$ & $0.033 \pm 0.012(0.03 \pm 0.01)$ \\
Lobster & $135 \pm 20(128 \pm 4)$ & $0.027 \pm 0.001(<0.5)$ & $0.02 \pm 0.01(<0.02)$ & $0.103 \pm 0.015(0.10 \pm 0.02)$ \\
Coconut water^ & $58.1 \pm 5.8$ & $<0.028^{\circ}$ & $0.006 \pm 0.003$ & $0.193 \pm 0.044(0.168 \pm 0.003)$ \\
\hline
\end{tabular}

${ }^{\circ}$ Estimated value

${ }^{\wedge} \mathrm{Bql}^{-1}$

The IAEA, Vienna provided a standard for an intercalibration exercise as part of a Coordinated Research Program (CRP) involving 14 different countries. Our results from that exercise are compared in Table 21 with the IAEA accepted values.

An interlaboratory comparison of split samples was conducted as part of the Rongelap Reassessment Project between our laboratory and those of Dr. Paretzke, GSF, Munich, Germany and Dr. Boikat at the Department of Public Health in Hamburg, Germany. Dr. Paretzke joined one of our field missions during which soil and vegetation samples were collected and divided in the field. Equal amounts of soil and vegetation were sent to each of the laboratories. The fresh vegetation 
Table 20. Mean Radionuclide concentrations from eight laboratories in biota samples collected inside, outside and on land of Mururoa Atoll (Bq kg-1 wet weight); LLNL values are in parentheses.

\begin{tabular}{lcc}
\hline \multicolumn{1}{c}{ Sample } & $238 \mathrm{Pu}$ & $239+240 \mathrm{Pu}$ \\
\hline Fish Rangiroa & $<0.00014^{\circ}(<0.00014)$ & $0.00012 \pm 0.00003(<0.00014)$ \\
Fish Sector & $0.000037 \pm 0.000006(<0.003)$ & $0.00029 \pm 0.00005(<0.002)$ \\
$\quad$ & & \\
Forth & $<0.00016^{\circ}(<0.0002)$ & $0.000184 \pm 0.000075(<0.0002)$ \\
Fish Sector South & $<0.00020^{\circ}(<0.0003)$ & $0.00016 \pm 0.00009(<0.0003)$ \\
Fish Sector Wast & $0.000158 \pm 0.000024(<0.0001)$ & $0.000411 \pm 0.000131(<0.0001)$ \\
Clam & $0.148 \pm 0.006(0.144 \pm 0.007)$ & $0.618 \pm 0.033(0.62 \pm 0.03)$ \\
Turbo & $0.0147 \pm 0.0010(0.014 \pm 0.001)$ & $0.110 \pm 0.007(0.112 \pm 0.008)$ \\
Lobster & $0.00032 \pm 0.00012(<0.0003)$ & $0.0021 \pm 0.0002(0.0023 \pm 0.0005)$ \\
Coconut water^ & $<0.000036^{\circ}(<0.00002)$ & $0.000046 \pm 0.000005(<0.00002)$ \\
\hline${ }^{\circ}$ Estimated value & & \\
^ Bql ${ }^{-1}$ & &
\end{tabular}

Table 21. IAEA Intercalibration Exercise as part of a Coordinated Research Program $\left(\mathrm{Bq} \mathrm{kg}{ }^{-1}\right)$.

\begin{tabular}{|c|c|c|c|c|}
\hline & \multicolumn{2}{|c|}{ Soil IAEA 6} & \multicolumn{2}{|c|}{ Grass IAEA 373} \\
\hline & ${ }^{137} \mathrm{Cs}$ & ${ }^{134} \mathrm{Cs}$ & ${ }^{137} \mathrm{Cs}$ & ${ }^{134} \mathrm{Cs}$ \\
\hline$\overline{\mathrm{LLNL}}$ & $43 \pm 3$ & $<3$ & $11,368 \pm 441$ & $461 \pm 14$ \\
\hline IAEA & 40.9 & - & 11,568 & 451 \\
\hline
\end{tabular}

samples were divided as evenly as possible. However, it is impossible to get the exact same coconut, frond, Pandanus fruit, or arrowroot sample. Consequently, there are slight variations in the age of coconuts and Pandanus fruit in the two samples and slight differences in the location of arrowroot taken. Some of the statistical error shown in the tables could be do to this sample variability. But overall, even with this potential variability, the comparative results are very good.

The results of the analysis of the vegetation samples from Rongelap and Ailinginae Atolls are shown in Table 22. The mean ratio of the Paretzke/Boikat data to LLNL data was 0.96 . Shown in Table 23 are similar results for vegetation samples collected at Bikini Atoll. The mean ratio of Paretzke/Boikat data to LLNL data is 1.04. 


\section{IAEA}

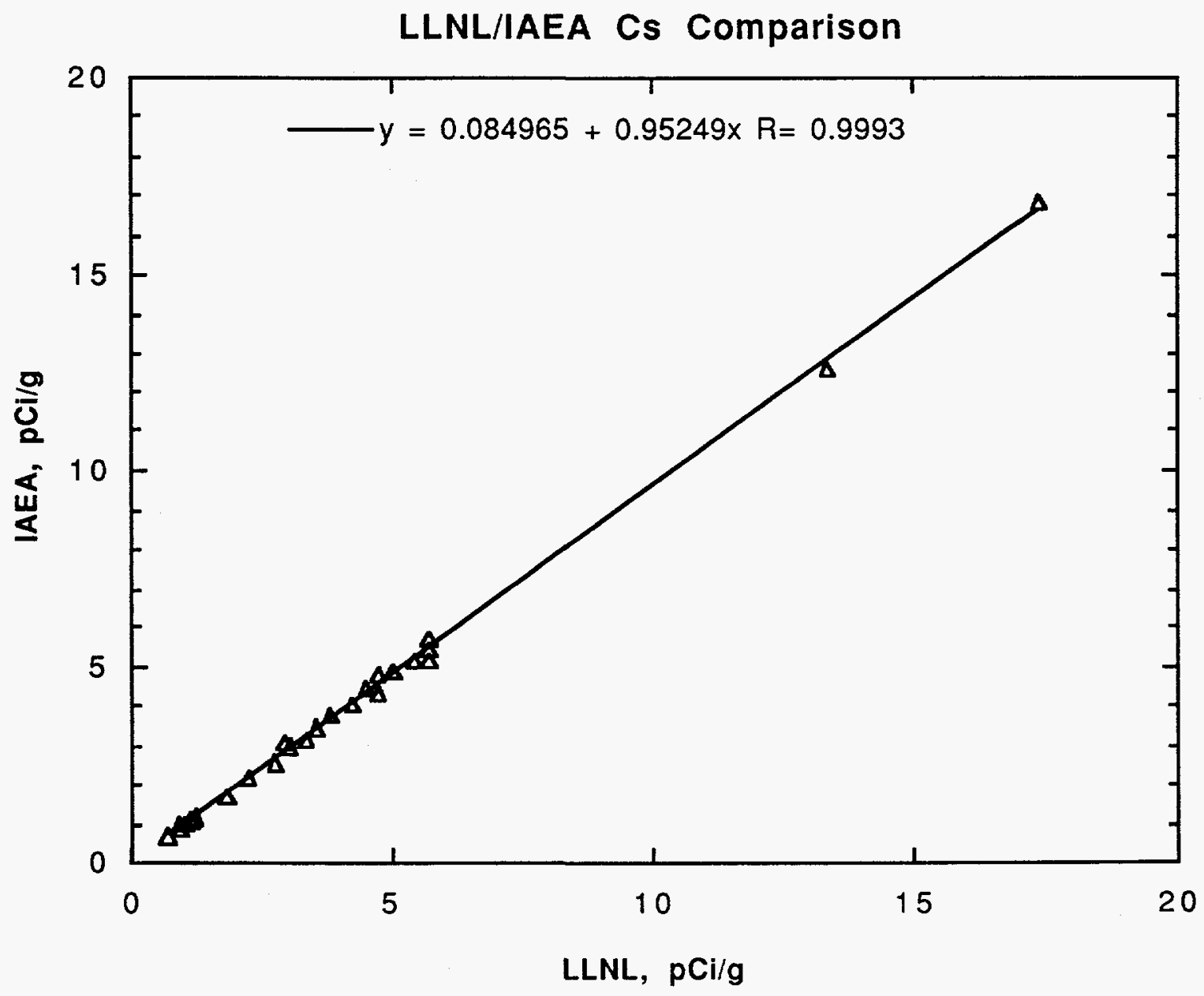

Figure 14. LLNL/IAEA ${ }^{137}$ Cs Comparison. 


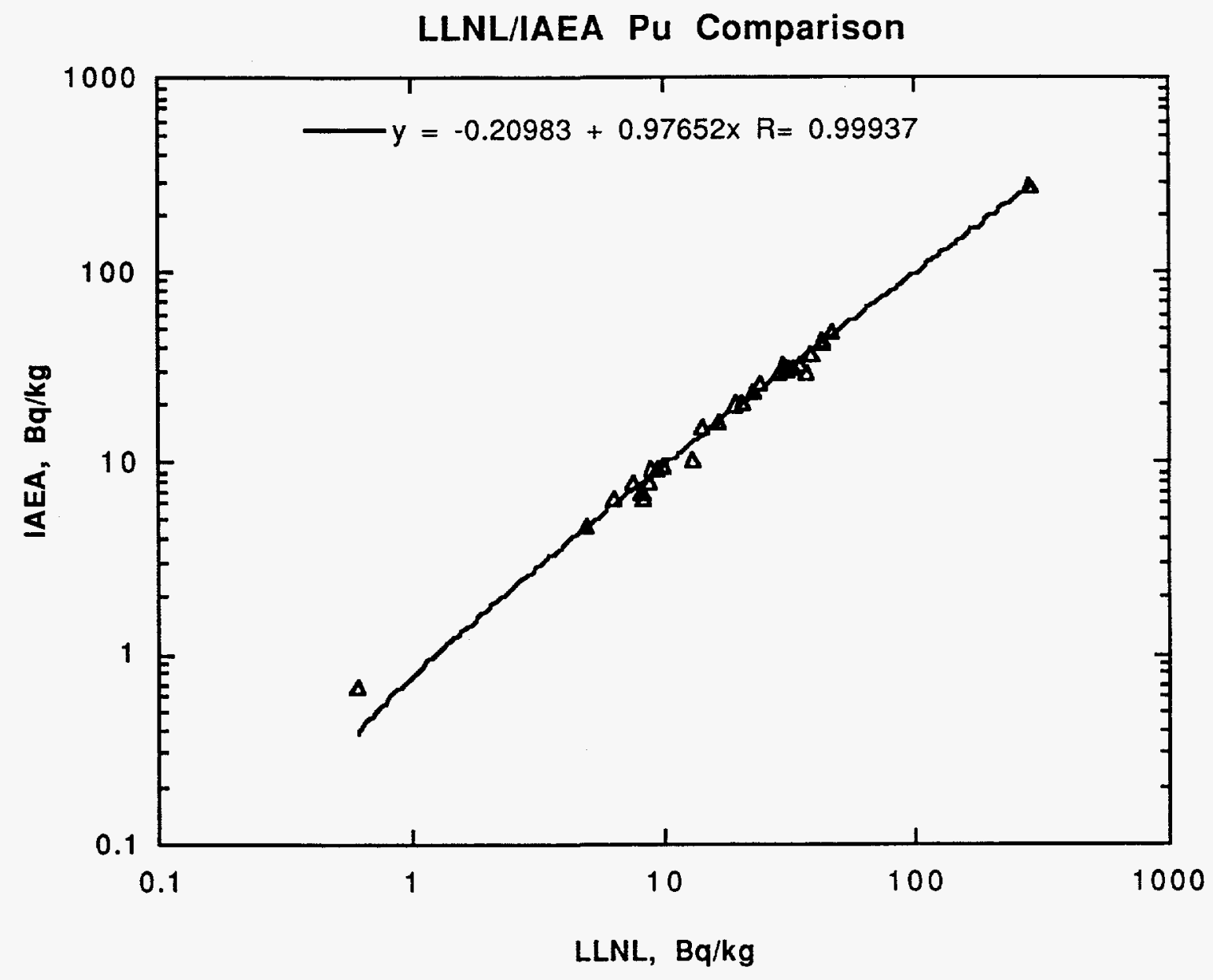

Figure 15. LLNL/IAEA Pu Comparison. 
Table 22. Interlaboratory comparison of split samples for ${ }^{137} \mathrm{Cs}$ in Ailinginae and Rongelap vegetation samples - Rongelap Reassessment Program versus Lawrence Livermore National Laboratory.

\begin{tabular}{cccc}
\hline \multirow{2}{*}{$\begin{array}{c}\text { Atoll and } \\
\text { sample type }\end{array}$} & \multicolumn{2}{c}{$\begin{array}{c}137 \text { Cs concentration } \\
\text { (pCi/g wet weight) }\end{array}$} & $\begin{array}{c}\text { Ratio of Paretzke and } \\
\text { Boikat to LLNL }\end{array}$ \\
\cline { 2 - 3 } & Paretzke and Boikat & LLNL & 1.0 \\
\cline { 2 - 3 } Ailinginae & 0.45 & 0.45 & 0.99 \\
Coconut meat & 0.69 & 0.77 & 1.06 \\
Coconut meat & 0.67 & 0.63 & 0.88 \\
Coconut meat & 0.96 & 1.09 & 1.04 \\
Coconut crab & & & 0.53 \\
Rongelap & 4.8 & 4.6 & 1.13 \\
Coconut meat & 2.4 & 4.5 & 0.90 \\
Coconut meat & 4.4 & 3.9 & 1.24 \\
Breadfruit & 4.7 & 5.2 & 1.24 \\
Coconut meat & 21 & 17 & 0.78 \\
Arrow toot & 26 & 21 & 0.86 \\
Pandanus & 6.2 & 7.9 & 0.92 \\
Coconut meat & 1.9 & 2.2 & 0.96 \\
Lime meat & 1.1 & 1.2 & 0.93 \\
Coconut meat & 2.6 & 2.7 & 1.02 \\
Coconut meat & 14 & 15 & 0.96 \\
Pig muscle & 6.3 & 6.2 & Mean \\
Chicken muscle & & & \\
\hline
\end{tabular}

Table 23. Interlaboratory comparison of split samples for ${ }^{137} \mathrm{Cs}$ in Bikini vegetation samples - Rongelap Reassessment Program versus Lawrence Livermore National Laboratory.

\begin{tabular}{clccc}
\hline $\begin{array}{c}\text { Paretzke } \\
\text { Sample No. }\end{array}$ & Sample type & \multicolumn{2}{c}{$\begin{array}{c}137 \mathrm{Cs} \text { concentration } \\
(\mathrm{pCi} / \mathrm{g} \text { wet weight) }\end{array}$} & $\begin{array}{c}\text { Ratio of Paretzke } \\
\text { to LLNL }\end{array}$ \\
\cline { 3 - 4 } & & Paretzke & 17.2 & \\
\hline B2 & Coconut frond & 18.9 & 7.8 & 1.10 \\
B3 & Breadfruit & 6.4 & 25.7 & 0.82 \\
B4 & Copra meat & 27.0 & 18.0 & 1.05 \\
B5 & Coconut fluid & 16.0 & 26.4 & 0.89 \\
B6 & Coconut frond & 35.0 & 43.2 & 1.33 \\
B11 & Copra meat & 43.5 & 25.2 & 1.01 \\
B12 & Copra fluid & 28.4 & 21.6 & 1.13 \\
B13 & Coconut frond & 27.9 & 157.0 & 1.29 \\
B14 & Copra meat & 161.0 & 72.1 & 1.03 \\
B15 & Copra fluid & 65.3 & 71.2 & 0.91 \\
B16 & Coconut bread & 63.7 & 44.7 & 0.89 \\
& & 44.8 & & Mean1.04 \\
\hline
\end{tabular}




\section{Split Sample Comparisons}

The results of the intercomparison of split soil samples are shown in Table 24. The mean ratio of Paretzke/Boikat to LLNL is 0.77 . The reason for this bias is a direct result of the difference in processing the soil samples. We screen the soils through $2 \mathrm{~mm}$ mesh, eliminating the large size particles. Then $>2 \mathrm{~mm}$ fraction is retained and analyzed separately if of interest. We adopted this screening procedure because we wanted to develop concentration ratios (CR) between the edible food crop and soil. The plant root system essentially interacts with the smaller soil particles. Concentration of ${ }^{137} \mathrm{Cs}$ is greater in the small particle size fraction; the concentration is much lower in the particles greater than $2 \mathrm{~mm}$ in size. The variability in the $C R$ is greatly reduced if this screening procedure is adopted for calcarious, coral soils.

Table 24. Interlaboratory comparison of split samples for ${ }^{137} \mathrm{Cs}$ in Ailinginae and Rongelap soil samples - Rongelap Reassessment Program versus Lawrence Livermore National Laboratory.

\begin{tabular}{cccc}
\hline \multirow{2}{*}{$\begin{array}{c}\text { Atoll and } \\
\text { sample type }\end{array}$} & \multicolumn{2}{c}{$\begin{array}{c}137 \mathrm{Cs} \text { concentration } \\
\text { (pCi/g wet weight) }\end{array}$} & $\begin{array}{c}\text { Ratio of Paretzke } \\
\text { and Boikat to } \\
\text { LLNL }\end{array}$ \\
\cline { 2 - 3 } & $\begin{array}{c}\text { Paretzke and } \\
\text { Boikat }\end{array}$ & LLNL & \\
\hline Ailinginae & & & \\
Soil $(0-10 \mathrm{~cm})$ B & 1.1 & 0.82 & 1.34 \\
Soil $(0-10 \mathrm{~cm})$ B & 4.6 & 7.4 & 0.62 \\
Soil $(0-10 \mathrm{~cm})$ B & 0.98 & 1.73 & 0.57 \\
Soil $(10-20 \mathrm{~cm})$ B & 0.3 & 0.48 & 0.63 \\
Rongelap & & & \\
Soil $(0-10 \mathrm{~cm})$ B & 3.3 & 3.2 & 1.03 \\
Soil $(0-10 \mathrm{~cm})$ B & 13 & 18 & 0.72 \\
Soil $(0-10 \mathrm{~cm})$ B & 15 & 24 & 0.63 \\
Soil $(10-20 \mathrm{~cm})$ B & 0.97 & 1.3 & 0.75 \\
Soil $(0-10 \mathrm{~cm})$ P & 8.5 & 11 & 0.77 \\
Soil $(0-10 \mathrm{~cm})$ P & 9.5 & 13 & 0.73 \\
Soil $(0-10 \mathrm{~cm})$ P & 1.9 & 3.63 & 0.53 \\
Soil $(0-10 \mathrm{~cm})$ P & 8.8 & 9.71 & 0.91 \\
\hline
\end{tabular}


Drs. Paretzke and Boikat ground up the entire soil sample for analysis. Consequently, the overall ${ }^{137} \mathrm{Cs}$ concentration is lower because of "dilution" with the large particle size fraction. If we analyze for ${ }^{137} \mathrm{Cs}$ the large size fraction from our screening procedure and reconstruct the total soil from the two size fractions $(<2 \mathrm{~mm}$ and $>2 \mathrm{~mm})$ then the results are the same as for Paretzke and Boikat.

We participated in another recent intercalibration exercise run by the Republic of the Marshall Island (RMI) Nation Wide Radiological Study (NWRS). The results are shown in Table 25 where LLNL is listed as Lab 2. The soil samples were collected by the NWRS, homogenized, and distributed to the participating laboratories.

Table 25. Intercomparison Results for Soil Samples from RMI Nationwide Radiological Survey. (All units are $\mathrm{Bg} \mathrm{kg}^{-1}$; Error is \pm 1 sigma).

\begin{tabular}{|c|c|c|c|c|c|c|c|c|c|c|}
\hline \multirow[b]{3}{*}{ Radionuclide } & \multicolumn{10}{|c|}{ Sample 09So1V } \\
\hline & \multicolumn{2}{|c|}{$\mathrm{LAB} 1$} & \multicolumn{2}{|c|}{ LAB 2 (LLNL) } & \multicolumn{2}{|c|}{ LAB 3} & \multicolumn{2}{|c|}{ LAB 4} & \multicolumn{2}{|c|}{ LAB 5} \\
\hline & Estimate & Error & Estimate & Error & Estimate & Error & Estimate & Error & Estimate & Error \\
\hline${ }^{137} \mathrm{Cs}$ & 968 & 17 & 850 & 30 & & & 202 & 0.20 & 752 & 37.68 \\
\hline${ }^{60} \mathrm{Co}$ & 120 & 7.5 & 101 & 4 & & & 23.4 & 0.16 & 94.7 & 3.02 \\
\hline${ }^{102} \mathrm{Rh}$ & 48 & 9 & & & & & 10.7 & 0.06 & 39.8 & 0.72 \\
\hline${ }^{101} \mathrm{Rh}$ & 1 & 0.5 & & & & & & & & \\
\hline \multicolumn{11}{|l|}{${ }^{207} \mathrm{Bi}$} \\
\hline \multicolumn{11}{|l|}{${ }^{208} \mathrm{Tl}$} \\
\hline${ }^{152} \mathrm{Eu}$ & 26 & 4 & & & & & 6.25 & 0.14 & 17.5 & 0.37 \\
\hline${ }^{154} \mathrm{Eu}$ & 3 & 0.5 & & & & & & & 2 & 0.16 \\
\hline${ }^{155} \mathrm{Eu}$ & & & 53 & 3 & & & 16.3 & 0.31 & 58 & 2.13 \\
\hline${ }^{125} \mathrm{Sb}$ & 2 & 0.5 & & & & & & & & \\
\hline${ }^{241} \mathrm{Am}$ & & & 420 & 20 & & & 68.8 & 0.34 & 383 & 19.23 \\
\hline $239,240 \mathrm{Pu}$ & 2375 & 81 & 2510 & 75 & 2446 & 346 & & & & \\
\hline \multirow[t]{3}{*}{${ }^{238} \mathrm{Pu}$} & & & 1180 & 35 & 1146 & 170 & & & & \\
\hline & \multicolumn{10}{|c|}{ Sample 09S83a } \\
\hline & \multicolumn{2}{|c|}{ LAB 1} & \multicolumn{2}{|c|}{ LAB 2 (LLNL) } & \multicolumn{2}{|c|}{ LAB 3} & \multicolumn{2}{|c|}{ LAB 4} & \multicolumn{2}{|c|}{ LAB 5} \\
\hline Radionuclide & Estimate & Error & Estimate & Error & Estimate & Error & Estimate & Error & Estimate & Error \\
\hline${ }^{137} \mathrm{Cs}$ & 103 & 2.5 & 103 & 4 & & & 106 & 0.64 & 75.2 & 5.00 \\
\hline${ }^{60} \mathrm{Co}$ & 17 & 0.5 & 15.5 & 0.7 & & & 16.9 & 0.47 & 11.7 & 3.30 \\
\hline \multicolumn{11}{|l|}{${ }^{102} \mathrm{Rh}$} \\
\hline \multicolumn{11}{|l|}{${ }^{101} \mathrm{Rh}$} \\
\hline $\begin{array}{l}{ }^{207} \mathrm{Bi} \\
{ }^{208} \mathrm{Tl}\end{array}$ & 7 & 0.5 & 7.4 & 0.4 & & & 7.71 & 0.25 & 5.6 & 3.20 \\
\hline${ }^{152} \mathrm{Eu}$ & 8 & 1.5 & & & & & 10.1 & 0.61 & 6.2 & 2.10 \\
\hline${ }^{154} \mathrm{Eu}$ & & & & & & & & & & \\
\hline${ }^{155} \mathrm{Eu}$ & & & 13 & 1 & & & 17 & 0.88 & & \\
\hline $125 \overline{\mathrm{Sb}}$ & & & & & & & & & & \\
\hline${ }^{241} \mathrm{Am}$ & & & 252 & 8 & & & 284 & 1.14 & 252 & 5.20 \\
\hline $239,240 \mathrm{Pu}$ & 613 & 18.5 & 685 & 17 & 674 & 31 & & & 702 & 77 \\
\hline${ }^{238} \mathrm{Pu}$ & & & 80 & 2 & 73 & 13 & & & 79 & 18 \\
\hline
\end{tabular}


Table 25. Intercomparison Results for Soil Samples from RMI Nationwide Radiological Survey. (All units are Bq kg-1 ; Error is \pm 1 sigma) continued.

\begin{tabular}{|c|c|c|c|c|c|c|c|c|c|c|}
\hline \multirow[b]{3}{*}{ Radionuclide } & \multicolumn{10}{|c|}{ Sample 09S43A } \\
\hline & \multicolumn{2}{|c|}{ LAB 1} & \multicolumn{2}{|c|}{ LAB 2 (LLNL) } & \multicolumn{2}{|c|}{ LAB 3 } & \multicolumn{2}{|c|}{ LAB 4} & \multicolumn{2}{|c|}{ LAB 5} \\
\hline & Estimate & Error & Estimate & Error & Estimate & Error & Estimate & Error & Estimate & Error \\
\hline${ }^{137} \mathrm{Cs}$ & 13 & 0.5 & 12 & 0.5 & & & 11.8 & 0.51 & 10.6 & 0.55 \\
\hline${ }^{60} \mathrm{Co}$ & 4 & 0.5 & 3.7 & 0.2 & & & 3.87 & 0.33 & 3.7 & 0.13 \\
\hline \multicolumn{11}{|l|}{${ }^{102} \mathrm{Rh}$} \\
\hline \multicolumn{11}{|l|}{${ }^{101} \mathrm{Rh}$} \\
\hline${ }^{207} \mathrm{Bi}$ & 4 & 0.5 & 3.9 & 0.2 & & & 4.54 & 0.22 & 3.8 & 0.14 \\
\hline${ }^{208} \mathrm{Tl}$ & & & & & & & & & & \\
\hline${ }_{152} \mathrm{Fu}_{1}$ & & & & & & & & & & \\
\hline \multicolumn{11}{|l|}{${ }^{154} \mathrm{Eu}$} \\
\hline \multicolumn{11}{|l|}{${ }^{155} \mathrm{Eu}$} \\
\hline \multicolumn{11}{|l|}{${ }^{125} \mathrm{Sb}$} \\
\hline${ }^{241} \mathrm{Am}$ & & & 0.86 & 0.07 & & & 0.968 & 0.10 & 1 & 0.15 \\
\hline $239,240 \mathrm{Pu}$ & 3.4 & 0.25 & 3.9 & 0.2 & 3.7 & 0.34 & & & 3.8 & 0.26 \\
\hline${ }^{238} \mathrm{Pu}$ & & & 0.13 & 0.03 & & & & & 0.13 & 0.82 \\
\hline
\end{tabular}

A comparison of ${ }^{137} \mathrm{Cs}$ results in one of several split sample exercises with the RMI NWRS is shown in Table 26. The ratio of the NWRS results to LLNL results for 12 coconut fluid samples is $0.94 \pm 0.06$ and for 12 coconut meat samples is $1.15 \pm 0.18$. The ratio of ${ }^{137} \mathrm{Cs}$ concentrations in soil (NWRS/LLNL) for split soil samples exercise at Rongelap Atoll is $0.94 \pm 0.28$ for 61 samples taken in 1993 .

The continuing participation in interlaboratory - intercalibration exercises, standard certification, and analysis of split samples with other agencies, laboratories, and universities around the world are very important in our overall quest for excellence in our analytical facilities. We will maintain this type of activity as part of our standard operating procedure.

Table 26. Cross Comparison Between Lawrence Livermore National Laboratory and the RMI Nationwide Radiological Survey.

\begin{tabular}{|c|c|c|c|c|c|}
\hline \multirow[b]{2}{*}{ Island } & \multicolumn{2}{|c|}{ LLNL } & \multicolumn{2}{|c|}{ RMI } & \multirow[b]{2}{*}{$\begin{array}{l}\text { Ratio } \\
\text { RMI/ } \\
\text { LLNL }\end{array}$} \\
\hline & $\begin{array}{l}\text { Sample } \\
\text { number }\end{array}$ & $\begin{array}{c}{ }^{137} \mathrm{Cs} \\
\mathrm{Bq} / \mathrm{g} \\
\text { wet wt. }\end{array}$ & $\begin{array}{l}\text { Sample } \\
\text { number }\end{array}$ & $\begin{array}{c}{ }^{137} \mathrm{Cs} \\
\mathrm{Bq} / \mathrm{g} \\
\text { wet wt. }\end{array}$ & \\
\hline & \multicolumn{2}{|c|}{ coconut fluid } & \multicolumn{2}{|c|}{ coconut fluid } & \\
\hline Tufa & 4270 & 0.0042 & $26 s 84 j$ & 3.7E-03 & 0.88 \\
\hline Tufa & 4316 & 0.012 & $26 s 87 j$ & $1.2 \mathrm{E}-02$ & 1.03 \\
\hline Eniran & 4337 & 0.015 & $26 \mathrm{~s} 90 \mathrm{j}$ & $1.6 \mathrm{E}-02$ & 1.07 \\
\hline Eniran & 4346 & 0.0075 & $26 s 92 j$ & $6.8 \mathrm{E}-03$ & 0.90 \\
\hline Arbar & 4417 & 0.012 & $26 s 96 j$ & $1.0 \mathrm{E}-02$ & 0.87 \\
\hline
\end{tabular}


Table 26. Cross Comparison Between Lawrence Livermore National Laboratory and the RMI Nationwide Radiological Survey continued.

\begin{tabular}{|c|c|c|c|c|c|}
\hline \multirow[b]{2}{*}{ Island } & \multicolumn{2}{|c|}{ LLNL } & \multicolumn{2}{|c|}{ RMI } & \multirow[b]{2}{*}{$\begin{array}{l}\text { Ratio } \\
\text { RMI/ } \\
\text { LLNL }\end{array}$} \\
\hline & $\begin{array}{l}\text { Sample } \\
\text { number }\end{array}$ & $\begin{array}{c}{ }^{137} \mathrm{Cs} \\
\mathrm{Bq} / \mathrm{g} \\
\text { wet wt. }\end{array}$ & $\begin{array}{l}\text { Sample } \\
\text { number }\end{array}$ & $\begin{array}{c}{ }^{137} \mathrm{Cs} \\
\mathrm{Bq} / \mathrm{g} \\
\text { wet wt. }\end{array}$ & \\
\hline & \multicolumn{2}{|c|}{ coconut fluid } & \multicolumn{2}{|c|}{ coconut fluid } & \\
\hline Arbar & 4445 & 0.0073 & $26 s 99 j$ & $6.8 \mathrm{E}-03$ & 0.93 \\
\hline Erapuotsu & 4466 & 0.053 & $26 s 104 j$ & $4.9 E-02$ & 0.92 \\
\hline Erapuotsu & 4473 & 0.016 & $26 s 108 j$ & $1.5 \mathrm{E}-02$ & 0.96 \\
\hline Busch & 4597 & 0.017 & $26 s 111 j$ & $1.5 \mathrm{E}-02$ & 0.90 \\
\hline Busch & 4611 & 0.011 & $26 s 114 j$ & $1.1 \mathrm{E}-02$ & 0.96 \\
\hline Rongelap & 4722 & 0.014 & $26 s 125 j$ & $1.3 E-02$ & 0.95 \\
\hline \multirow[t]{2}{*}{ Rongelap } & 4875 & 0.029 & $26 s 126 j$ & 2.6E-02 & 0.90 \\
\hline & & & & $\begin{array}{c}\text { mean } \\
\text { Std }\end{array}$ & $\begin{array}{l}0.94 \\
0.06\end{array}$ \\
\hline Eniran & 4336 & 0.043 & $26 \mathrm{~s} 90 \mathrm{~m}$ & $5.5 E-02$ & 1.27 \\
\hline Eniran & 4345 & 0.018 & $26 \mathrm{~s} 92 \mathrm{~m}$ & $3.0 \mathrm{E}-02$ & 1.65 \\
\hline Arbar & 4416 & 0.057 & $26 \mathrm{~s} 96 \mathrm{~m}$ & $6.3 \mathrm{E}-02$ & 1.11 \\
\hline Arbar & 4444 & 0.021 & $26 \mathrm{~s} 99 \mathrm{~m}$ & $2.2 \mathrm{E}-02$ & 1.07 \\
\hline Erapuotsu & 4465 & 0.12 & $26 \mathrm{~s} 104 \mathrm{~m}$ & $1.4 \mathrm{E}-01$ & 1.16 \\
\hline Erapuotsu & 4472 & 0.057 & $26 \mathrm{~s} 108 \mathrm{~m}$ & $6.6 \mathrm{E}-02$ & 1.16 \\
\hline Busch & 4596 & 0.042 & $26 \mathrm{~s} 111 \mathrm{~m}$ & $4.0 \mathrm{E}-02$ & 0.94 \\
\hline Busch & 4610 & 0.044 & $26 \mathrm{~s} 114 \mathrm{~m}$ & $4.9 \mathrm{E}-02$ & 1.12 \\
\hline Rongelap & 4721 & 0.039 & $26 \mathrm{~s} 125 \mathrm{~m}$ & $4.1 \mathrm{E}-02$ & 1.05 \\
\hline \multirow[t]{3}{*}{ Rongelap } & 4874 & 0.067 & $26 \mathrm{~s} 126 \mathrm{~m}$ & $7.4 \mathrm{E}-02$ & 1.10 \\
\hline & & & & mean & 1.15 \\
\hline & & & & std & 0.18 \\
\hline
\end{tabular}

\section{References}

Jennings, C.D. and M.E. Mount (1983), The Northern Marshall Islands Radiological Survey: A Quality Control Program for Radiochemical Analysis, Lawrence Livermore National Laboratory, Livermore, CA, UCRL-52853 Pt. 5. 
Appendix A: Preparation of Duplicates 
The procedures used at LLNL to process the various sample types are described in detail in a paper titled "Field Collection and Laboratory Sample Processing Procedure for the Marshall Islands Program" (M.L. Stuart, 1995). For completeness, the procedures appropriate to the duplicates are briefly summarized.

The preparation of duplicate samples is simple and straightforward. The primary requirement is a processed sample of sufficient size (mass) to provide at least two aliquants for comparative radiochemistry. Once the sample is processed, great effort is taken to insure that the characteristics (packing density, sample weight) of the two aliquants are as similar as possible. This accomplished, the samples are then sealed, labeled, and forwarded for analysis. We feel confident that the methods used to produce duplicate aliquants yields samples that are close to being radiologically identical. Furthermore, the analyses performed by the participating laboratories seem to support this.

\section{Soil Duplicates}

Each soil sample (500 to $900 \mathrm{~g}$ ) is put into a new 1 gallon paint can, weighed, and placed in a forced-air oven for approximately one week. Afterwards, it is weighed every 24 hours and when a constant weight is noted, it is considered dry. Once dry, the can is sealed and placed on a rolling mill to loosen clods and stuck particles. After roll milling, the sample is passed through a set of progressively finer sieves to obtain coarse (greater then $2 \mathrm{~mm}$ ) and fine (less than $2 \mathrm{~mm}$ ) separations. The separations are weighed, recorded, and the fine portion returned to the can. Next, steel grinding balls are placed inside the can with the fine soil, the cover securely sealed, and then ball milled continuously until the particles have been ground into a fine powder. Once ground, the fine powder is mixed, and the necessary aliquants are canned, labeled, and forwarded for analysis. During the canning phase, great care is taken to assure that the characteristics of the duplicate pair (packing density, sample weights) are as close as possible to each other. Soil duplicates represent the largest fraction of duplicates prepared.

\section{Vegetation Duplicates}

Vegetation duplicates are almost exclusively prepared from composite coconut meat samples. All vegetation is maintained frozen at LLNL until processed. To ensure against contamination, fruits and roots are washed very carefully before dissection. Once the sample is separated into its various parts (i.e., meat, skin, and seeds), the individual parts are cut into smaller pieces, placed in clean plastic containers and weighed. Following weighing, the containers are placed in freeze-dryers and lyophilized until a constant weight is reached. The dried sample is then ground to a homogeneous texture, mixed, and aliquants taken. The aliquants are then hydraulically pressed into appropriate sample containers taking great care to assure that the characteristics of the duplicate pair (packing density, sample weights) are as close as possible. This completed, the samples are then sealed, labeled, then forwarded for analysis. 


\section{Terrestrial Animal Duplicates}

Terrestrial animal duplicates are primarily prepared from the meat and organs of pigs or chickens since they are the most common terrestrial animals encountered and collected. Processing procedures are essentially identical with those of the vegetation duplicates with the exception that the pigs are dissected in the field due to their size and the actual amount of tissue required to produce a suitable sample and duplicate. Following the dissection, each part is placed in a new, clean plastic bag that is then double sealed and labeled with the appropriate information. Again, after being processed through the laboratory, great care is taken to assure that the characteristics of the duplicate pair (packing density, sample weights) are as close as possible. This completed, the samples are then sealed, labeled, then forwarded for analysis.

\section{Marine Organism Duplicates}

Marine organism duplicates are primarily prepared from the tissues and organs of fish and mollusks. Processing procedures are essentially identical with that of the terrestrial animal duplicates with the following exceptions. Fish samples are caught and separated into individual species, double bagged, frozen, and returned to the laboratory for further processing. Mollusks, if possible, are removed from their shells, placed in plastic bags, frozen, and returned to the laboratory for further processing. After dissecting, tissues and organs from the same catch are pooled and wet weights determined. Pooling same catch tissue samples is necessary in order to obtain enough material (once dried or ashed) for suitable aliquants. The samples are then processed in one of two ways. The samples are either processed in the same manner the as the terrestrial animal duplicates or ashed. Since the first method has already been described, only a brief discussion of the later will be presented. The pooled tissues, placed in clean beakers, are put in an oven set at $90 \mathrm{C}$ and dried until a constant weight is reached. Once dried, the samples are placed in a muffle furnace set at $450 \mathrm{C}$ until a fine ash is achieved. The ash is homogenized and then, taking great care to assure that the characteristics of the duplicate pair (packing density, sample weights) are as close as possible, are packaged, labeled, and forwarded for analysis.

\section{References}

Stuart, M.L. (1995), Field Collection and Laboratory Sample Processing Procedure for the Marshall Island Program, Lawrence Livermore National Laboratory, Livermore, CA, UCRL-ID-120427. 
Appendix B: Preparation of Standards 
Because the purpose of the standard is to substantiate the analyses of other environmental samples, it is important that the character of the standard matches that of the representative samples as closely as possible. Any radioactivity in the standards needs to originate from the natural environment and not merely added to the samples from a solution in which the chemical forms might be quite different from those in the samples. Consequently, great effort was taken to ensure that each standard was prepared from material collected directly from the environment. This proved to be a problem for environmental samples of vegetation, marine and terrestrial animal tissues since they generally did not have enough radioactivity to serve as adequate standards. It was therefore necessary to spike them with environmentally labeled radioactive algae, in the same manner used by Volchok and Feiner at the DOE Environmental Measurements Laboratory (EML) to prepare standards for the DOE Intercalibration exercise (H. L. Volchok and M. Feiner, 1979).

\section{Soil Standard}

To prepare soil standards, large bulk samples of soil were collected from selected locations at Enjebi and Enewetak islands (Enewetak atoll) and at Eneu and Bikini islands (Bikini atoll) during four survey trips. The first bulk soil, taken in March 1979, was collected from Enjebi island (Enewetak atoll) followed by Bikini island (Bikini atoll, December 1981), Eneu island (Bikini atoll, July 1982), and finally Enewetak island (Enewetak atoll, February 1985). The subsequent standards created from these bulk soils were individually identified (as to origin) by the month and year that they were collected. Therefore, all soil standards created from Enjebi island bulk soil start with the designation "7903". Bikini island, Eneu island, and Enewetak island each start with "8112", "8207", and "8502" respectively. Overall, $142.7 \mathrm{~kg}$ and $196.2 \mathrm{~kg}$ of soil was collected from Enjebi and Enewetak islands respectively, while $165.3 \mathrm{~kg}$ and $18.3 \mathrm{~kg}$ of soil was collected from Eneu and Bikini islands, respectively. Since each island exhibits a different activity level, it was possible to obtain four distinct soil standards. Soil collected at the Marshall Islands was then shipped to LLNL where it was oven dried and ball milled in the same manner as the soil duplicates outlined previously. The steps taken next, deviated from the original NMIRS in that the bulk soil was not forwarded to WOSC for independent preparation. Since the procedures developed to create the NMIRS soil standards by WOSC had been well documented, with subsequent testing indicating homogeneity, it was decided that in order to expedite the preparation of the new soil standards, the procedures would instead be followed by the Marshall Island Program Soil Facility. Under the direction of Dr. C. D. Jennings (from WOSC), each bulk soil was sieved and homogenized in a large twin-cone blender by LLNL Soil Facility personnel. Aliquants were then canned and labeled to conform to the style of samples prepared at LLNL.

\section{Vegetation Standard}


During the preparation of the vegetation standard a problem occurred in production of a standard based on the coconut matrix. When the radioactively labeled algae was added to a sample of commercially bought coconut meat, the natural oils bound the algae in an effective "glue", producing problems in homogenization of the sample. Additional attempts made to correct this problem proved ineffective, so the decision was made to switch to a different matrix. Therefore, the vegetation standard "8510" (for the year and month the standard was completed) was created by adding a measured amount of the radioactively labeled algae to $88.6 \mathrm{~kg}$ of lyophilized commercial potato flakes. After homogenizing the entire sample in a twin-cone blender for three weeks, it was canned and labeled to conform to the style of samples prepared at LLNL. We feel confident that this does not detract from the quality of the standard, or the ability of the standard to represent a proper vegetation matrix for analysis by the participating laboratories.

\section{Terrestrial Animal Standard}

The terrestrial animal standard was prepared by taking a large sample of beef purchased from a local supermarket that was then dried and ashed at LLNL. The ash (approximately $250 \mathrm{~g}$ ) was then sent to WOSC where it was spiked with a known amount of standardized radioactively labeled algae, blended, and re-ashed at $400 \mathrm{C}$. The re-ashed beef sample was then blended in a small twin-cone blender, canned and labeled to conform to the style of samples prepared at LLNL.

\section{Marine Organism Standard}

The marine organism standard was made from fish samples that were collected from the Marshall Islands and then ashed at LLNL with the resultant product shipped to WOSC. The ash (approximately $2 \mathrm{~kg}$ ) was then spiked with a known amount of standardized radioactively labeled algae, blended and then re-ashed at 400 C. The re-ashed sample was then blended again in a small twin-cone blender, canned, and labeled to conform to the style of samples prepared at LLNL.

\section{References}

Volchok, H.L. and M. Feiner (1979), A Radioanalytical Laboratory Intercomparison Exercise, United States Department of Energy, Environmental Measurements Laboratory, New York, NY, EML-366. 
Appendix C: Certification of Standards 
The certification of standards requires two phases. The first requirement shows that the methods used to prepare the standards produces samples that are homogeneous. After the standards were prepared, homogeneity was tested by measuring ${ }^{137} \mathrm{Cs}$ in a random selection of aliquants by non-destructive analysis via gamma spectroscopy. As shown in Table $\mathrm{C} 1$, there was excellent agreement among the various standards of vegetation and soil. Fractional standard deviations for the " 8510 " vegetation standard and the "7903", "8112", "8207", and "8502" soil standards measured by gamma spectroscopy were $5.8 \%, 4.8 \%, 2.7 \%, 2.2 \%$ and $1.8 \%$ respectively. Analyzed radiochemically, independent measurements of ${ }^{137} \mathrm{Cs}$ on the "8510" vegetation standard and the "7903", "8112", "8207", and "8502" soil standards show fractional standard deviations in their certified values of $6.4 \%, 6.7 \%, 8.2 \%, 5.7 \%$, and $6.2 \%$ respectively. Since soil standards contained no augmented radioactivity, follow up analyses of $239+240 \mathrm{Pu}$ and ${ }^{241} \mathrm{Am}$ were performed radiochemically by Environmental Measurements Laboratory (EML), Western Oregon State College, Oregon State University (WOSC, OSU), North Carolina State University (NCSU), Pacific Northwest Laboratory (PNL), and Thermo Analytical Norcal (TMA) laboratories. Fractional standard deviations for $239+240 \mathrm{Pu}$ analyzed radiochemically for the "7903", "8112", "8207", and "8502" soil standards were $3.3 \%, 7.5 \%, 5.2 \%$, and $10 \%$ respectively. (Tables $\mathrm{C} 2-\mathrm{C} 10$ ). On the basis of the results obtained from gamma spectroscopy and follow up radiochemistry analyses for ${ }^{137} \mathrm{Cs}$ and $239+240 \mathrm{Pu}$, we feel that sufficient evidence exists that the procedures used to prepare the standards produces homogeneous samples. Furthermore, because the terrestrial animal and marine organism standards were produced in the same fashion as the vegetation samples, we feel that their homogeneity becomes also established.

The second phase requires that the activity level of the standards be well established. This was accomplished in two ways. First, the radioactivity of the algae used to spike the samples of vegetation, fish, and beef had been well characterized by EML, and because it was used to prepare samples for the DOE Intercalibration exercise, the measurements were well corroborated $(\mathrm{H}$. L. Volchok and M. Feiner, 1979). Establishing radioactivity levels for standards of vegetation, marine organism, and terrestrial animal then became a simple matter of adding known amounts of algae to the proper matrix. Second, after producing samples with a particular activity level, all standards except the terrestrial animal standard were analyzed radiochemically. Tables $\mathrm{C} 2,3$, and 9 show the results of these analyses performed on the augmented samples. In Table C10 only the expected values for the terrestrial animal standard are presented. Because the terrestrial animal standard was prepared by the same method as the vegetation and marine organism standards, and due to the limited amount of standard produced, no radiochemical analyses were performed. We feel confident that the expected activity level of the terrestrial animal standard represents an actual activity concentration and the values obtained from the participating laboratories seem to corroborate this. Soil standards were different in that no radioactively labeled algae was added to them. Since radiochemical analyses of the soil standards were performed to establish homogeneity, their activity levels became well corroborated between the analyzing 
Table C1. Cs-137 (in pCi/gram dry weight $\pm \%$ fractional standard deviation) measured by gamma-ray spectrometry in a random selection of vegetation and soil standards.

\begin{tabular}{|c|c|c|c|c|c|}
\hline Sample & $\begin{array}{l}\text { Vegetation } \\
\text { standard } \\
8510\end{array}$ & $\begin{array}{c}\text { Soil } \\
\text { standard } \\
7903\end{array}$ & $\begin{array}{c}\text { Soil } \\
\text { standard } \\
8112\end{array}$ & $\begin{array}{c}\text { Soil } \\
\text { standard } \\
8207\end{array}$ & $\begin{array}{c}\text { Soil } \\
\text { standard } \\
8502\end{array}$ \\
\hline 1 & $2.3 \pm 3.7 \%$ & $17 \pm 1.1 \%$ & $0.94 \pm 3.6 \%$ & $5.6 \pm 1.3 \%$ & $0.89 \pm 2.5 \%$ \\
\hline 2 & $2.1 \pm 4.0 \%$ & $17 \pm 0.9 \%$ & $1.1 \pm 1.9 \%$ & $5.5 \pm 1.3 \%$ & $0.91 \pm 2.8 \%$ \\
\hline 3 & $2.4 \pm 2.7 \%$ & $18 \pm 1.0 \%$ & $1.0 \pm 2.6 \%$ & $5.6 \pm 1.2 \%$ & $0.92 \pm 2.3 \%$ \\
\hline 4 & $2.0 \pm 4.5 \%$ & - & $1.0 \pm 2.7 \%$ & $6 \pm 1.4 \%$ & $0.90 \pm 2.5 \%$ \\
\hline 5 & $2.3 \pm 2.8 \%$ & - & $0.95 \pm 2.9 \%$ & $5.8 \pm 1.4 \%$ & $0.92 \pm 1.4 \%$ \\
\hline 6 & $2.1 \pm 5.7 \%$ & - & $1.0 \pm 2.8 \%$ & $5.6 \pm 1.1 \%$ & $0.9 \pm 2.4 \%$ \\
\hline 7 & $2.3 \pm 2.3 \%$ & - & $1.0 \pm 3.4 \%$ & $5.5 \pm 1.2 \%$ & $0.92 \pm 1.2 \%$ \\
\hline 8 & $2.1 \pm 2.9 \%$ & - & $0.93 \pm 2.2 \%$ & $5.6 \pm 1.1 \%$ & $0.94 \pm 2.5 \%$ \\
\hline 9 & - & - & $1.0 \pm 2.4 \%$ & $5.5 \pm 1.2 \%$ & $0.92 \pm 1.6 \%$ \\
\hline 10 & - & - & $0.99 \pm 2.4 \%$ & $5.6 \pm 1.3 \%$ & $0.91 \pm 2.5 \%$ \\
\hline 11 & - & - & $1.0 \pm 3.2 \%$ & $5.6 \pm 1.1 \%$ & $0.9 \pm 2.4 \%$ \\
\hline 12 & - & - & & $5.7 \pm 1.0 \%$ & $0.94 \pm 2.9 \%$ \\
\hline 13 & - & - & & $5.7 \pm 1.1 \%$ & $0.94 \pm 2.4 \%$ \\
\hline 14 & - & - & & $5.7 \pm 1.0 \%$ & $0.92 \pm 2.5 \%$ \\
\hline 15 & - & - & & $5.7 \pm 1.2 \%$ & $0.93 \pm 1.6 \%$ \\
\hline Mean & $\overline{2.2}$ & 17 & 1.0 & 5.6 & 0.917 \\
\hline $\begin{array}{l}\text { Std dev of } \\
\text { mean (\%) }\end{array}$ & 5.8 & 2.7 & 4.8 & 2.2 & 1.8 \\
\hline
\end{tabular}

Table C2. Radionuclides measured in vegetation standard (7808) samples. All analyses performed radiochemically except as noted.

\begin{tabular}{lcccc}
\hline Values or & \multicolumn{4}{c}{ Radio nuclide (pCi/g \pm fractional standard deviation) } \\
\cline { 2 - 5 } laboratory & \multicolumn{2}{c}{$137 \mathrm{Cs}$} & $239+240 \mathrm{Pu}$ & $241 \mathrm{Am}$ \\
\cline { 2 - 5 } & - & $2.7 \pm 20 \%$ & $0.017 \pm 20 \%$ & $0.0041 \pm 20 \%$ \\
\hline Expected & $3.3 \pm 5.8 \%(3)$ & $2.4 \pm 11.7 \%(3) \mathrm{a}$ & $0.015 \pm 10 \%(3)$ & $0.0048 \pm 23 \%(3)$ \\
EML & $3.3 \pm 10 \%$ & $2.7 \pm 10 \%$ & $0.016 \pm 10 \%$ & $0.0054 \pm 10 \%$ \\
LLNL & $3.8 \pm 8.0 \%(4)$ & $2.7 \pm 2.6 \%(10)$ & $0.016 \pm 4.7 \%(16)$ & $0.0054 \pm 1.7 \%(4)$ \\
WOSC,OSU & $3.3 \pm 10 \%$ & $2.7 \pm 10 \%$ & $0.016 \pm 10 \%$ & $0.0054 \pm 10 \%$ \\
Certified & $3.3 \pm$
\end{tabular}

NOTE: Number of replicates are in parentheses.

a Measured by gamma-ray spectroscopy. 
laboratories. Tables C4 - C8 show the results of these analyses. We are confident that the established activities, or the expected values in the case of the terrestrial animal standard, are correct within the tolerance quoted in Tables C2-C10. This has been further demonstrated by the high degree of compliance by the participating laboratories.

Table C3. Radionuclides measured in vegetation standard (8510) samples. All analyses performed radiochemically.

Values or

laboratory

Radio nuclide ( $\mathrm{pCi} / \mathrm{g} \pm$ fractional standard deviation)

\begin{tabular}{ccccc} 
& $90 \mathrm{Sr}$ & $137 \mathrm{Cs}$ & $239+240 \mathrm{Pu}$ & $241 \mathrm{Am}$ \\
\cline { 2 - 5 } EC & $2.5 \pm 13 \%(3)$ & $2 \pm 1.6 \%$ & $0.015 \pm 3.9 \%$ & - \\
EML & - & - & $0.013 \pm 18 \%$ & - \\
TMA & $2.7 \pm 5.7 \%(5)$ & $2.2 \pm 4.2 \%(5)$ & $0.016 \pm 3.7 \%(5)$ & $0.0085 \pm 8.4 \%(5)$ \\
Certified & $2.6 \pm 9.2 \%$ & $2.2 \pm 6.4 \%$ & $0.015 \pm 10 \%$ & $0.0085 \pm 8.4 \%$ \\
\hline
\end{tabular}

NOTE: Number of replicates are in parentheses.

Table C4. Radionuclides measured in soil standard (7808). All analyses performed radiochemically except as noted.

\begin{tabular}{ccccc}
\hline \multirow{2}{*}{$\begin{array}{c}\text { Values or } \\
\text { laboratory }\end{array}$} & \multicolumn{4}{c}{ Radio nuclide (pCi/g \pm fractional standard deviation) } \\
\cline { 2 - 5 } & $90 \mathrm{Sr}$ & $137 \mathrm{Cs}$ & $239+240 \mathrm{Pu}$ & $241 \mathrm{Am}$ \\
\hline EML & $0.089 \pm 4.1 \%(3)$ & $0.037 \pm 3.7 \%(3) \mathrm{a}$ & $0.035 \pm 9.8 \%(3)$ & $0.014 \pm 7 \%(3)$ \\
LLNL & - & - & $0.037 \pm 0.6 \%(2)$ & - \\
WOSC,OSU & - & $0.036 \pm 3.8 \%(8)$ & $0.036 \pm 5.4 \%(10)$ & $0.016 \pm 7.2 \%(4)$ \\
Certified & $0.089 \pm 10 \%$ & $0.036 \pm 10 \%$ & $0.036 \pm 10 \%$ & $0.016 \pm 10 \%$ \\
\hline
\end{tabular}

NOTE: Number of replicates are in parentheses.

a Measured by gamma-ray spectroscopy.

Table C5. Radionuclides measured in soil standard (7903). All analyses performed radiochemically.

\begin{tabular}{ccccc}
\hline \multirow{2}{*}{$\begin{array}{c}\text { Values or } \\
\text { laboratory }\end{array}$} & \multicolumn{4}{c}{ Radio nuclide $(\mathrm{pCi} / \mathrm{g} \pm$ fractional standard deviation) } \\
\cline { 2 - 5 } & $90 \mathrm{Sr}$ & $137 \mathrm{Cs}$ & $239+240 \mathrm{Pu}$ & $241 \mathrm{Am}$ \\
\hline EC & $27 \pm 1.9 \%(3)$ & $15 \pm 2.0 \%$ & $7.2 \pm 10.0 \%$ & - \\
LLNL & - & - & $7.7 \pm 1.7 \%(6)$ & - \\
TMA & $30 \pm 7.1 \%(5)$ & $18 \pm 3.4 \%(5)$ & $8.0 \pm 1.7 \%(5)$ & $5.6 \pm 3.0 \%(5)$ \\
Certified & $29 \pm 8.3 \%$ & $18 \pm 6.7 \%$ & $7.8 \pm 3.3 \%$ & $5.6 \pm 3.0 \%$ \\
\hline
\end{tabular}

NOTE: Number of replicates are in parentheses. 
Table C6. Radionuclides measured in soil standard (8112). All analyses performed radiochemically.

\begin{tabular}{ccccc}
\hline \multirow{2}{*}{$\begin{array}{l}\text { Values or } \\
\text { laboratory }\end{array}$} & \multicolumn{4}{l}{ Radio nuclide $(\mathrm{pCi} / \mathrm{g} \pm$ fractional standard deviation) } \\
\cline { 2 - 5 } & $90 \mathrm{Sr}$ & $137 \mathrm{Cs}$ & $239+240 \mathrm{Pu}$ & $241 \mathrm{Am}$ \\
\hline CLI & $0.87 \pm 21 \%(2)$ & - & - & - \\
EC & - & $0.91 \pm 0.7 \%$ & $0.18 \pm 6.7 \%(2)$ & $0.11 \pm 2.4 \%(2)$ \\
NCSU & $0.85 \pm 10 \%$ & - & - & - \\
PNL & $0.97 \pm 5.6 \%$ & - & - & $0.11 \pm 1.4 \%(4)$ \\
TMA & $1.0 \pm 7.5 \%(7)$ & $0.86 \pm 9.2(4)$ & $0.16 \pm 5.2 \%(4)$ & - \\
Certified & $0.97 \pm 11 \%$ & $0.87 \pm 8.2 \%$ & $0.17 \pm 7.5 \%$ & $0.11 \pm 1.7 \%$ \\
\hline
\end{tabular}

NOTE: Number of replicates are in parentheses.

Table C7. Radionuclides measured in soil standard (8207). All analyses performed radiochemically.

\begin{tabular}{ccccc}
\hline \multirow{2}{*}{$\begin{array}{c}\text { Values or } \\
\text { laboratory }\end{array}$} & \multicolumn{4}{c}{ Radionuclide $(\mathrm{pCi} / \mathrm{g} \pm$ fractional standard deviation) } \\
\cline { 2 - 5 } & $90 \mathrm{Sr}$ & $137 \mathrm{Cs}$ & $239+240 \mathrm{Pu}$ & $241 \mathrm{Am}$ \\
\hline EC & $3.5 \pm 2.7 \%(3)$ & - & $1.1 \pm 8.2 \%$ & - \\
EML & - & $5.4 \pm 1.2 \%$ & - & - \\
LLNL & - & - & $1.16 \pm 6.4 \%(6)$ & - \\
TMA & $4.1 \pm 2.2 \%(5)$ & $5.9 \pm 5.8 \%(5)$ & $1.1 \pm 4.0 \%(5)$ & $0.74 \pm 2.6 \%(5)$ \\
RESL & - & $5.7 \pm 2.4 \%$ & - & - \\
Certified & $3.9 \pm 8.1 \%$ & $5.8 \pm 5.7 \%$ & $1.1 \pm 5.2 \%$ & $0.74 \pm 2.6 \%$ \\
\hline
\end{tabular}

NOTE: Number of replicates are in parentheses.

Table C8. Radionuclides measured in soil standard (8502). All analyses performed radiochemically.

\begin{tabular}{ccccc}
\hline \multirow{2}{*}{$\begin{array}{c}\text { Values or } \\
\text { laboratory }\end{array}$} & \multicolumn{4}{c}{ Radio nuclide (pCi/g \pm fractional standard deviation) } \\
\cline { 2 - 5 } & $90 \mathrm{Sr}$ & $137 \mathrm{Cs}$ & $239+240 \mathrm{Pu}$ & $241 \mathrm{Am}$ \\
\hline EC & $0.59 \pm 6.9 \%(3)$ & $0.94 \pm 1.4 \%$ & $0.19 \pm 18 \%$ & - \\
EML & - & - & $0.18 \pm 11 \%$ & - \\
LLNL & - & - & $0.19 \pm 9.4 \%(6)$ & - \\
TMA & $0.60 \pm 13 \%(5)$ & $1.0 \pm 6.2 \%(5)$ & $0.18 \pm 14 \%(5)$ & $0.12 \pm 7.9 \%(5)$ \\
Certified & $0.60 \pm 11 \%$ & $0.99 \pm 6.2 \%$ & $0.19 \pm 10 \%$ & $0.12 \pm 7.9 \%$ \\
\hline
\end{tabular}

NOTE: Number of replicates are in parentheses. 
Table C9. Radionuclides measured in marine organism standard samples. All analyses performed radiochemically except as noted.

\begin{tabular}{ccccc}
\hline Values or & \multicolumn{4}{c}{ Radionuclide (pCi/g \pm fractional standard deviation) } \\
\cline { 2 - 5 } laboratory & $90 \mathrm{Sr}$ & $137 \mathrm{Cs}$ & $239+240 \mathrm{Pu}$ & $241 \mathrm{Am}$ \\
\cline { 2 - 5 } & $16.7 \pm 20 \%$ & $10.8 \pm 20 \%$ & $68.9 \pm 20 \%$ & $16.8 \pm 20 \%$ \\
Expected & - & - & $78.8 \pm 5.7 \%(2)$ & $17.5 \pm 12 \%(2) \mathrm{a}$ \\
LLNL & - & $12.1 \pm 4.1 \%(3)$ & $77.5 \pm 10 \%(3)$ & $16.7 \pm 10 \%(2)$ \\
WOSC,OSU & $16.9 \pm 20 \%(3)$ & $12 \pm 10 \%$ & $78 \pm 10 \%$ & $17 \pm 10 \%$ \\
Certified & $17 \pm 20 \%$ & $10 \%$
\end{tabular}

NOTE: Number of replicates are in parentheses.

a Measured by gamma-ray spectroscopy.

Table C10. Expected values of radionuclides in terrestrial animal samples (pCi/kg).

\begin{tabular}{cccc}
\hline${ }^{90} \mathrm{Sr}$ & ${ }^{137} \mathrm{Cs}$ & ${ }^{239+240 \mathrm{Pu}}$ & $241 \mathrm{Am}$ \\
\hline $67 \pm 20 \%$ & $48 \pm 20 \%$ & $0.3 \pm 20 \%$ & $0.074 \pm 20 \%$ \\
\hline
\end{tabular}

\section{Additional Samples}

In addition to the vegetation, soil, terrestrial animal, and marine organism standards mentioned previously, two other samples were used in the evaluation of data analyzed from the participating laboratories. These, referred to as the "8502PFA06B00270" vegetation sample and the "EN3BC" soil standard, were used to fill a gap created when proper standards were either not available or not yet created. Their use was limited to LRE's gamma spectroscopy analyses and accounted for only a small number of comparison evaluations. We feel confident that the use of these two intermediate samples in no way detracts from the overall quality of the analyses performed by LRE.

\section{PFA06B00270 Coconut Sample}

The method used to make the "8502PFA06B00270" sample is identical with those used to process the vegetation standards with the following exceptions. First, the "8502PFA06B00270" vegetation sample was composed of coconut meat taken from Bikini island, Bikini Atoll, Republic of the Marshall Islands. Second, no radioactively labeled algae was added to the coconut sample. Substantiation of an accepted value was determined by non-destructive gamma-ray spectroscopy at both the LLNL Health and Ecological Assessment division (HEA), formerly the Environmental Sciences Division (ESD) and the LLNL Nuclear Chemistry division (NC). Table C11 shows the reported values obtained from the two analyses. 
Table C11. Radionuclides measured in vegetation standard 8502PFA06B00270. All analyses performed by gamma-ray spectroscopy.

\begin{tabular}{ccccc}
\hline \multirow{2}{*}{$\begin{array}{c}\text { Values or } \\
\text { laboratory }\end{array}$} & \multicolumn{5}{c}{ Radionuclide (dpm/gm wet weight) } \\
\cline { 2 - 5 } & $90 \mathrm{Sr}$ & $137 \mathrm{Cs}$ & $239+240 \mathrm{Pu}$ & $241 \mathrm{Am}$ \\
\hline LLNL-HEA & - & 634 & - & - \\
LLNL-NCb & - & 645 & - & - \\
Accepted Value & - & 634 & - & - \\
\hline
\end{tabular}

NOTE: Number of replicates are in parentheses.

a Lawrence Livermore National Laboratory; Health and Ecological Assessment Division.

b Lawrence Livermore National Laboratory; Nuclear Chemistry Division.

\section{EN3BC Soil Standard}

The "EN3BC" calcareous soil standard was prepared for use as a gamma detector calibration standard during the Enewetak Radiological Survey of 1972. A solution containing accurately known amounts of ${ }^{60} \mathrm{Co},{ }^{106} \mathrm{Ru},{ }^{137} \mathrm{Cs},{ }^{152} \mathrm{Eu},{ }^{155} \mathrm{Eu}$, and ${ }^{241} \mathrm{Am}$ was prepared and aliquots taken. These aliquots were dried and mixed with powdered coral taken from Midway Atoll (processed in the same manner as the other soil standards), homogenized, and given the designation of "EN3". All "EN3" standard solutions used for this calibration standard were cross-checked with standards from the International Atomic Energy Authority and Laboratoire de Metrologie des Rayonnements Ionisants (U.S. Atomic Energy Commission, 1973). Certification of the "EN3BC" soil standard was determined by three separate analyses. First, the sample was assayed by non-destructive gamma spectroscopy by the Nuclear Chemistry Division, LLNL in 1972. In 1981, two separate analytical methods were performed again by the Nuclear Chemistry Division, LLNL. Method A used non destructive gamma spectroscopy similar to the original assay, while Method B involved chemically dissolving 20 gram aliquants of the coral standard and performing gamma spectroscopy on aliquants of the resulting solutions. Table C12 shows the reported values obtained from the analyses of these events, as well as the certified value used for the "EN3BC" standard (Personal communications from Ken Marsh, 1994). 
Table C12. Radionuclides measured in soil standard EN3BC.

\begin{tabular}{lccccc}
\hline \multirow{2}{*}{$\begin{array}{c}\text { Values or } \\
\text { Laboratory }\end{array}$} & \multicolumn{5}{c}{ Radio nuclide (dpm/gm \pm counting error) } \\
\cline { 2 - 5 } & ${ }^{60} \mathrm{Co}$ & \multicolumn{5}{c}{${ }^{137} \mathrm{Cs}$} & ${ }^{152} \mathrm{Eu}$ & ${ }^{155} \mathrm{Eu}$ & ${ }^{241} \mathrm{Am}$ \\
\hline LLNL $^{\mathrm{a}}$ & $169 \pm 1.4 \%$ & $170 \pm 1.8 \%$ & $1250 \pm 1.0 \%$ & $4270 \pm 1.0 \%$ & $1330 \pm 1.5 \%$ \\
LLNL $^{\mathrm{b}}$ & $175 \pm 1.0 \%(4)$ & $178 \pm 1.8 \%(4)$ & $1440 \pm 1.0 \%(4)$ & $4930 \pm 1.0 \%(4)$ & $1580 \pm 2.0 \%(4)$ \\
LLNLc & - & $157 \pm 2.1 \%(3)$ & $1330 \pm 0.4 \%(3)$ & $4760 \pm 1.7 \%(3)$ & $1430 \pm 1.5 \%(3)$ \\
Certified & $169 \pm 1.4 \%$ & $170 \pm 1.8 \%$ & $1250 \pm 1.0 \%$ & $4270 \pm 1.0 \%$ & $1330 \pm 1.5 \%$ \\
\hline
\end{tabular}

NOTE: Number of replicates are in parentheses.

a LLNL; Nuclear Chemistry Division; 1972; Original assay.

b LLNL; Nuclear Chemistry Division; 1981; Analyzed by method A.

c LLNL; Nuclear Chemistry Division; 1981; Analyzed by method B.

\section{References}

Marsh, Ken (1994), Personal communications.

United States Atomic Energy Commission (1973), Enewetak Radiological Survey, Nevada Operations Office, Las Vegas, Nevada, NVO-140, Vol. 1, pp. 433-434. 